University of Rhode Island

DigitalCommons@URI

Open Access Dissertations

1977

\title{
Time and Frequency Domain Representations of the Left Ventricle: Theoretical and Experimental Results
}

Dennis James Arena

University of Rhode Island

Follow this and additional works at: https://digitalcommons.uri.edu/oa_diss

\section{Recommended Citation}

Arena, Dennis James, "Time and Frequency Domain Representations of the Left Ventricle: Theoretical and Experimental Results" (1977). Open Access Dissertations. Paper 787.

https://digitalcommons.uri.edu/oa_diss/787

This Dissertation is brought to you for free and open access by DigitalCommons@URI. It has been accepted for inclusion in Open Access Dissertations by an authorized administrator of DigitalCommons@URI. For more information, please contact digitalcommons-group@uri.edu. 


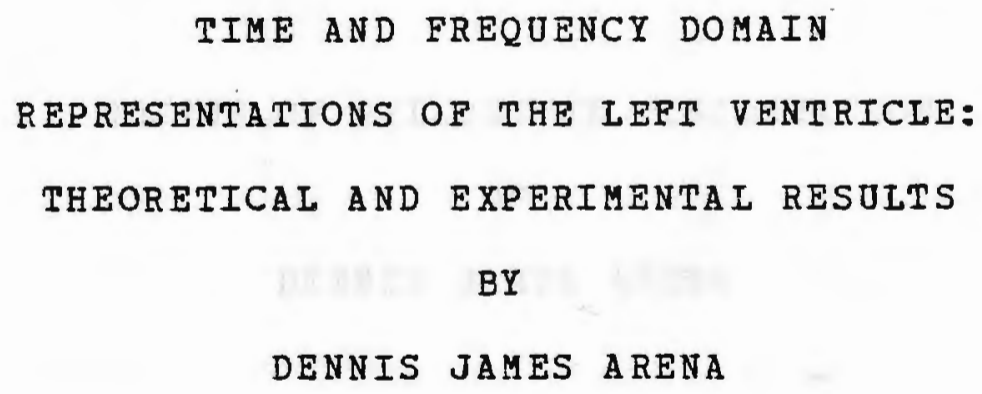

A DISSERTATION SUBMITTED IN PARTIAL FULFILLMENT OF THE REQUIREMENTS FOR THE DEGEEE OF DOCTOR OF PHILOSOPHY IN ELECTRICAL ENGINEERING 


\section{DOCTOR OF PHILOSOPHY DISSERTATION \\ OP \\ DENNIS JAMES ARENA}

A pproved

Dissertation Committee

Major Professor
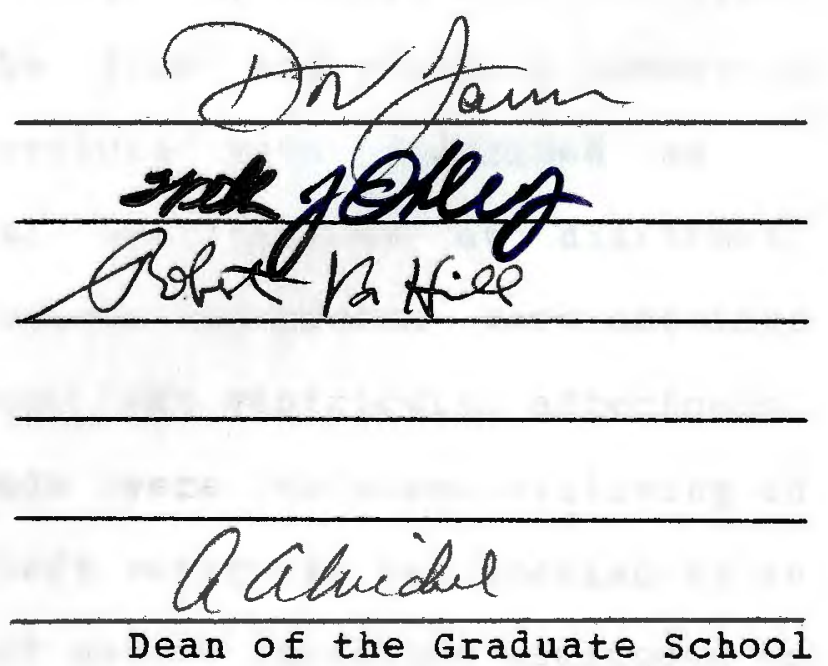
ABSTRACT OF THE THESIS

Time and Frequency Domain

Representations of the Left Ventricle:

Theoretical and Experimental Results

by Dennis James arena

Thesis Director: Dr. Dov Jaron

A frequency domain and a time domain model of the left ventricle are described in this work. These representations provide insight into the function of the healthy left ventricle and show how ventricular function may be altered by heart disease.

In developing the frequency domain representation of the left ventricle, the flow and pressure waveforms generated by the left ventricle were described as superpositions of sinusoidal oscillations at different frequencies. Flow and pressure waveforms were obtained experimentally at two different left ventricular afterloads. The two different afterloads were obtained utilizing an intraaortic balloon. The left ventricle was modeled by an equivalent source pressure and source impedance analogous to a Thevenin's equivalent representation. The model parameters (source pressure and source impedance) appear to be sensitive to cardiovascular changes such as myocardial infarction and increased left ventricular end-diastolic pressure. The source pressure expressed in the time domain may be a useful myocardial contractility index. For aortic 
input impedance much greater than source impedance, a change in left ventricular afterload would result in small change in aortic pressure. In this case the left ventricle would be functioning as a pressure source. BY comparing the source resistance and aortic input resistance, the left ventricle appears to be a D.C. pressure source.

For analysis in the time domain, the left ventricle was represented by truncated, confocal ellipsoids approximated by a series of cylindrical shells. The properties of the left ventricle were distributed over the cylindrical sections. The timing and sequence of contraction of the cylindrical shells were prescribed to simulate the mechanical action of the left rentricle. Flow and pressure waveforms produced by the model were similar to those obtained experimentally. Results of the simulation indicate that the pressure distribution in the ventricular chamber may be a useful index for determining the status of the left ventricle. 
ACKNOWLEDGUENTS

It was a privilege to work under the influence and guidance of Dr. Dov Jaron. Dr. Jaron's intelligence and integrity were recourses for me in performing this research.

I also wish to thank Dr. Nilliam ohley for his consultation and perpetual optimism.

The Author

The research concerning the frequency domain analysis of the left ventricle was supported in part by a subcontract to Sinai Hospital of Detroit under a program project grant USPHS Grant HL-13737. 
TABLE OF CONTENTS

Page

ABSTRACT OF THE THESIS - . . . . . . . . . . . . . . ii

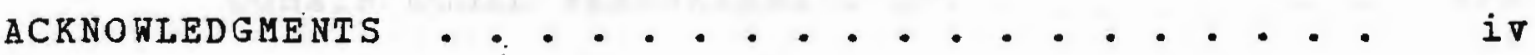

IIST OF TABLES • • . . . . . . . . . . . . . . . . vii

IIST OF FIGURES - . - . . . . . . . . . . . . . . . viii

Chapter

I. INTRODUCTION . . . . . . . . . . . . . . . 1

II. PHYSIOLOGIC BACKGROUND . . . . . . . . . . . 4

Anatomy of the Left Ventricle . . . . . . 4

Dynamics of the left Ventricle . . . . . 6

III. FREQUENCY DOMAIN REPRESENTATION . . . . . . . . 13

Introduction . . . . : . . . . . . 13

TheorY . . . . . . . . . . . . 15

Methods . . . . . . . . . . . . 18

Results . . . . . . . . . . . . . . 22

Discussion . . . . . . . . . . . 23

IV. TIME DOHAIN REPRESENTATION . . . . . . . . . . 65

Introduction . . . . . . . . . . . 65

The Model . . . . . . . . . . . 67

Results . . . . . . . . . . . . . . 89

Discussion . . . . . . . . . . . . 93 
Sumary of Results. . . . . . . . . 109

7. DISCUSSION . . . . . . . . . . . . 161 A PPENDICES

A. PHYSIOLOGIC BACKGROUND APPENDIX • • • . . . . 166 Structure of Myocardium . . . . . . . 166 Mechanism of Contraction . . . . . . . 169

B. COMPUTER PROGRAM to CalcUlate FREQUENCy DOMAIN MODEL PARAMETERS . . . . . . . . . 178

C. COMPUTER PROGRAM TO CALCOLATE LEFT VENTRICULAR PRESSURE-VOLUME RELATIONSHIP . . . . . . . . . . . 197

D. COMPUTER PROGRAM TO CALCULATE

THE TIME DOMAIN REPRESENTATION

PARAMETERS ....................... 200

E. COMPARISON BEThEEN THE INERTIAL FORCE

OF THE MYOCARDIUM AND THE FORCE

GENERATING STATIC PRESSURE •. . . . . . . 218

LIST OF REPERENCES . . . . . . . . . . . . . . . 221

INDEX . . . . . . . . . . . . . 230 
LIST OF TABLES

Table

Page

3.1 Model Parameters and Left Ventricular Enddiastolic pressure, "HIGH-LOW" Runs . . . 29,30

3.2 Model Parameters and Left Ventricular Enddiastolic Pressure, "LON-HIGH" Runs . . . 31,32

3.3 Model Parameters vs. Left Ventricular Enddiastolic Pressure, All Runs . . . . . . 33,34

3.4 Mean Aortic Pressure vs. Left Ventricular End-diastolic Pressure ........ 35,36

4.1 End-diastolic Constraints . . . . . . . 111,112

4.2 Aortic Input Impedance . . . . . . . . . 113,114

4.3 Percent Change of Model Dimensions with Respect to End-diastolic Dimensions . . . 115,116

4.4 Percent Change of Left Ventricular Wall Thickness with Respect to the Enddiastolic Value ... . . . . . . . 117,118 
LIST OF FIGORES

Figure

Page

2.1 Anatomy of the Heart . . . . . . . . . 9,10

2.2 Timing of Cardiac Events . . . . . . . . . 11,12

3. 1 Thevenin Equivalent Circuit . . . . . . . 37,38

3.2 Experimental setup . . . . . . . . . 39,40

3.3 Experimental Data . . . . . . . . . . 4 4,42

3.4 Source Pressure (PG) . . . . . . . . . . . . 43.44

3.5 Source Impedance (ZG) . . . . . . . . . . 45,46

3. 6 Source Pressure vs. Left Ventricular End-diastolic Pressure, Dog 1 . . . . 47,48

3.7 Source Pressure vs. Left Ventricular End-diastolic Pressure, $\operatorname{Dog} 2$. . . . 49,50

3.8 Source Impedance vs. Left Ventricular End-diastolic Pressure, Dog 1 ... . . 51,52

3.9 Source Impedance vs. Left Ventricular End-diastolic Pressure, $\operatorname{Dog} 2$. . . . . 53,54

3. 10 Mean Aortic Pressure vs. Left Ventricular End-diastolic Pressure, Dog $1 . . . .55,56$

3. 11 Mean Aortic Pressure vs. Left Ventricular End-diastolic Pressure, Dog 2 . . . . 57.58

3.12 Time Domain Source Pressure, Dog $1 . . . . .59,60$

3.13 Time Domain Source Pressure, Dog $2 . . . \cdot .61,62$

3. 14 Source Impedance and Aortic Impedance . . . 63,64 4.1 Confocal Ellipses . . . . . . . . . . . 119,120 4.2 Model End-diastolic Dimensions . . . . . . 121,122 
4.3 Model End-diastolic Configuration . . . 123,124

4.4 Pressure-stress Relationship . . . . . 125,126

4.5 Inertial Forces . . . . . . . . 127,128

4.6 Cylindrical shell Configuration . . . . 129,130

4.7 Pressure-volume Relationships ...... 131,132

4.8 Model Dimension Changes . . . . . . 133,134

4.9 Model Outside Diameter Changes . . . . . 135,136

4.10 Model Chamber Outline . . . . . . . 137,138

4.11 Model Output raveforms . . . . . . . 139,140

4.12 Model Pressure Distribution at the End

of Isovolumic Contraction . . . . . 141,142

4.13 Model Pressure Distribution During

Ejection . . . . . . . . . 143,144

4.14 Model Results for Myocardial Infarction

Simulation............. 145,146

4.15 Left Ventricular Pressure-volume

Relationship.......... 147,148

4.16 Left Ventricular Diameter Changes . . . 149,150

4.17 Midpoint Left Ventricular Diameter . . . . 151,152

4.18 Equatorial Left Ventricular Diameter . . . 153,154

4.19 Left Ventricular Basal Dimensions . . . . 155,156

4.20 Left Ventricular Outside Diameter . . . 157,158

4.21 Left Ventricular Wall Thickness . . . . 159,160 APPENDIX A

1 Muscle Fiber Bundle . . . . . . . . 172,173

2 Myocardial Cell . . . . . . . . 174,175

3 The Sarcomere . . . . . . . . . 176,177 
CHAPTER I

INTRODUCTION

of the four chambers of the heart, the left ventricle performs the major portion of the work needed to supply blood to the circulation. Consequently, this chamber is most susceptible to failure. A quantitative analysis of left ventricular function is desirable in order to determine the status of the left ventricle.

Recently, some of the commom parameters used to analyze left ventricular function and problems associated with such evaluations have been reviewed $(1,2)$. Many parameters used to assess left ventricular pump function are influenced by extracardiac factors. For instance, cardiac output is often used to evaluate cardiac performance. But cardiac output is not a sensitive index of left ventricular function because homeostatic mechanisms tend to maintain cardiac ouput in response to cardiovascular changes. One homeostatic mechanism is the regulation of systemic vascular tone (left ventricular afterload).

Two representations of the left ventricle are presented herein. In the frequency domain representation, 
page 2

left ventricular function is described by two parameters; source pressure and source impedance. These parameters may be useful in the evaluation of cardiac performance. Source pressure and source impedance are not functions of left ventricular afterload as, for instance, cardiac output is.

The time domain representation of the left

ventricle is developed by simulating the dynamics of the left ventricle through the cardiac cycle. Results from the model show that the pressure distribution within the ventricular chamber may be indicative of the status of the left ventricle. The pressure gradients within the chamber are also independent of left ventricular afterload.

The thesis is presented in modular form. One familiar with the physiology and biophysics of the circulation could skip the chapter on "Physiologic Background" and proceed onto the chapters on left ventricular representations without missing any of the reported results. Furthermore, one interested in only one of the left ventricular representations may proceed directly to the chapter on that model. No background information, data or results are reported for one representation that are required knowledge for studying the other representation. An additional section on physiologic background appears in the Appendix which provides information regarding the cellular structure and function of myocardium.

Each left ventricular representation is described with its own detailed Introduction and Discussion. The 
Discussion appearing at the end of the thesis is a brief summary concerning the usefulness of both representations. 
CHAPTER II

PHYSIOLOGIC +BACKGROUND

A preliminary step in studying heart function is understanding the structure and nature of contraction of the myocardium.

A. Anatomy of the Left Ventricle

The heart is composed of four chambers; the left and right atria and the left and right ventricles. Deoxygenated blood from the systemic circulation enters the right atrium and passes through the tricuspid valve into the right ventricle. The right ventricle pumps the deoxygenated blood through the pulmonary valve into the pulmonary circulation. The blood is oxygenated by the lungs in the pulmonary circulation, and returns to the left atrium of the heart. From there, the blood enters the left ventricle through the mitral valve. The left ventricle pumps the oxygenated blood through the aortic valve and into the systemic circulation via the aortic artery.

The right ventricle pumps against a mean pressure 
of about $15 \mathrm{~mm}$ Hg. The left ventricle pumps against a mean pressure of about $100 \mathrm{~mm}$ Hg. Since the ventricles pump blood at the same flow rate, the left ventricle must perform about six times the amount of work that the right ventricle performs in maintaining the circulation. Consequently, the left ventricle contains much more muscle mass than the right ventricle.

The "skeleton" of the heart is a fibrous framework of connective tissue (Figure 2.1). The atria, ventricles, valves and arterial trunks are connected to this frame. The atria and arterial trunks are attached to the superior surface of the frame; the ventricles to the inferior surface (3) .

The shape of the left ventricle (IV) is similar to an eggshell with its top cut off (4). The truncated end of the eggshell corresponds to the base of the LV. The intact end of the eggshell corresponds to the apex of the $I V$. The base of the $L V$ is attached to the skeleton of the heart encompasing the openings for the mitral and aortic valves. The wall of the $L V$ is thickest at the greatest circumference (equator) and thinnest at the apex (4). The muscle fibers in the ventricular wall are mostly oriented circumferentially and do not change orientation significantly through the cardiac sycle. There are more longitudinally oriented muscle fibers in the apical region than in the rest of the LV (5).

In the wall of the IV which separates the right and 
page 6

left ventricular chambers (interventricular septum), a fascicle of purkinje fibers (left bundle branch) descends from the base toward the apex. The bundle divides anteriorly and posteriorly and ramifies into the peripheral Purkinje network (6).

B. Dynamics of the Left Ventricle

During the filling phase of the cardiac cycle, the myocardium is in the resting state. The inlet valves from the atria to the ventricles are open; the outlet valves from the ventricles to the arterial trunks are closed. The atria and ventricles are being passively filled with blood from the systemic and pulmonary circulations.

Electrical activity in the heart begins (under normal conditions) in the sinoatrial node located in the wall of the right atrium. The pacemaker cells in the node initiate the depolarization impulse. The impulse follows specialized conduction pathways to the atrioventricular node (internodal tracts) and to the left atrium (Bachmann's bunde) (6). The spread of depolarization over the atria causes atrial contraction which complements the filling of the ventricles.

Normally, the depolarization impulse can reach the ventricles only via the atrioventricular node (AVN) which is located at the base of the right atrium. The impulse incurs a delay in transmission at the $\mathrm{AVN}$ (which is convenient to 
allow the atria to complete contraction before the ventricles begin contracting). From the AVN the impulse passes into the right ventricle to the rapidly conducting Purkinje fibers of the bundle of His and thence to the right and left bundle branches of the right and left ventricles, respectively.

Hence, the depolarization impulse enters the IV via the left bundle branch. The impulse passes along Purkinje fibers in the interventricular septum to the apical region of the $L \nabla$. The wave of depolarization of ventricular myocardium thus starts at the apex and moves up toward the base (7). As a result, ventricular contraction begins near the apex and moves toward the base where the outgoing vessels are located (8) .

Initial LV contraction raises ventricular pressure causing closure of the inlet valve (mitral valve). Until the pressure generated within the $\mathrm{LV}$ is greater than that in the aorta, the outlet valve (aortic valve) remains closed. Hence, during this phase of cardiac contraction, the IV is a closed space and the chamber volume cannot change (isovolumic contraction).

During the isovolumic contraction phase of the cardiac cycle, there is little or no change in IV length. A narrowing of the apical region occurs which displaces blood toward the base causing expansion of the IV in the vicinity of the aortic valve (9). When the pressure in the LV exceeds that in the aorta, the aortic valve opens and the IV 
ejects blood into the aorta.

During the ejection phase of the cardiac cycle, the ventricle shortens slightly (9), but the ventricular chamber volume is reduced primarily by a reduction circumferentially rather than longitudinally (10) .

Near the end of the ejection phase, the ventricular myocardium ceases contraction and the pressure in the $\mathrm{LV}$ declines. When ventricular pressure declines below aortic pressure, the aortic valve closes. The ventricular myocardium continues to relax and chamber pressure continues to fall. When IV pressure falls below left atrial pressure, the mitral valve opens and the filling phase of the cardiac cycle begins. Figure 2.2 displays the timing of cardiac events in a typical cardiac cycle. 
Figure 2.1. Anatomic components of the beart. The atria and arterial trunks are connected to the superior surface of the fibrous skeleton of the heart; the ventricles to the inferior surface. (3) 


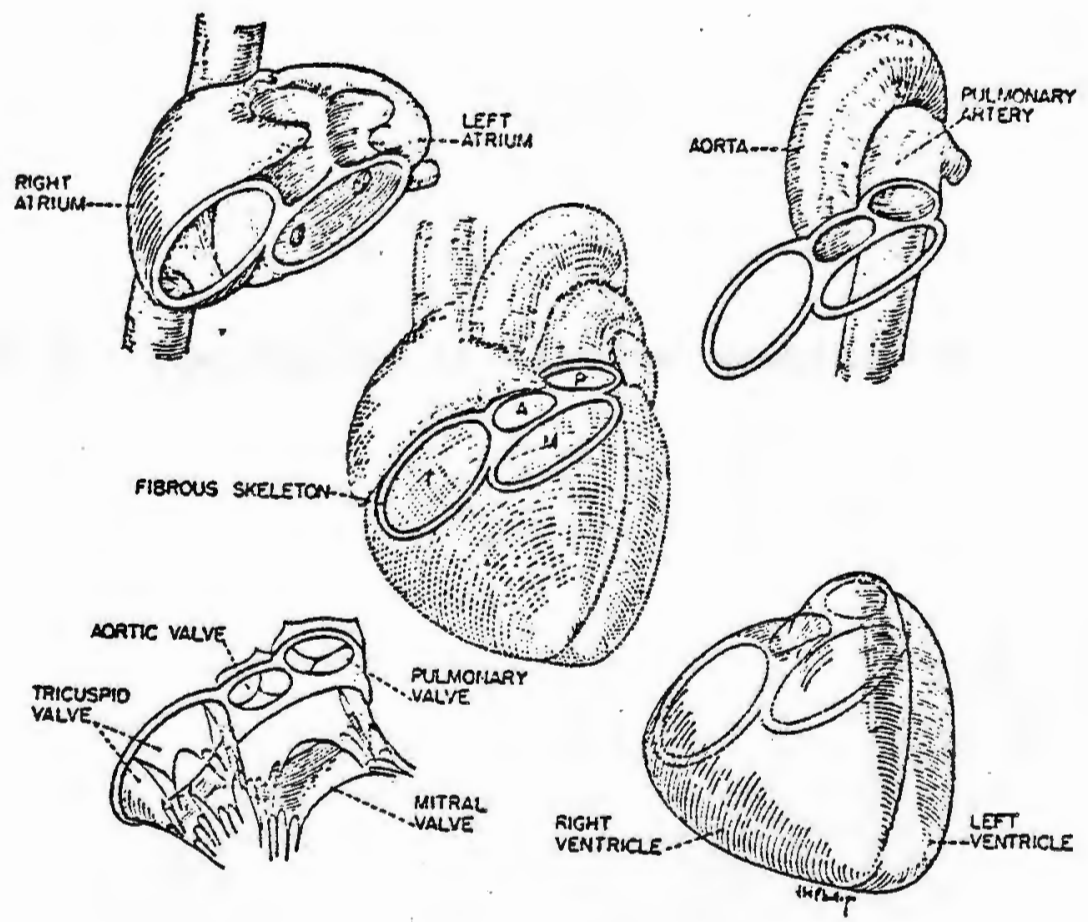

Figure 2.1 
page

11

Figure 2.2. The timing of cardiac events. (7) 


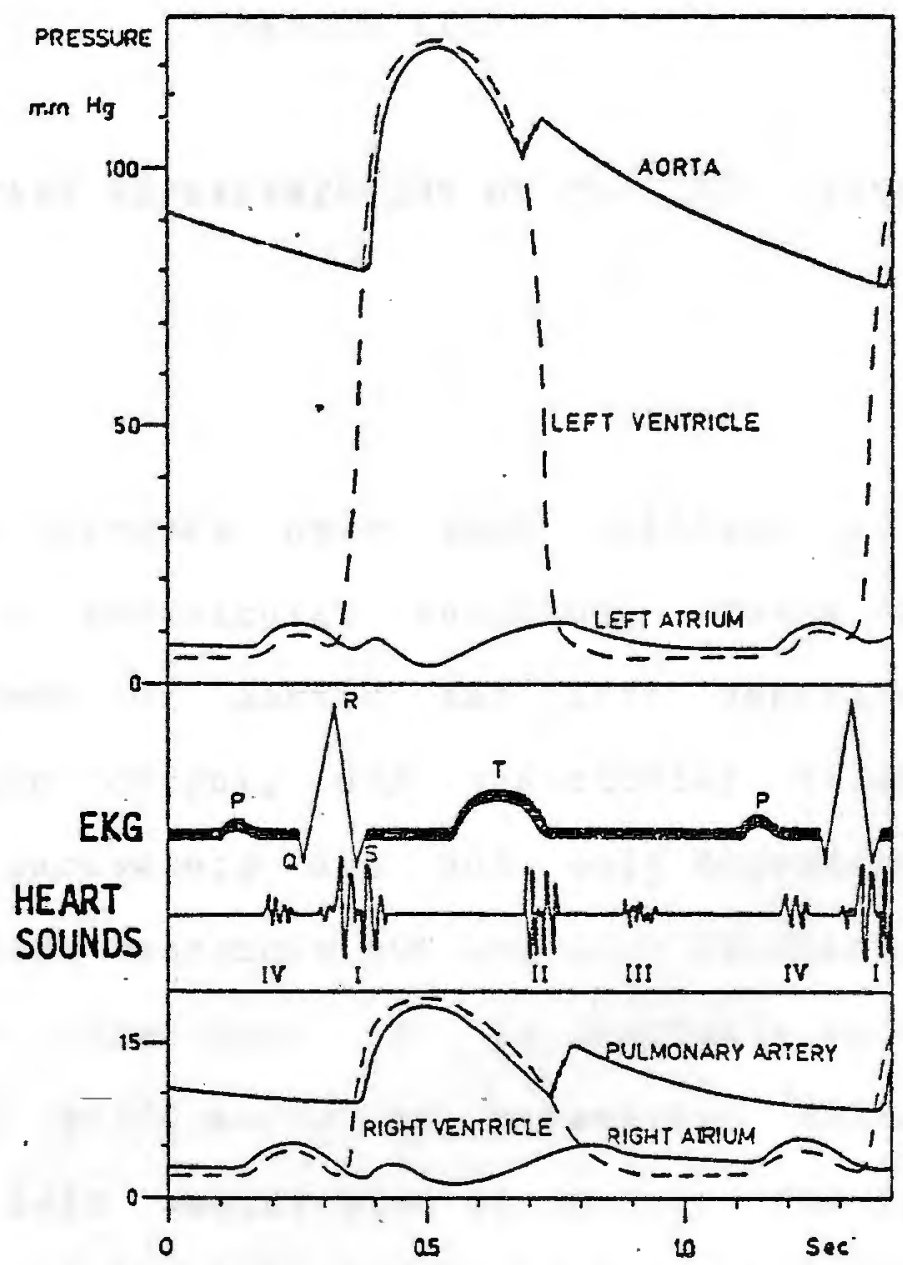

Figure 2.2 
CHAPTER III

FREQUENCY DOMAIN REPRESENTATION OF THE IEFT VENTRICLE

A. Introduction

Numerous methods have been utilized to provide analysis of left ventricular function. These methods include measurement of aortic and left ventricular pressures, cardiac output, and ventricular volumes. However, these parameters are not only dependent on the status of the left ventricle but are also functions of the left ventricular afterload. It is desirable to evaluate left ventricular performance by parameters which are independent of left ventricular afterload. The frequency domain analysis of the left ventricle described herein may provide useful parameters for left ventricular performance.

The left ventricle has been represented by an equivalent source pressure and source impedance analogous to

Portions of this chapter were included in a final report to Sinai Hospital of Detroit in 1976. This work was supported in part by a subcontract to Sinai Hospital under a program project grant USPHS Grant HL-13737 with Dr. Dov Jaron as principal investigator. The experimental data used in this analysis were collected by Dr. Jaron at Sinai Hospital. 
2) Can these parameters provida an indication of the functional properties of the heart?

3) Can changes in the parameters be related to changes in the physiologic properties of the system?

\section{B. Theory}

1. Assumptions Used in the Analysis

The model parameters (source pressure and source impedance) were determined in the frequency domain utilizing the principle of superposition. Therefore, the system being modeled was assumed to be linear and possess time-invariant properties. It was also assumed that the properties of the left ventricle could be represented by lumped parameters.

2.- Determination of Model Parameters

The equivalent source pressure and source impedance are expressed in terms of left ventricular pressure and aortic flow. In the Therenin's equivalent circuit (Figure 3.1), pressure is analogous to voltage and flow is analogous to current. By applying Ohm's law and Kirchhoff's voltage law to the circuit of Figure 3.1 at two different load conditions, two equations with two unknowns result:

$$
P G(\omega)-P L V_{1}(\omega)=Q_{1}(\omega) Z G(\omega)
$$


and

$$
P G(\omega)-P L V_{2}(\omega)=Q_{2}(\omega) Z G(\omega)
$$

where:

$$
\begin{aligned}
& \text { PG = equivalent source pressure } \\
& Z G \text { = equivalent source impedance } \\
& \text { PIV = left ventricular pressure } \\
& Q=\text { aortic flow } \\
& \omega=\text { angular frequency } \\
& \text { and the subscripts } 1 \text { and } 2 \text { refer to load } \\
& \text { conditions } 1 \text { and } 2 \text {. }
\end{aligned}
$$

Solution of the two equations provides expressions for the model parameters:

$$
\begin{gathered}
P G(\omega)=\frac{Q_{2}(\omega) P L V_{1}(\omega)-Q_{1}(\omega) P L V_{2}(\omega)}{Q_{2}(\omega)-Q_{1}(\omega)} \\
Z G(\omega)=\frac{P L V_{2}(\omega)-P L V_{1}(\omega)}{Q_{1}(\omega)-Q_{2}(\omega)}
\end{gathered}
$$

one non-linearity of the cardiovascular system is the aortic valve. The valve was not considered part of the source. By using left ventricular pressure and aortic flow 
in the calculation of the model parameters, the valve was excluded from the Thevenin's equivalent circuit.

3. Time Domain Source Pressure

The source pressure is equivalent to left ventricular pressure under zero flow conditions. A cycle of source pressure presented in the time domain, therefore, represents the left ventricular pressure that would be generated during an isovolumic heart cycle.

4. Nature of the Generator

The load presented to the left ventricle can be obtained by $(16)$ :

$$
Z A O(\omega)=\frac{P A O(\omega)}{Q(\omega)}
$$

where:

$$
\begin{aligned}
& \text { ZAO = aortic input impedance } \\
& \text { PAO = aortic pressure. }
\end{aligned}
$$

To assess whether the heart can be considered a flow source or a pressure source, a comparison must be made between the source impedance and the aortic input impedance. For aortic 
page 18

impedance much greater than source impedance, a change in load impedance would result in little change in aortic pressure. Under such conditions the heart could be considered a pressure source. For source impedance much greater than aortic impedance a change in load impedance would result in little change in flow, thus the heart could be considered a flow source. The aortic valve was not included in the source impedance or in the aortic input impedance. For the D. C. case, if the valve is assumed to have negligible resistance, the source resistance and aortic input resistance can be compared to determine if the left ventricle functions as a pressure source or a flow source.

c. Methods

1. Experimental Procedure

Two hundred and eleven experimental runs were performed on two aduit mongrel dogs. The animals were anesthetized with sodium pentobarbital (25 $\mathrm{mg} / \mathrm{kg}$ IV) and artificially ventilated. The chest was opened through the forth intercostal space. Millar catheters were introduced in the left ventricle through the apex and in the ascending aorta through the carotid artery. A Biotronex electromagnetic flow probe was placed around the aorta near its origin and attached to a Biotronex BL610 flowmeter. A cylindrical intraaortic balloon was placed in the descending aorta via the femoral artery. Left ventricular pressure, 
aortic pressure, and aortic flow were simultaneously recorded (Figure 3.2) .

Two different ventricular load conditions were obtained by using the intraaortic balloon in the following manner: In one procedure, hemodynamic data were recorded under steady state conditions over several heart cycles with the balloon deflated. This provided data for one load condition. The balloon was then inflated precisely at the beginning of diastole, partially occluding the aorta. It was left inflated for a few heart beats. The hemodynamic data recorded during the first heart cycle with the balloon inflated were used for the second load condition. Experimental runs utilizing this procedure were termed "LOW-HIGH" runs (Figure 3.3).

In the second procedure, the balloon was inflated for several minutes until the system became stable and hemodynamic parameters reached a steady state. Hemodynamic parameters were recorded for several heart beats providing data for one load condition. The balloon was then deflated precisely at the end of diastole. Hemodynamic data recorded during the first heart cycle with the balloon deflated were used for the second load condition. Experimental runs utilizing this procedure were termed "HIGH-LOH" runs.

Since compensatory mechanisms tend to change left ventricular function in response to changes in the systemic load, it was essential to consider hemodynamic data before such changes occurred. Consequently, hemodynamic data 
page 20

during only the first heart cycle following the change in load were used to calculate the model parameters (17).

In adition, a few times during the experiment, aortic pressure and flow were recorded for a few heart cycles with the balloon deflated. This provided data for the calculation of aortic input impedance.

Four experimental preparations were utilized in the study: 1) control (C); 2) cholinergic and beta-adrenergic blockade (B), obtained using atropine sulfate $(3.0 \mathrm{mg} / \mathrm{kg})$ and propranalol hydrochloride $(1.5 \mathrm{mg} / \mathrm{kg})(18-20) ; 3)$ acute myocardial ischemia (MI), induced by ligation of all major branches of the anterior descending coronary artery; and 4) a combination of myocardial ischemia and blockade (MI+B). Data were obtained from DOG 1 for the (C), (B), and (MI+B) preparations and from DOG 2 for the (C) and (MI) preparations.

2. Data Analysis

Data were digitized on line at a rate of 120 samples per second and stored. Typical time domain data collected for a "LOW-HIGH" run are displayed in Figure 3.3. Fourier analysis was performed on the data off line. Frequency domain data were corrected with respect to instrument frequency response and for the distance between aortic flow and pressure measurement sites (21).

The "steady state" cycles of flow and pressure were 
averaged to provide one load condition. To assure that the "steady state" condition had been reached, and to remove the effect of any abnormal cycles from the "steady state" average, the following procedure was utilized. If the magnitude of the D.C. or fundamental component of any of the averaged cycles differed from their respective average by $10 \%$ or more, or if the number of samples of any of the averaged cycles differed from the average number of samples by $5 \%$ or more, the cycle was discarded from the analysis. The remaining "steady state" cycles were reaveraged. This procedure was repeated until no cycles were discarded or until a minimum number of averaged cycles was reached. In the latter case, the analysis was stopped and the experimental run was not included in the results.

The first heart cycle after the change of state was used as the second load condition. Source pressure, source impedance and aortic impedance were calculated in the frequency domain for the D.C. component and for ten harmonics. In addition, left ventricular end-diastolic pressure (LVEDP) and mean aortic pressure of the "steady state" were determined for each run.

Statistical significance for the differences of model parameters between groups was determined using student's t-test. 
D. Results

Typical results for source pressure and source impedance are shown in Figure 3.4 and Figure 3.5 for the D.C. and seven harmonics. Higher harmonics than the seventh were neglected because of large errors due to instrumentation uncertainties and scatter of the physiologic data. In the present work, only the D.C. and fundamental components of the model parameters were studied in detail.

The D.C. and fundamental components of the model parameters were averaged for each experimental preparation in each dog. The results are tabulated with standard errors and $P$ values representing significant difference from control (C) in Table 3.1 and Table 3.2. For both the "HIGH-ION" and "ION-HIGH" runs, the D.C. and fundamental components of the source pressure for the B, MI, and MI+B groups are significantly lower than the respective components for the control group. The D.C. and fundamental components of the source impedance for the B, MI, and MI+B groups show no consistent significant differences from the control group. It can be seen from Table 3.1 and Table 3.2 that the model parameters for the "HIGH-Lon" runs are in general higher than the respective parameters for the "LON-HIGH" IUns. The LVEDP of the "HIGH-LOW" runs are also higher than those of the "LOH-HIGH" runs.

In order to study how the model parameters vary over a wide range of IVEDP, the results of the "HIGH-LOW" and "LOH-HIGH" runs were pooled. A linear regression was 
page 23

performed on the D.C. components of the model parameters vs. IVEDP. The results of the linear regression, including correlation coefficients, are displayed in Table 3.3. The slopes of the lines for the D.C. components of source pressure and source impedance are all positive with relatively high correlation coefficients (Figures 3.6, 3.7, 3.8, 3.9). Poor correlation to a linear regression was found for the fundamental components of the model parameters.

Linear regressions were also performed for mean aortic pressure vs. IVEDP. These results are displayed in Table 3.4. The slopes of the lines are all positive with relatively high correlation coefficients (Figures 3.10. 3.11).

The source pressure was reconstructed in the time domain by inverse Fourier analysis. Typical results are displayed in Figure 3.12 and Figure 3.13 .

Aortic input impedance was compared to the source impedance. Typical results are displayed in Figure 3.14 for the D.C. and seven harmonics.

E. Discussion

The representation of the left ventricle as a source pressure in series with a source impedance has been tested on isolated heart preparations and in-vivo. The parameters appear to be responsive to cardiovascular changes 
such as MI and increased LVEDP. It has been suggested that source pressure expressed in the time domain be used as a myocardial contractility index (22). By comparing source impedance and aortic impedance the pump characteristics of the left ventricle can be determined.

1. Model Parameter Response to Cardiovascular Changes In a recent study the Thevenin equivalent representation was applied to isolated cat hearts. The purpose was to determine how the model parameters change after coronary occlusion (15). It was determined by that investigation that subsequent to acute ischemia there occurred a significant decrease in the D.C. component of source pressure with no significant change in the D.C. component of source impedance. The present study indicates similar results when the model is applied to dog hearts, in-vivo. In addition, a significant decline in the fundamental component of source pressure was found after MI. Although significant changes in some groups for both the D.C. and fundamental components of source impedance were observed, no consistent trend can be reported.

Elzinga et. al. also studied the changes in model parameters with changes in IVEDP in isolated cat hearts (14). They varied the preload on the heart at constant afterload and determined that increases in IVEDP cause an increase in the D.C. component of source pressure with no 
page 25

significant change in the D.C. component of source impedance. When studying the heart in-vivo, it is not possible to segregate the effects of preload and afterload. Therefore, in the present work the preload to the heart could not be varied at constant afterload as was done in the isolated heart study. The model parameters were studied as a function of IVEDP without maintaining constant afterload. The results confirm Elzinga's observation regarding the dependence of the D.C. component of source pressure on IVEDR. Furthermore, the results of the present study show that this relationship is approximately linear. The other observation by Elzinga et. al., that the D.C. component of source impedance is not a function of IVEDP, was not confirmed in this study. Instead, it was observed that they are also approximately linearly related.

It was shown in isolated cat hearts that the D.C. component of source pressure which bad been decreased by coronary occlusion could be restored to its control value by increasing IVEDP (15). The D.C. Component of source impedance did not change with coronary occlusion or with subsequent increase in LVEDP. Consequently, Elzinga et. al. concluded that in the isolated heart preparation, the D.C. components of the parameters cannot be utilized to differentiate between the normal and the compensated heart (15). In contrast to Elzinga's work, the results of the present work indicate that an increase in LVEDP following myocardial ischemia in-vivo, would restore the D.C. 
component of source pressure but would simultaneously raise the D.C. component of source impedance. Thus, in-viro, the heart undergoing compensation after MI by increased LVEDP could be differentiated from the normal heart by its elevated D.C. component of source impedance.

2. IVEDP as a Function of Mean Aortic Pressure It has been reported that an increase in coronary perfusion pressure is accompanied by an increase in left ventricular diastolic pressure (23). A similar observation is noted with increased aortic end-diastolic pressure (15). In the present work, LVEDP was found to be an almost linearly increasing function of mean aortic pressure. In the "HIGH-LOW" runs, the aorta was partially occluded during the "steady state" by the inflated balloon. This caused an elevated mean aortic pressure which in turn caused an elevated IVEDP. Therefore, the D.C. components of the model parameters, apparently dependent on IVEDP, are higher for "HIGH-LOW" runs than for "LOW-HIGH" runs.

\section{Time Domain Source Pressure}

The rate at which left ventricular pressure rises has been recognized as indicative of the inotropic state. This led to the use of peak $\mathrm{dp} / \mathrm{dt}$ as a contractility index (24). More recently, dp/dt during isovolumic contraction 
was shown to be a useful index of cardiac contractility (25) .

In a clinical environment, it may be difficult to study the short isovolumic phase of the cardiac cycle. It may be difficult and deleterious to completely occlude the aorta in order to study an isovolumic heart cycle. The time domain source pressure waveform may provide a convenient means of observing the isovolumic contractility indices.

To evaluate the status of the left ventricle, the source pressure could be determined from measurements of left ventricular pressure and aortic flow. Otilizing inverse Fourier transform the source pressure could be displayed in the time domain. Since the source pressure is equivalent to left ventricular pressure under zero flow conditions, the time domain source pressure is equivalent to the left ventricular pressure waveform that would be generated by an isovolumic heart cycle. Thus, utilizing the source pressure an entire isovolumic heart cycle may be studied without total occlusion of the aorta.

The time domain source pressure waveforms indicate that denervation caused dp/dt to decline and subsequent MI caused a further decline (Figure 3.12). MI without denervation caused a decline in dp/dt (Figure 3.13). These results indicate the potential usefulness of dp/dt of the time domain source pressure as a contractility index.

It has been suggested that myocardial infarction interferes with the normal excitation-contraction linkage 
(26). Infarcted myocardium may not be able to contract and interacts with healthy tissue in a passive manner. The presence of "passive" tissue within the myocardial infarcted left ventricle may be the cause of decreased dp/dt during contraction.

4. The Heart as a D.C. Pressure Source

Elzinga et. al. reported that for the isolated cat heart preparation, the source resistance is the same order of magnitude as the systemic peripheral resistance (14). The results of the present study indicate substantial differences between those parameters in-vivo. Values for systemic peripheral resistance calculated in the present study are close to those previously reported for dogs (16). The values for systemic peripheral resistance calculated herein are, however, about an order of magnitude greater than the source resistance calculated in the present study (Figure 3.14). Thus, for the D.C. Case, the results suggest that the heart is functioning as a pressure source. This is in agreement with the results of previous work which utilized in-vivo dog heart preparations (27). A limitation to any in-vivo preparation is its susceptibility to neural responses. However, the results of the present work suggest that even in the denervated group (B) the left ventricle functions as a pressure source for the D.C. case. 
Table 3.1. Model parameters and left ventricular end-diastolic pressure, "HIGH-LOW" runs.

N - number of runs

SEM - standard error

D.C. - D.C. Component of model parameters

FOND - fundamental component of model parameters

P - significant difference level with respect to control

NS - not significant 


\begin{tabular}{|c|c|c|c|c|c|c|c|c|c|c|c|c|c|c|c|c|}
\hline \multirow[b]{2}{*}{ DOG } & \multirow[b]{2}{*}{ GROUP } & \multirow[b]{2}{*}{$N$} & \multicolumn{2}{|c|}{ LVEDP } & \multicolumn{6}{|c|}{ SOURCE PRESSURE (mm hg) } & \multicolumn{6}{|c|}{ SOURCE IMPEDANCE (dyne*sec/ $\mathrm{cm}^{\star \star 5}$ ) } \\
\hline & & & MEAN & SEM & D.C. & SEM & $\mathbf{P}$ & FUND & SEM & $\mathbf{P}$ & D.C. & SEM & $\mathbf{P}$ & FUND & SEM & $P$ \\
\hline 1 & C & 14 & 14.46 & 0.47 & 79.33 & 1.08 & - & 80.71 & 0.73 & - & 541.72 & 14.45 & - & 480.64 & 36.83 & - \\
\hline 1 & B & 24 & 8 & 0.26 & 60.61 & 1.15 & .001 & 51.56 & 0.92 & .001 & 511.64 & 6 . & .05 & 356.11 & 49.64 & NS \\
\hline 1 & $M I+B$ & 18 & 20.12 & 0.26 & 50.43 & 0.71 & .001 & 44.10 & 0.54 & .001 & 598.19 & 16.24 & .025 & 306.17 & 22.23 & NS \\
\hline 2 & 0 & 22 & 21.67 & $0.43 \mid$ & .98 & 1.50 & - & 45 & 1.66 & - & 99 & 12.70 & - & 63 & 33 & - \\
\hline 2 & MI & 29 & 20.59 & $0.15 \mid$ & 65.02 & 1.17 & .001 & 49.89 & $0.77 \mid$ & .001 & 495.12 & 10.06 & .05 & 797.76 & 30.99 & .05 \\
\hline
\end{tabular}

Table 3.1 
Table 3.2. Model parameters and left ventricular end-diastolic pressure, "LOW-HIGH" Iuns.

$\mathbb{N} \quad$ - number of runs

SEl - standard error

D.C. - D.C. component of model parameters

FOND - fundamental component of model parameters

$P$ - significant difference level with respect to control

NS - not significant 


\begin{tabular}{|c|c|c|c|c|c|c|c|c|c|c|c|c|c|c|c|c|}
\hline \multirow[b]{2}{*}{ DOG } & \multirow[b]{2}{*}{ GROUP } & \multirow[b]{2}{*}{$\mathrm{N}$} & \multicolumn{2}{|c|}{ LVEDP } & \multicolumn{6}{|c|}{ SOURCE PRESSURE ( $\mathrm{mm} \mathrm{hg}$ ) } & \multicolumn{6}{|c|}{ SOURCE IMPEDANCE (dyne $e^{\star} \mathrm{sec} / \mathrm{cm}^{\star \star 5}$ ) } \\
\hline & & & MEAN & SEM & D.C. & SEM & $\mathbf{P}$ & FUND & SEM & $\mathbf{P}^{\prime}$ & D.C. & SEM & $\mathbf{P}$ & FUND & SEM & $\mathbf{P}$ \\
\hline 1 & C & 13 & 10.20 & 0.36 & $\mid 57.31$ & 0.81 & - & 68.53 & 1.00 & - & 157.09 & 38.17 & - & 400.78 & 54.27 & - \\
\hline 1 & B & 23 & 15.16 & 0.26 & 48.79 & 0.63 & .001 & 50.82 & $0.69 \mid$ & .001 & 188.60 & 6.44 & NS & 323.63 & 13.68 & NS \\
\hline 1 & $\mathrm{MI}+\mathrm{B}$ & 19 & 14.91 & 0.27 & 44.19 & 0.61 & .001 & 45,16 & 0.53 & .001 & 356.51 & 20.00 & .001 & 414.67 & 25.54 & NS \\
\hline 2 & C & 23 & 10.15 & 0.25 & 49.66 & $0.84 \mid$ & - & 60.29 & 1.01 & - & 221.05 & 17.23 & - & 526.55 & 27.71 & - \\
\hline 2 & MI & 26 & 13.71 & 0.35 & 47.21 & $0.60 \mid$ & .025 & 49.85 & $0.71 \mid$ & .001 & 216.82 & 15.88 & NS & 644.64 & $25.34 \mid$ & .005 \\
\hline
\end{tabular}

Table 3.2 
Table 3.3. Model parameters vs. left ventricular end-diastolic pressure, "HIGH-LOW" and "LOW-HIGH" runs.

DC - D.C. component of model parameters

$\mathbb{N}$ - number of runs

R - regression coefficient

I - correlation coefficient 


\begin{tabular}{|c|c|c|c||c|c||c|c|}
\hline \multicolumn{9}{|c|}{} & \multicolumn{2}{|c|}{ SOURCE PRESSURE DC } & \multicolumn{2}{|c|}{ SOURCE IMPEDANCE DC } \\
\hline DOG & GROUP & N & LVEDP RANGE $(\mathrm{mm} \mathrm{hg})$ & R(mm hg/mm hg) & $r$ & R(dyne $\left.{ }^{\star} \mathrm{sec} / \mathrm{cm}^{\star \star 5}\right) /(\mathrm{mm} \mathrm{hg})$ & $r$ \\
\hline 1 & $\mathrm{C}$ & 27 & $8.1-17.0$ & 3.99 & .889 & 68.66 & .824 \\
\hline 1 & $\mathrm{~B}$ & 47 & $12.7-24.0$ & 1.86 & .877 & 44.19 & .939 \\
\hline 1 & MI $+\mathrm{B}$ & 37 & $13.5-22.2$ & 1.26 & .855 & 34.63 & .685 \\
\hline 2 & $\mathrm{C}$ & 45 & $8.5-25.6$ & 2.08 & .965 & 20.61 & .885 \\
\hline 2 & MI & 55 & $10.2-22.5$ & 2.33 & .844 & 34.26 & .819 \\
\hline
\end{tabular}

Table 3.3 
Table 3.4. Mean aortic pressure vs. left ventricular end-diastolic pressure, "HIGH-IOW" and "LOW-HIGH" runs. $N$ - number of runs

R - regression coefficient I - correlation coefficient 


\begin{tabular}{|c|c|c|c||c|c|}
\hline \multicolumn{3}{|c||}{} & \multicolumn{2}{|c|}{ MEAN AORTIC PRESSURE } \\
\hline DOG & GROUP & N & LVEDP RANGE $(\mathrm{mm} \mathrm{hg})$ & R(mm hg/mm hg $)$ & $r$ \\
\hline 1 & C & 27 & $8.1-17.0$ & 4.93 & .886 \\
\hline 1 & B & 47 & $12.7-24.0$ & 2.92 & .835 \\
\hline 1 & MI+B & 37 & $13.5-22.2$ & 1.31 & .638 \\
\hline 2 & C & 45 & $8.5-25.6$ & 3.29 & .981 \\
\hline 2 & MI & 55 & $10.2-22.5$ & 3.84 & .844 \\
\hline
\end{tabular}

Table 3.4 
Figure 3.1. Thevenin's equivalent circuit.

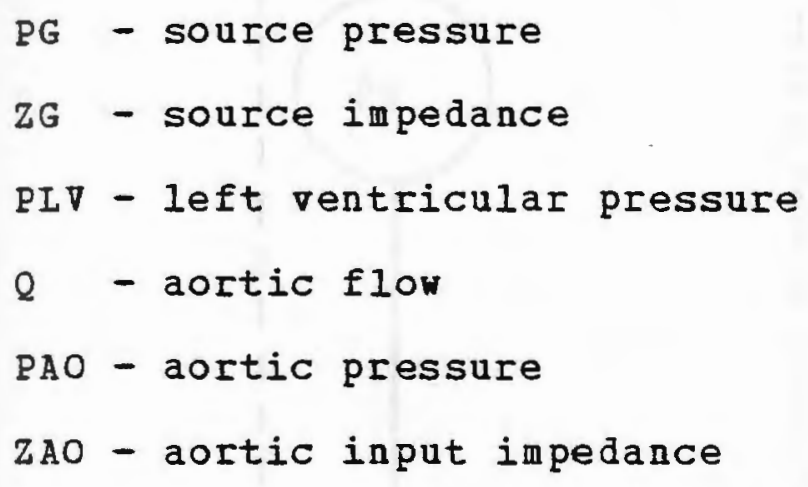




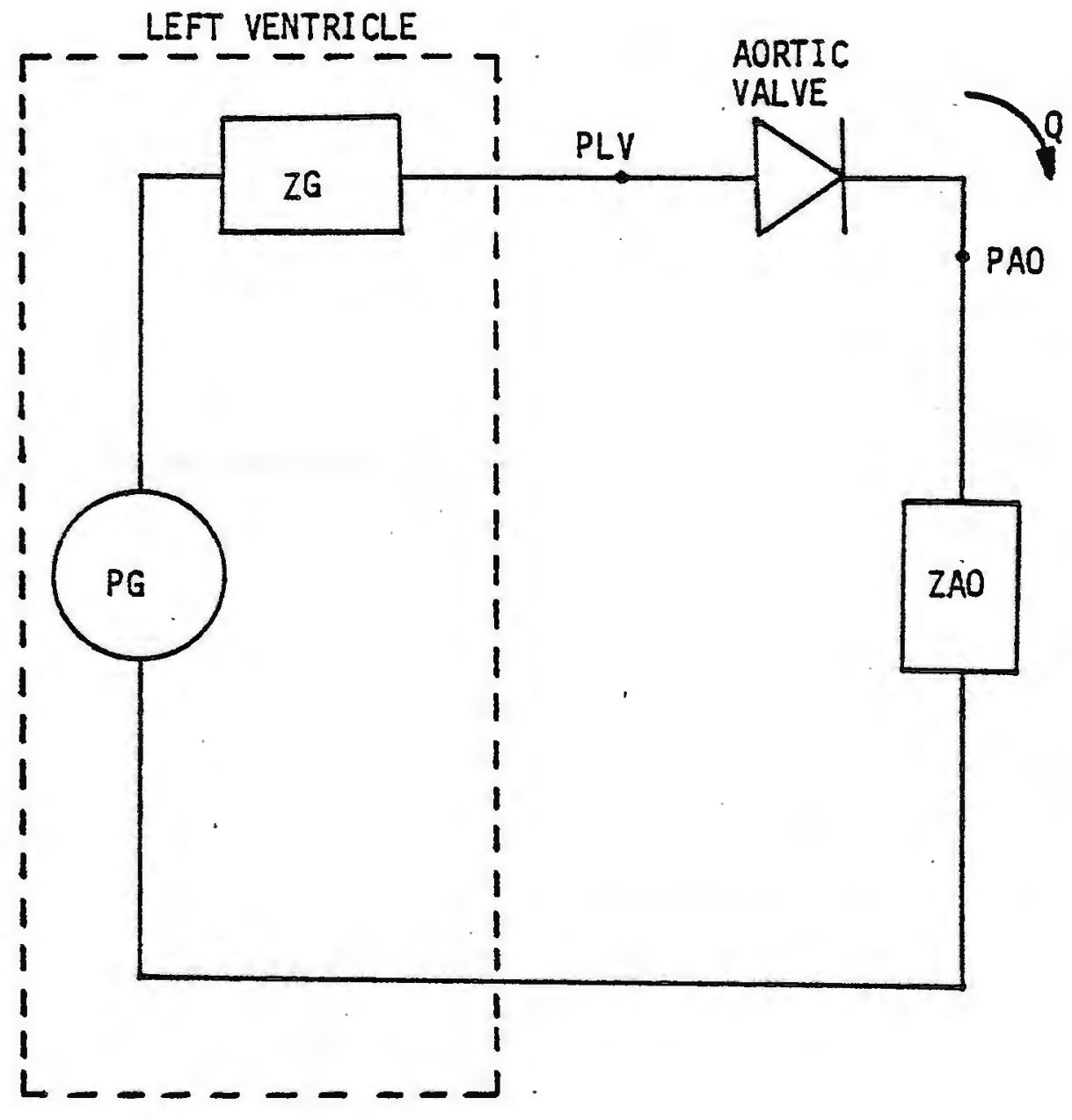

Figure 3.1 
Figure 3.2. Experimental setup. 


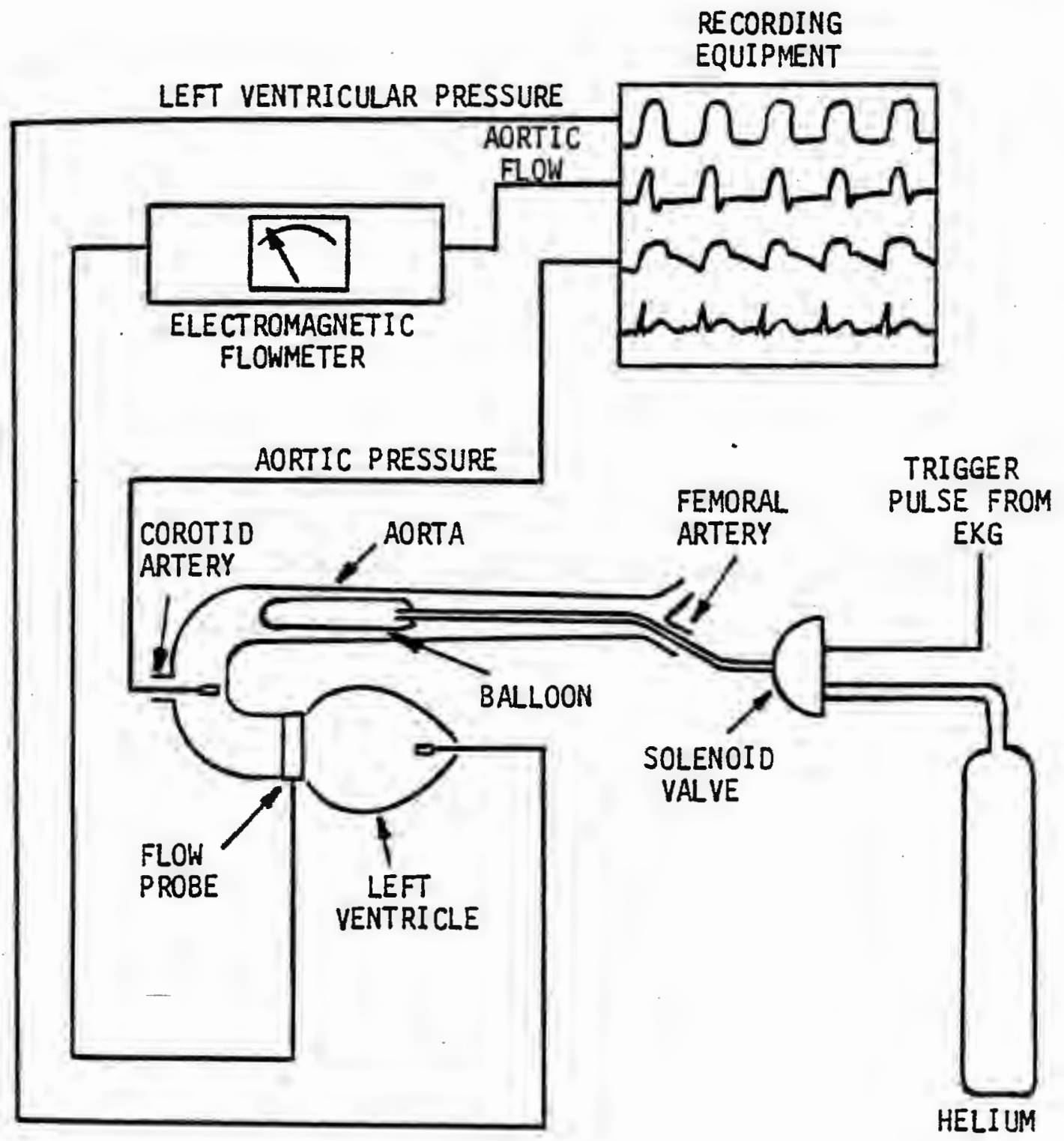

Figure 3.2 
page 41

Figure 3.3. Typical experimental data recorded for a "IOW-HIGH" run. 


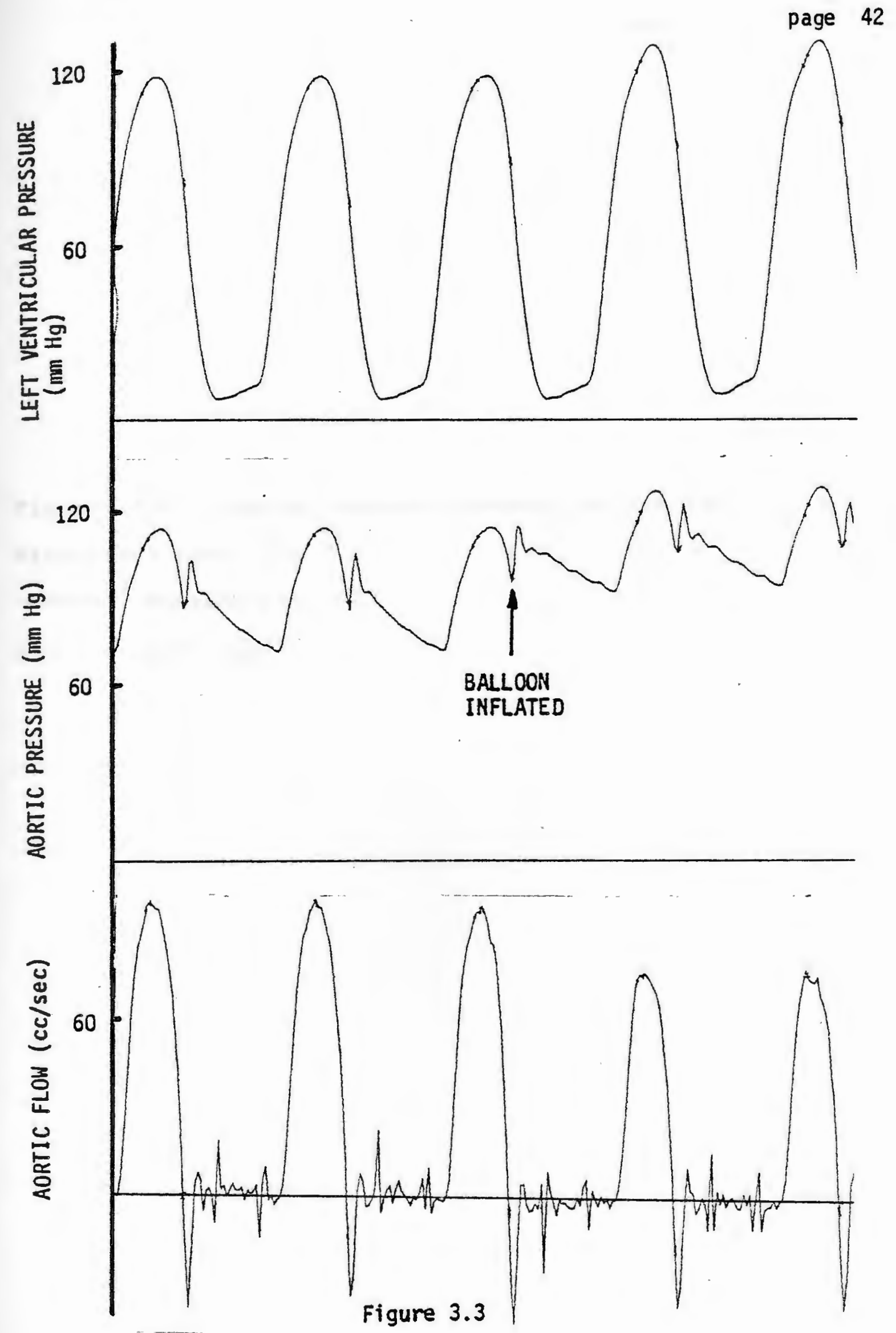


page 43

Figure 3.4. Typical source pressure (magnitude), "LOW-HIGH" IUnS, DOg 2.

control run (C)

-- (MI) run 
page 44

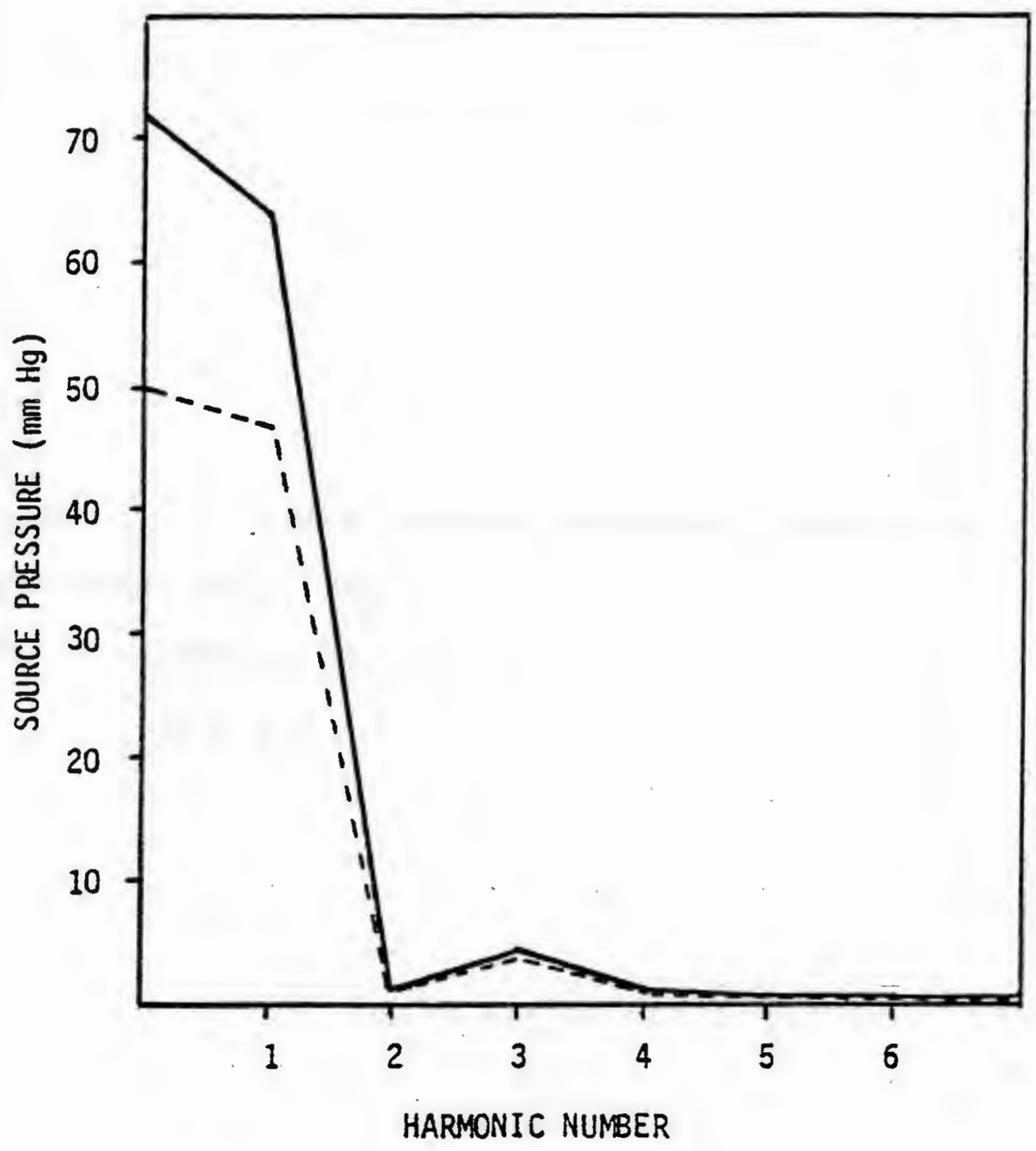

Figure 3.4 
page $\quad 45$

Figure 3.5. Typical source impedance (magnitude), "LOW-HIGH" runs, DOg 2.

control Iun (C)

- - (MI) IUn 


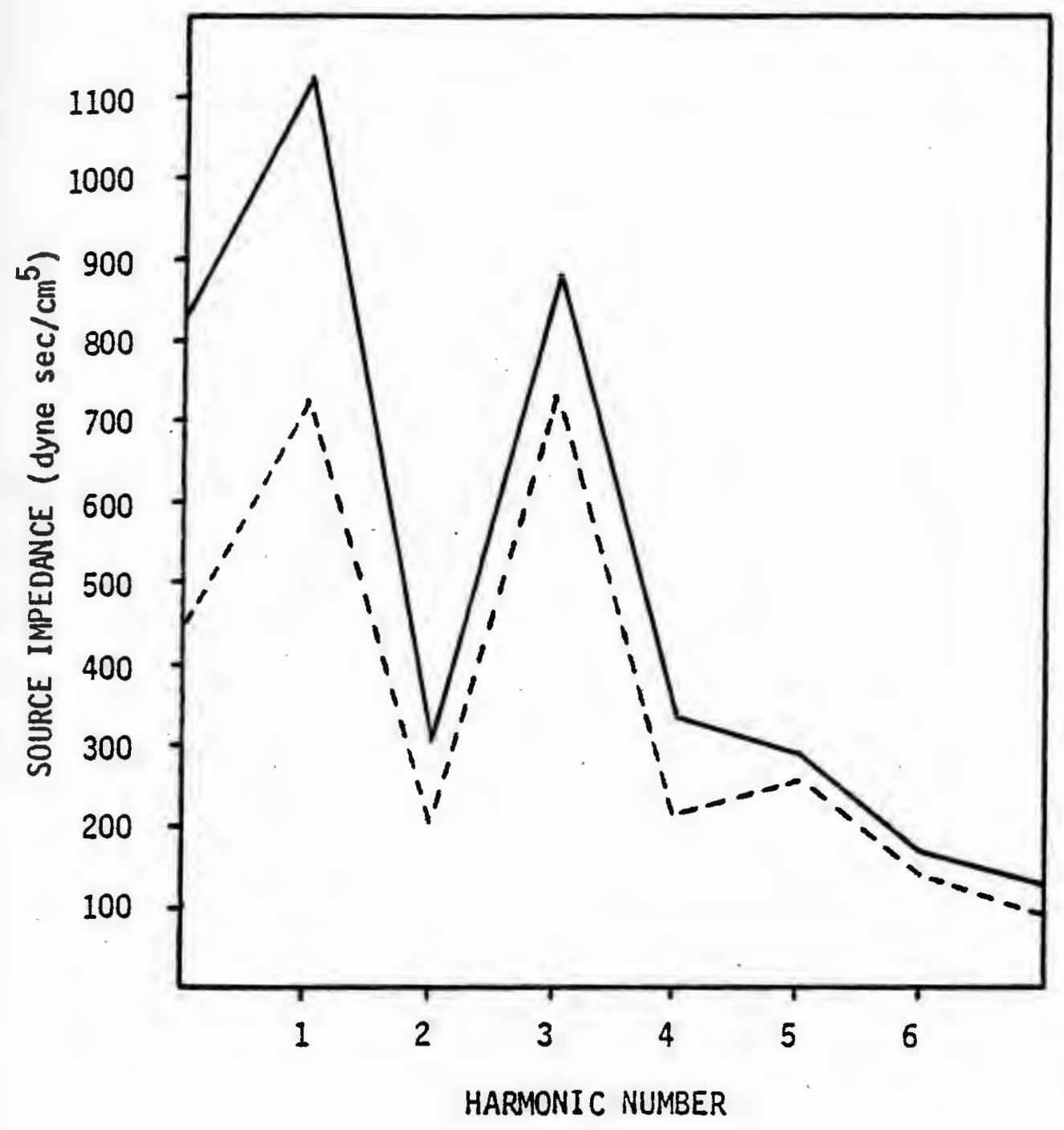

Figure 3.5 
Figure 3.6. Source pressure vs. left ventricular end-diastolic pressure, Dog 1. $N$ - control run (C)

D - (B) Iun $X-(M I+B)$ run 


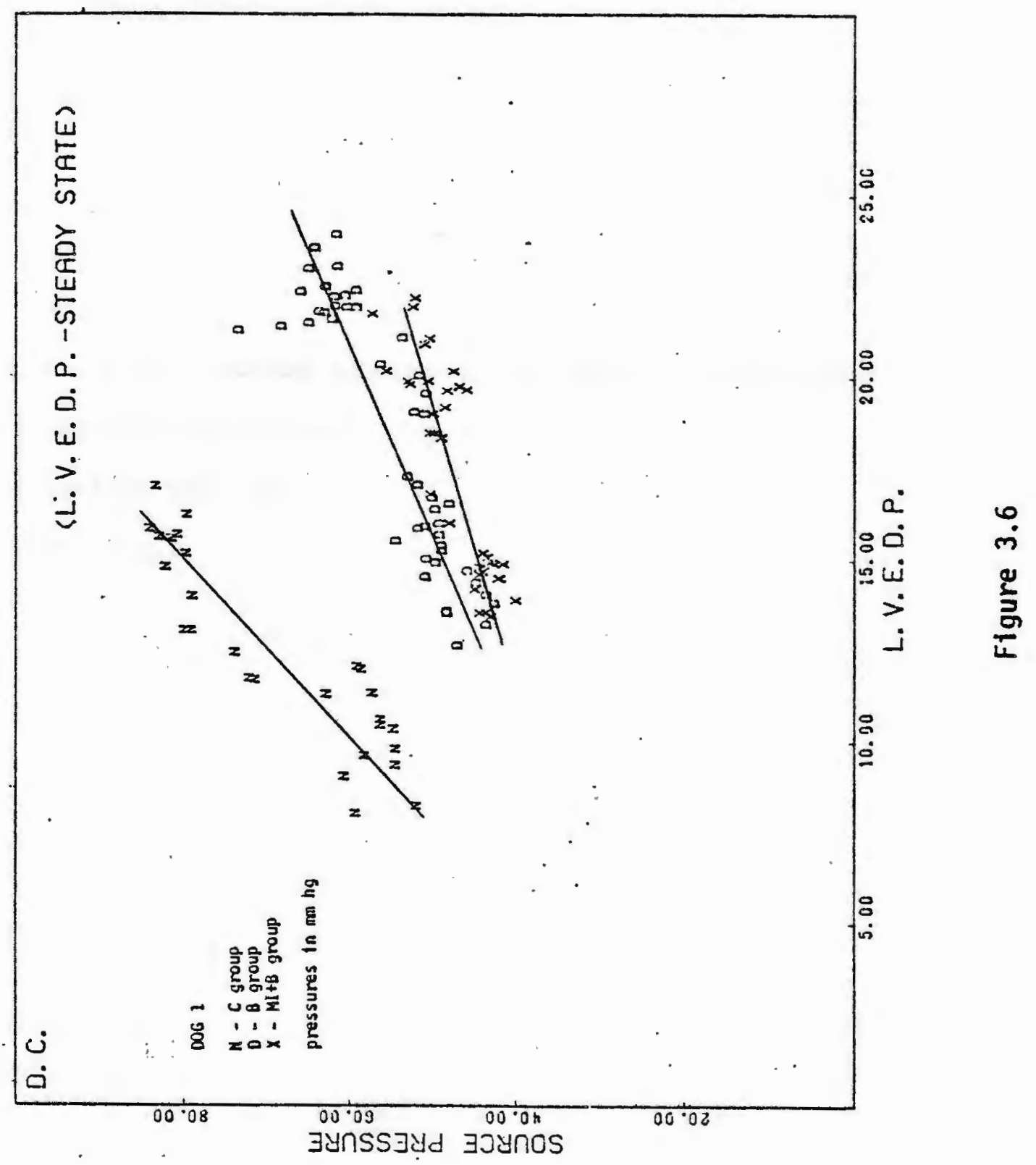


page 49

Figure 3.7. Source pressure vs. left ventricular end-diastolic pressure, Dog 2.

$\mathbb{N}$ - control run (C)

$0-$ (MI) run 


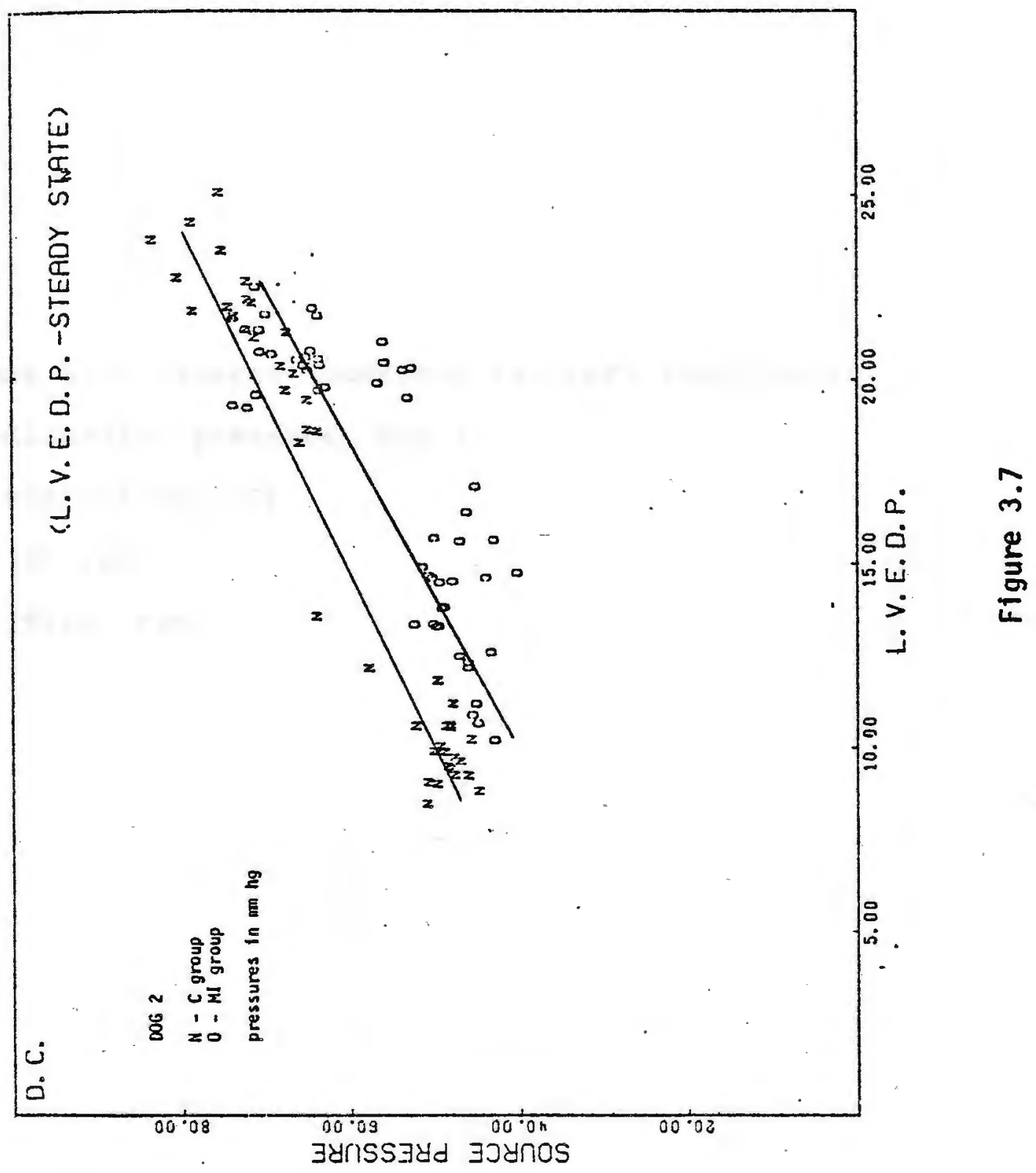


Figure 3.8. Source impedance $v$ s. left ventricular end-diastolic pressure, Dog 1. N - control run (C)

D - (B) Iun

$Z-(M I+B)$ run 


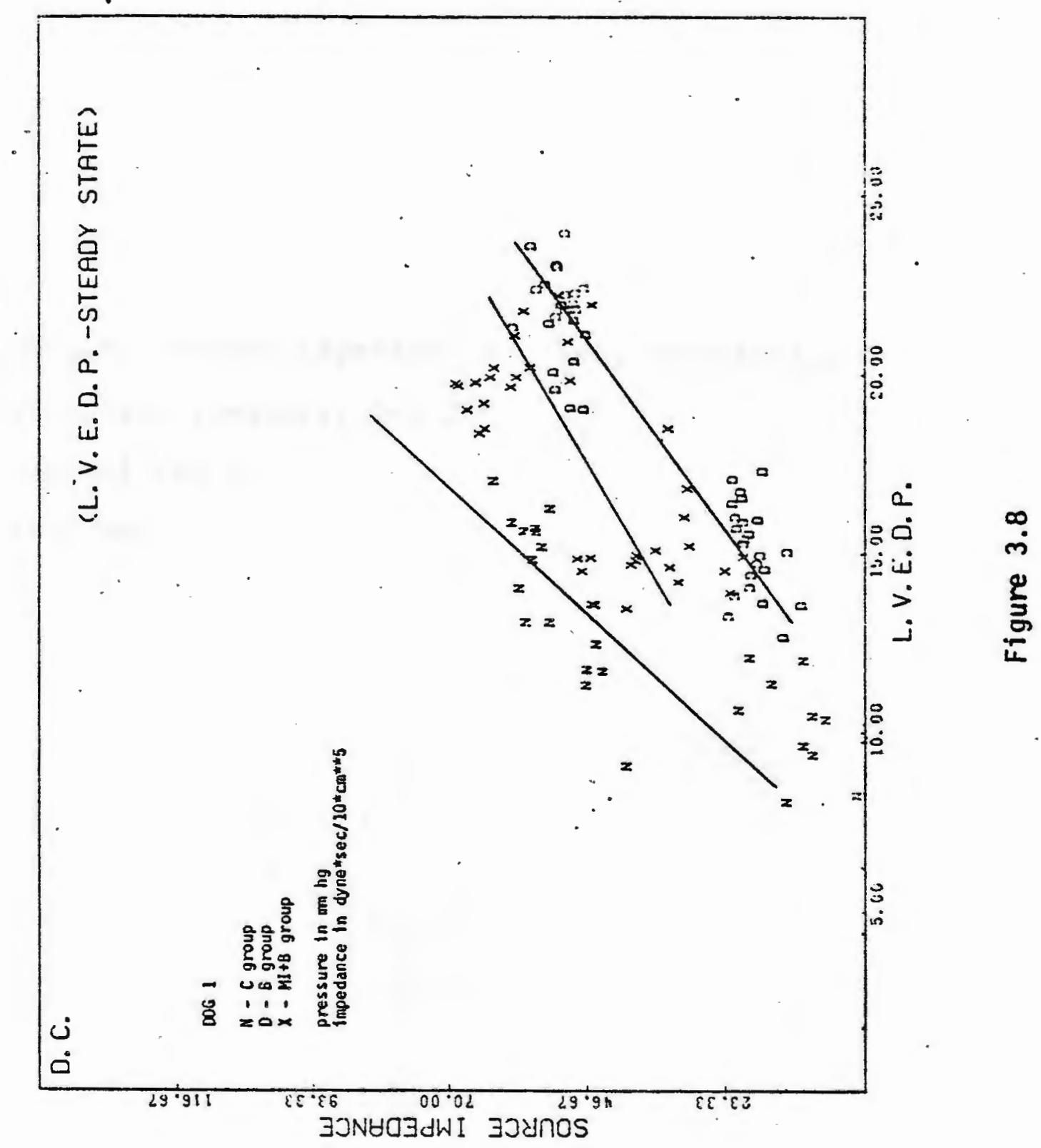


Figure 3.9. Source impedance vs. left ventricular end-diastolic pressure, Dog 2.

$N$ - control Iun (C)

o- (MI) run 


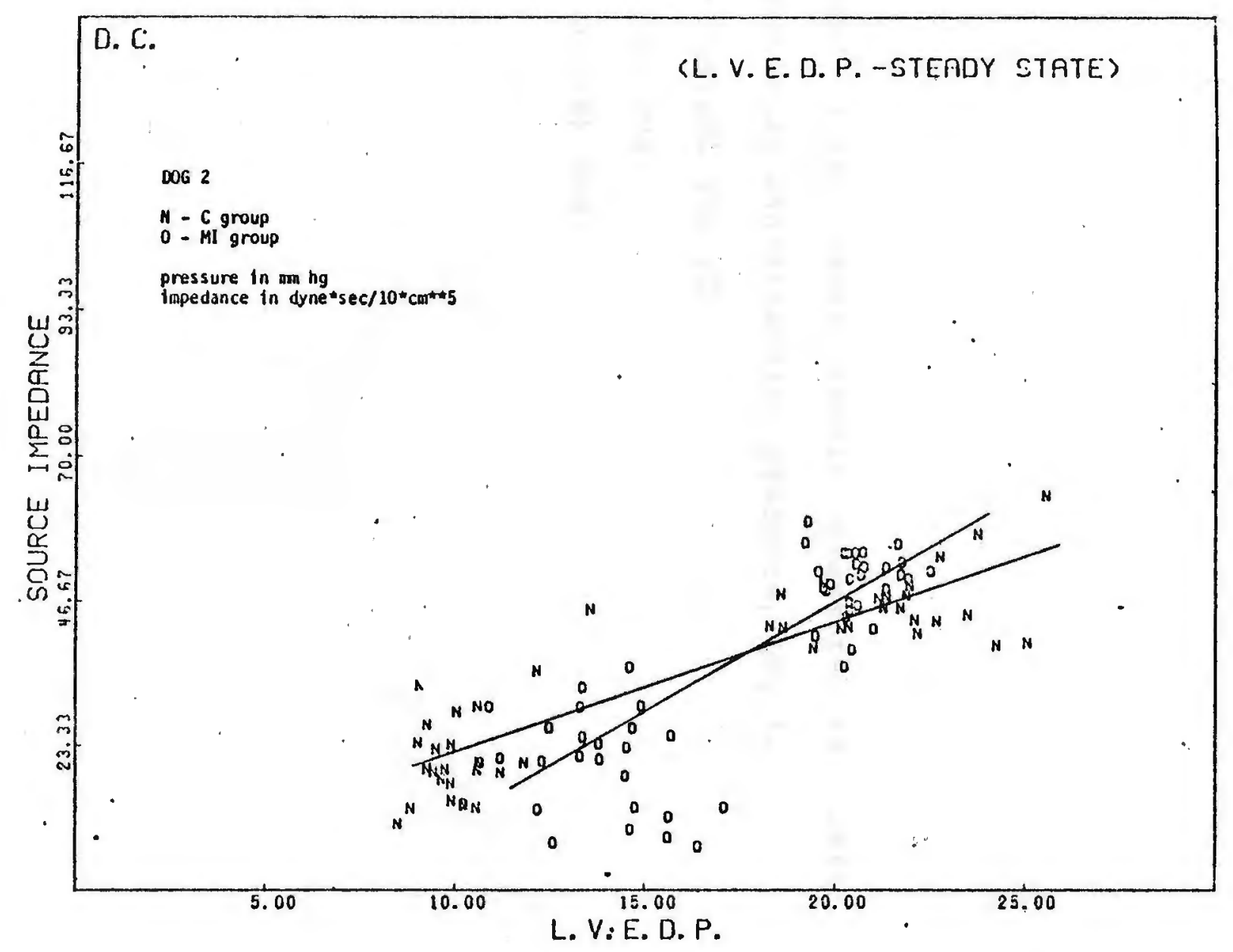

Figure 3.9 
page 55

Figure 3.10. Mean aortic pressure vs. left ventricular end-diastolic pressure, Dog 1. $N$ - control run (C)

$D-(B)$ Iun

$X-(M I+B)$ IUn 


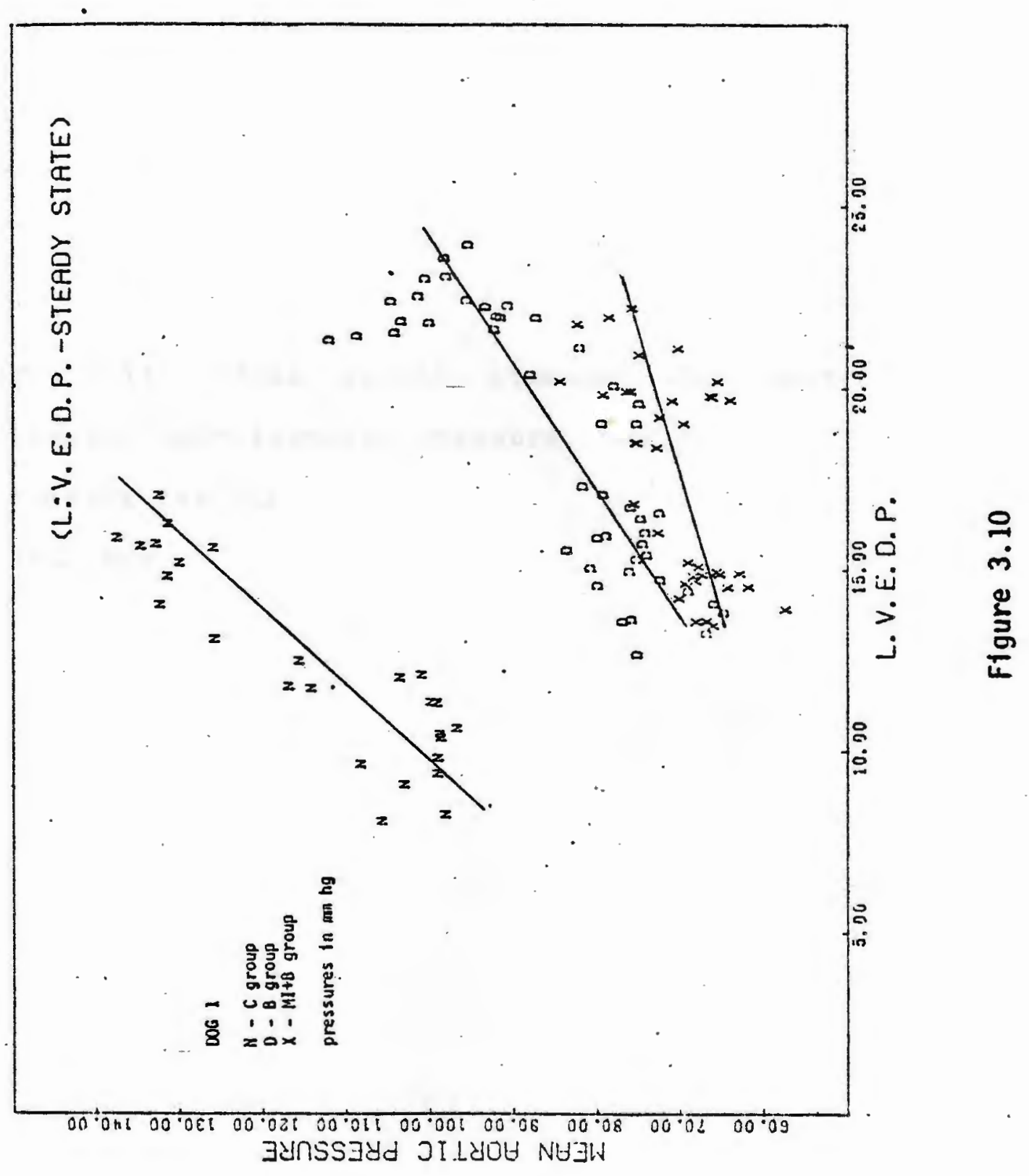


page 57

Figure 3.11. Mean aortic pressure vs. left ventricular end-diastolic pressure, Dog 2 . $N$ - control run (C)

0 - (MI) Iun 


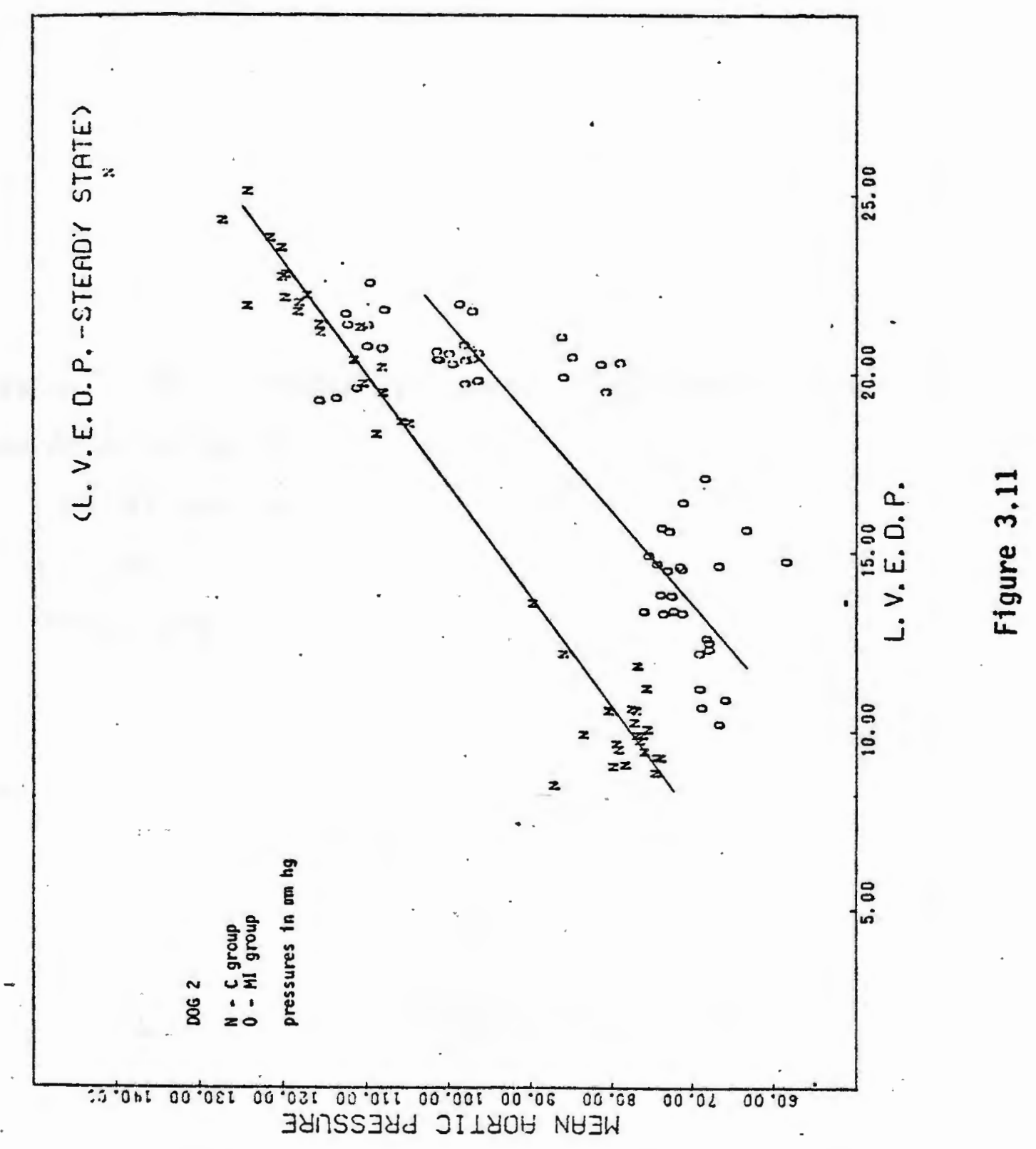


page 59

Figure 3.12. Source pressure displayed in the time domain, Dog 1.

$N$ - control Iun (C)

D - (B) run

$X-(M I+B)$ IUn 


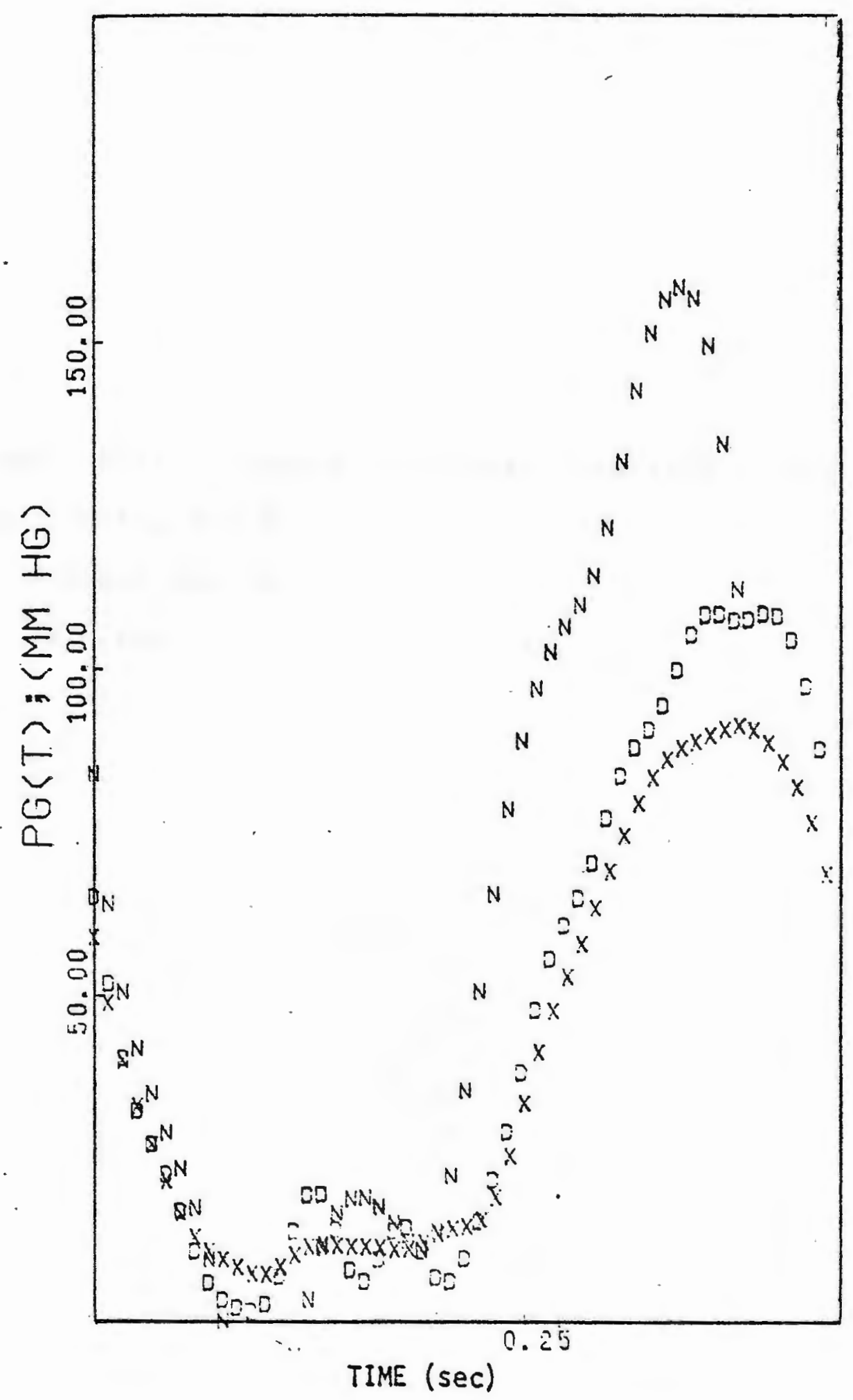

Figure 3.12 
page 61

Figure 3.13. Source pressure displayed in the time domain, Dog 2 .

$\mathbb{N}$ - control run (C)

o - (UI) run 


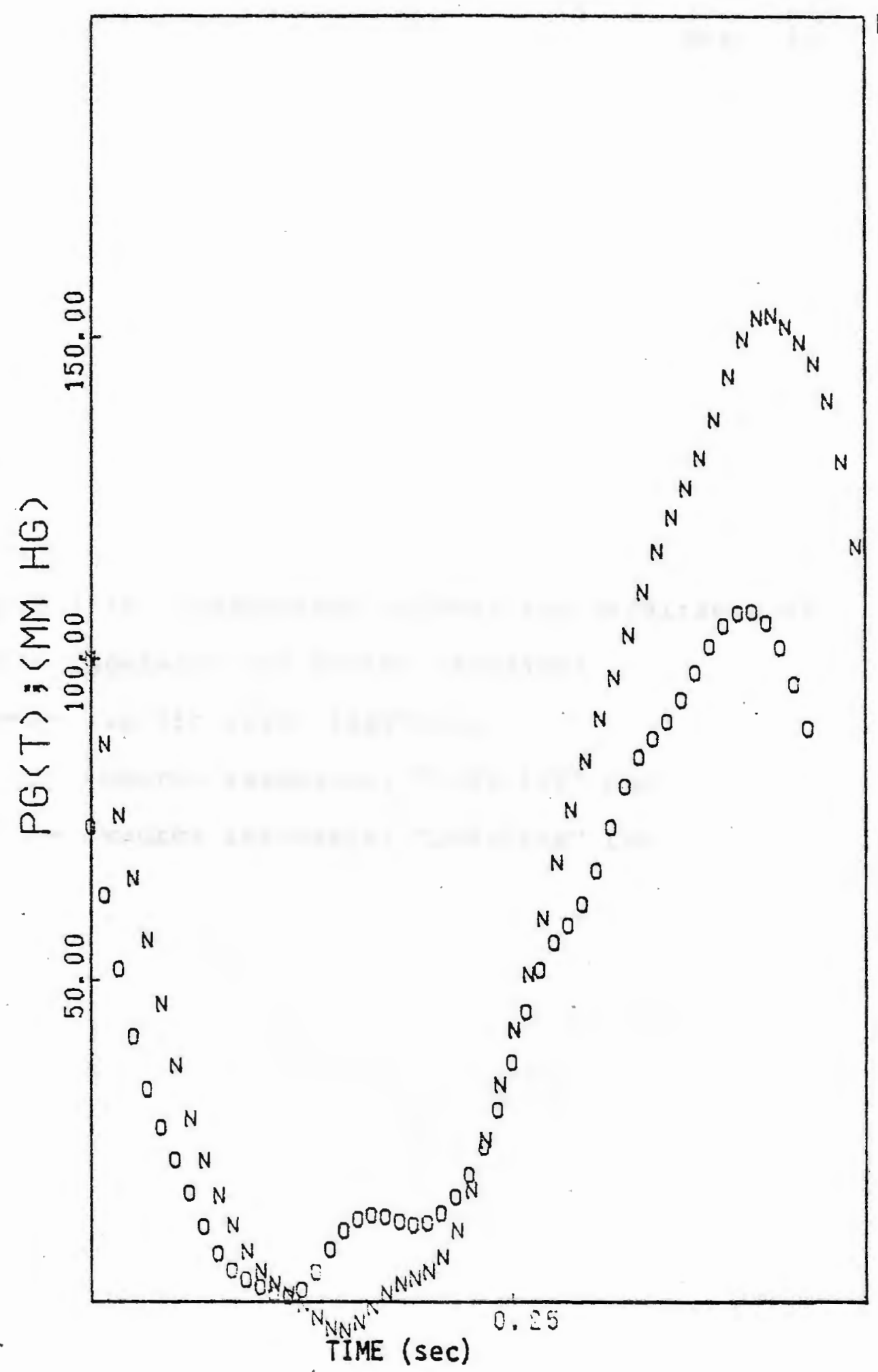


page 63

Figure 3.14. Comparison between the magnitudes of aortic impedance and source impedance.

- aortic input impedance

- - - source impedance, "HIGH-LON" run

- - - source impedance, "LOW-HIGH" run 


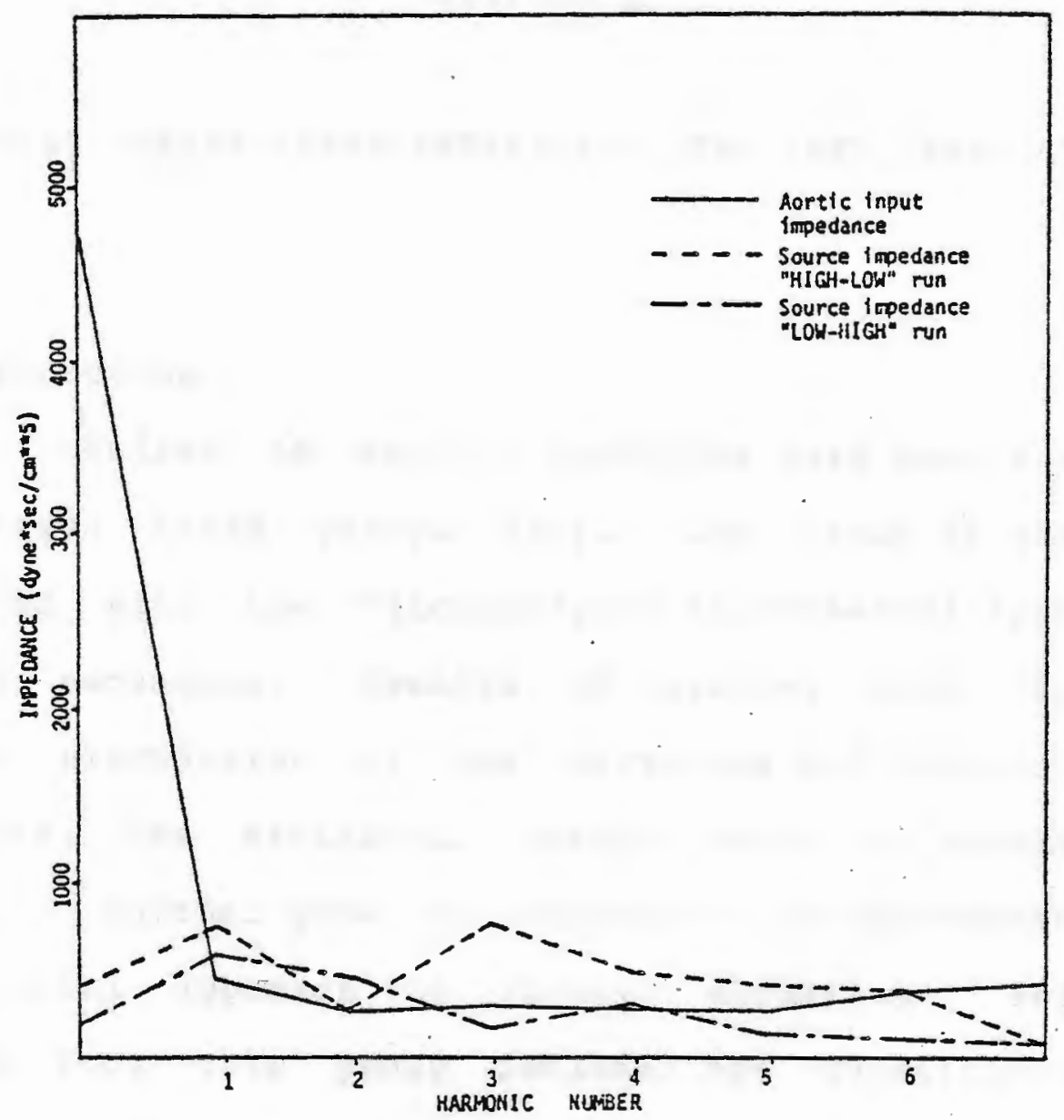

Figure 3.14 
CHAPTER IV

TIME DOMAIN REPRESENTATION OF THE LEFT VENTRICLE

A. Introduction

Studies of cardiac mechanics have been classified into three broad groups (28). One group of studies is concerned with the "microscopic" experimental approach to cardiac mechanics, Results of studies from this group include elucidation of the structure and function of the sarcomere, the myofibril, cardiac cells and muscle fibers (29-33). Another group is concerned with the "macroscopic" experimental approach to cardiac mechanics. Results of studies from this group include the quantification of myocardial tissue properties, such as the stress-strain relationship of myocardium $(34,35)$. The third group is concerned with a theoretical approach involving the analysis of mathematical models. For instance, the frequency domain models of the left ventricle (11-13) are included in results of studies from this group.

*

Portions of this research were presented at the Fifth New England Bioengineering Conference in Durham, New Hampshire, April. 1976. 
page 66

The purpose of this research is to develop a quantitative description of left ventricular function. Techniques and information from the three groups of cardiac mechanics studies are used. That is, a mathematical model of the left ventricle is presented which utilizes macroscopic information obtained from the left ventricle in-vivo and from myocardium in-vitro and which is consistent with microscopic cellular mechanics.

A major problem in applying cellular mechanics to the entire left ventricle arises due to the asynchrony of excitation of the left ventricle (36). The fibers of the left ventricle do not contract in a uniform fashion. During isovolumic contraction some fibers are shortening while others are being stretched (37).

Another major problem arises due to the fact that the load against which the left ventricle contracts is a complex function of time (36). This load contains inertial, frictional and elastic components (38).

Pressure generated within the ventricular chamber is a function of the geometry of the left ventricle and the stress developed within the ventricular wall. For a given myocardial stress, the intraventricular pressure is a function of the chamber radius (3) and the wall thickness (39). The distribution of stresses in the left ventricular wall is not only a function of fiber tension but also of the spatial orientation of the fibers (5).

Hence, an understanding of the relationship between 
forces of contraction in muscle fibers to the pressures and flows generated by the left ventricle requires detailed information such as fiber orientation, wall curvature, sequence of contraction, wall thickness (40) and left ventricular afterload (36).

The mathematical model presented here was developed with consideration of the above concepts as they pertain to the healthy left ventricle. Results of the simulated cardiac cycle are shown. With alterations in model parameters (as may be indicated by microscopic and macroscopic studies on infarcted myocardium) a refinement of the model should be capable of describing the function of a left ventricle containing myocardial infarct.

B. The Model

1. Geometric Formulation of the Model

The left ventricle was modeled with the constraint that the endocardial and epicardial surfaces can be represented by truncated confocal ellipsoids $(4,28,41)$. This representation conforms to the cutoff eggshell shape of the left ventricle and accounts for the spatial variation in left ventricular wall thickness. Due to the symmetry of the left ventricle (42), the modeling ellipsoids can be considered ellipses of revolution and can be studied in two dimensions. The equation of an ellipse (Figure 4.1) is 


$$
\frac{x^{2}}{a^{2}}+\frac{y^{2}}{b^{2}}=1
$$

where

$$
\begin{aligned}
x & =\text { location of a point along the } x \text {-axis, } \\
y & =\text { location of a point along the } y \text {-axis, } \\
2 b & =\text { major axis, } \\
2 a & =\text { minor axis. }
\end{aligned}
$$

The volume of an ellipsoid is

$$
\text { volume }=\frac{4 \pi}{3} a^{2} b
$$

The focal length (the distance from the center to either focal point) is

$$
c=\left(b^{2}-a^{2}\right)^{\frac{1}{2}}
$$

A confocal ellipse has the same focal length,

$$
c=\left(B^{2}-A^{2}\right)^{\frac{1}{2}}
$$

where $2 \mathrm{~B}=$ major axis, 


$$
2 \mathrm{~A}=\text { minor axis, }
$$

and,

$$
\frac{x^{2}}{A^{2}}+\frac{y^{2}}{B^{2}}=1
$$

Hence, for confocal ellipsoids (Figure 4.1),

$$
b^{2}-a^{2}=B^{2}-A^{2}
$$

2. Evaluation of Constants

In the present model the ellipsoids are confocal only at end-diastole. The end-diastolic dimensions were chosen as shown in Table 4.1 to be in the range of values used by other investigators $(4,28)$. These investigators obtained end-diastolic dimensions from measurements on canine left ventricles.

The inner semimajor (b) and inner semiminor (a) axes were determined from equations (4-2) and (4-7) and the values of RATIO and VOLOME. 


$$
\text { RATIO }=\frac{b}{a}
$$

$$
b=a \cdot \text { RATIO }
$$

The value of RATIO used is given in Table 4.1. volume is the volume contained by the intact ellipsoids. The value of VOLUME was such that the truncated ellipsoids contained the designated end-diastolic volume.

$$
\begin{aligned}
& \text { VOLUME }=\frac{4}{3} \pi a^{2} b \\
& a=\left(\frac{3 \text { VOLUME }}{4 \pi \text { RATIO }}\right)^{1 / 3}
\end{aligned}
$$

Thus, equations $(4-8)$ and $(4-9)$ were solved as two simultaneous equations in two unknowns, (a) and (b). The outer semiminor axis (A) was determined from the value of THICK (Table 4.1) and the inner semiminor axis (a):

$$
\text { THICK }=A-a
$$




$$
A=T H I C K+a
$$

The outer semimajor axis was determined from equation (4-6):

$$
b^{2}-a^{2}=B^{2}-A^{2}
$$

$$
B=\left(A^{2}+b^{2}-a^{2}\right)^{\frac{1}{2}}
$$

With constants (a) and (b) evaluated, given a $y$ dimension (y1), the corresponding $x$ locations of two points on the inner ellipsoid $\left(x_{1},-x 1\right)$ vere determined from equation (4-1) (Figure 4.1). Likewise, the corresponding $x$ locations on the outer ellipsoid $(\times 2,-\times 2)$ were found from equation (4-5) utilizing the values of (A) and (B) (Figure 4.1).

The ellipsoids were truncated at the "basal plane" as specified by the value of TRUNC (Table 4.1, Figure 4.1). The truncated ellipsoids were divided into cylindrical shells of equal height $(\Delta y)$. The y location of the midpoint of each shell $(\Delta y / 2)$ was determined. The end-diastolic inside and outside radii of each cylindrical shell vere determined by finding the $x$ locations on the inner and outer ellipsoids corresponding to the $Y$ locations of the midpoint of each shell (Figure 4.2). The inside end-diastolic radius 
(I (ed)) and the end-diastolic shell thickness (h(ed)) were determined for each cylindrical shell from the end-diastolic inside and outside radii. The resulting end-diastolic configuration of the left ventricle is displayed in Figure $4 \cdot 3$.

In addition to the end-diastolic geometric constraints, other specifications for the model were the total number of cylindrical segments, the end-diastolic pressure, cardiac output, heart rate, duration of isovolumic contraction and duration of ejection.

3. Assumptions Osed in the Analysis

1) The ventricular chamber has a uniform pressure distribution at end-diastole.

2) Stress is circumferential and uniform throughout the wall of each cylindrical shell.

3) The strain in the wall of each cylindrical shell can be represented by the strain at the midwall of the shell.

4) Blood is an incompressible, Newtonian fluid.

5) Flow through each cylindrical shell is laminar and unidirectional. 
6) The cylindrical shells contract sequentially, beginning at the ventricular apex.

7) The shells contract until a given stroke volume is produced, the radius of each shell changes sinusoidally and in proportion to the end-diastolic radius of the shell.

8) If the radius of a cylindrical shell reaches its end-systolic radius before the other shells have completed contraction it remains at that radius until all the shells reach their end-systolic radii.

9) During contraction, the inertia of the myocardium is negligible compared to forces generating static pressure.

10) The volume of cardiac muscle is conserved during contraction.

11) During isorolumic contraction, the volume of blood displaced by contracting shells is distributed in the shells of relaxed myocardium such that equal strain is produced in the passive shells.

4. Dynamics of the Model

a) Method of Contraction

Stress in the cylindrical shells was assumed to be 
circumferential. In consequence, contraction of the cylindrical shells is circumferential and there is no shortening of the left ventricle along the longitudinal axis during the simulated cardiac cycle. Whenever the radius of a cylindrical shell changes from its end-diastolic radius (I (ed)), the wall thickness of the shell is adjusted from its end-diastolic value (h(ed)) to conserve the volume of the shell wall. The volume of the shell wall is

$$
V_{m}=\pi(r(\text { ed })+h(\text { ed }))^{2} \Delta y-\pi(r(\text { ed }))^{2} \Delta y
$$

where

$$
v_{m}=\text { volume of the shell wall. }
$$

For conservation of volume at any radius, $r$, different from I(ed) the wall thickness, $h$, is adjusted from h(ed) so that:

$$
\pi(r(\text { ed })+h(\text { ed }))^{2} \Delta y-\pi(r(\text { ed }))^{2} \Delta y=\pi(r+h)^{2} \Delta y-\pi r^{2} \Delta y
$$

which reduces to, 


$$
h^{2}+2 r h-\left(2 r(\text { ed }) h(\text { ed })+h(\text { ed })^{2}\right)=0
$$

and solving for $h$,

$$
h=-r+\left(r^{2}+\left(2 r(e d) h(e d)+h(e d)^{2}\right)\right)^{\frac{1}{2}}
$$

where $I=$ the new inside radius of the shell

$\mathrm{h}=$ the adjusted wall thickness.

To simulate the action of the left ventricle in the model, contraction is initiated in the cylindrical shells sequentially, beginning at the ventricular apex.

b) Pressure-stress Relationship

Throughout the cardiac cycle, stress in the wall of each cylindrical shell is related to the pressure within the shell by the law of Laplace (Figure 4.4). The pressure within each cylindrical shell exerts an outward force on the shell, such that,

$$
\text { FORCE }=\text { PRESSURE } \cdot A R E A=P(2 r \Delta y)
$$


which is opposed by the sum of the forces in the two shell walls,

$$
\Sigma \text { FORCES }=2 \cdot S T R E S S \cdot A R E A=2 \sigma(h \Delta y)
$$

where $P$ = pressure within the shell

$r$ = inside radius of the shell

$\Delta y=$ height of the shell

$h=$ wall thickness of the shell from equation (4-16)

$\sigma=$ stress in the wall of the shell.

By equating these forces, an expression is obtained which relates wall stress to chamber pressure;

$$
\text { P2ray }=2 \sigma h \Delta y
$$

$$
P=\frac{\sigma h}{r}
$$

c) Stress-strain Relationship

Until contraction begins in a cylindrical shell, the shell mass exhibits the passive stress-strain properties of myocardium. These properties were derived from a 
stress-strain relationship for soft biological tissue (34):

$$
\sigma=B\left(\lambda^{2}-1 / \lambda\right) e^{a\left(\lambda^{2}+2 / \lambda-3\right)}
$$

where $\sigma=$ stress = force per unit cross-sectional area

$$
\begin{aligned}
\lambda & =\text { strain }=I / L(0) \\
L(0) & =\text { unstrained length of tissue } \\
L & =\text { strained length of tissue } \\
\alpha, B & =\text { constants. }
\end{aligned}
$$

The constants evaluated by Weiss for canine myocardium (35) are:

$$
\begin{aligned}
& a=3.0 \\
& B=5.0 \mathrm{~m} \mathrm{Hg}
\end{aligned}
$$

d) Pressure-volume Relationship

cylindrical shells which are not contracting exhibit passive compliant properties representing the compliance of myocardium in the passive state. These properties were derived from the stress-strain relationship of myocardium and the pressure-stress relationship of the cylindrical shells.

To establish the pressure-volume relationship of 
page 78

the model, the unstrained configuration of the cylindrical shells had to be determined. Tissue length $(L)$ is represented in the model by the midcircumference of the cylindrical shells;

$$
L=2 \pi(r+h / 2)
$$

Stress in the wall of the shell at end-diastole ( $\sigma(e d)$ ) was determined from end-diastolic geometry and end-diastolic pressure (P(ed)):

$$
\sigma(\text { ed })=\frac{P(\text { ed }) r(e d)}{h(e d)}
$$

Tissue length at end-diastole (L(ed)) is

$$
L(\text { ed })=2 \pi(r(\text { ed })+h(\text { ed }) / 2)
$$

The unstrained length of tissue ( $L(0)$ ) was determined by an iterative process utilizing equation (4-21); 
page 79

$$
\sigma(e d)=\beta\left[\left(\frac{L(e d)}{L(0)}\right)^{2}-\frac{L(0)}{L(e d)}\right] e^{\alpha\left[\left(\frac{L(e d)}{L(0)}\right)^{2+} \frac{2 L(0)}{L(e d)}-3\right]}
$$

If the cylindrical shell contained volume, $v(0)$, corresponding to tissue length, L(0), the walls of the shell would be unstrained and unstressed. The pressure within the shell would be zero.

If a cylinarical shell contained a volume (V) greater than $\nabla(0)$, the valls of the shell would be strained. The volume contained by the shell:

$$
V=\pi r^{2} \Delta y
$$

solving for $r$,

$$
r=\left(\frac{V}{\pi \Delta y}\right)^{\frac{1}{2}}
$$

the adjusted wall thickness,

$$
h=-r+\left(r^{2}+2 r(\text { ed }) h(\text { ed })+h(\text { ed })^{2}\right)^{\frac{1}{2}}
$$


and the strained tissue length,

$$
L=2 \pi(r+h / 2)
$$

where $r, h, I=$ strained radius, thickness, tissue length,

and,

$$
\lambda=\frac{L}{L(0)}
$$

where $\lambda=$ strain.

Strain in the myocardium of the shell wall results in stress in the myocardium according to equation (4-21);

$$
\sigma=\beta\left(\lambda^{2}-1 / \lambda\right) e^{\alpha\left(\lambda^{2}+2 / \lambda-3\right)}
$$

The stress in the shell wall, in turn, results in pressure within the shell according to equation (4-20);

$$
P=\frac{\sigma h}{r}
$$


page 81

Hence, the volume in the shell is related to the compliant pressure in the shell according to the properties of the shell wall.

e) Simulated Isovolumic Contraction

Before opening of the aortic valve, each

contracting shell exhibits wall stress equal to the stress developed by active cardiac muscle in isometric contraction. The value of isometric stress used was a value obtained from tests on papillary muscles (43). The volume of blood expelled by the contracting shells is transfered to the shells which have not yet begun contracting. Distribution of the volume is in proportions that cause equal strain to the passive shells. The cylindrical shell corresponding to the outlet of the left ventricle (the point of fixation to the cardiac skeleton) was constrained from expanding during isovolumic contraction. This area does narrow during ejection (42). As the wave of contraction progresses from ventricular apex to ventricular base, additional segments develop active stress and fewer segments exhibit compliant stress. Hence, during the simulated isovolumic contraction of the left ventricle, the end-diastolic volume is contained by the left ventricle but the geometry of the left ventricle changes. Left ventricular flow begins when all the shells are contracting. It is not until all the cylindrical shells developed active stress that the pressure proximal to the aortic valve is greater than the pressure distal to the 
valve.

f) Simulated Ejection

The cylindrical shells contract until the specified stroke volume is produced. If the radius of a cylindrical shell reaches its end-systolic radius before the other shells have completed contraction, it remains at that radius until all the shells reach their end-systolic radii. That is, no cylindrical shell contracts and returns to exhibiting passive compliant properties until ejection is completed. This is similar to healthy left ventricular function in-vivo in which parts of myocardium do not relax during ejection. If such relaxation did occur during ejection, the healthy left ventricle would bulge in the vicinity of the relaxed myocardium compromising cardiac output.

Inertial forces generated within the ventricular chamber were determined by calculating the change in mcmentum produced by the contracting shells.

$$
\vec{F}_{I}=\frac{D}{D t}(m \vec{v})
$$

where

$$
\begin{aligned}
\overrightarrow{\mathrm{F}}_{\mathrm{I}} & =\text { inertial force } \\
\text { D } / \mathrm{Dt} & =\text { material time derivative } \\
\text { m } & =\text { mass accelerated by the shell }
\end{aligned}
$$




$$
\vec{\nabla}=\text { velocity vector }=v_{x} i+v_{y} j+v_{z} k
$$

Assuming there is no change in the mass accelerated;

$$
\begin{gathered}
\vec{F}_{I}=m \frac{D}{D t}(\vec{v}) \\
=m(\partial \vec{v} / \partial t+\vec{v} \cdot \nabla \vec{v}) \\
=m\left(\partial \vec{v} / \partial t+v_{x} \frac{\partial \vec{v}}{\partial x}+v_{y} \frac{\partial \vec{v}}{\partial y}+v_{z} \frac{\partial \vec{v}}{\partial z}\right) \\
=m \vec{a}
\end{gathered}
$$

where $\overrightarrow{\mathrm{a}}=$ acceleration

$\partial \vec{v} / \partial t=$ local acceleration

$\vec{\nabla} \cdot \nabla \vec{\nabla}=$ convective acceleration.

The flow through the cylindrical shells was assumed to be laminar. In adition, the velocity of the fluid is in one direction (the $\mathrm{y}$ direction);

$$
F_{I}=m\left(\frac{\partial v_{y}}{\partial t}+v_{y} \frac{\partial v_{y}}{\partial y}\right)
$$


page 84

For simplification, keeping in mind the unidirectional velocity, let the velocity in the $y$ direction equal $\nabla$;

$$
F_{I}=m\left(\frac{\partial v}{\partial t}+v \frac{\partial v}{\partial y}\right)
$$

For analysis of the model, equation $(4-32)$ was considered in finite intervals. Define $x(i, j)$ as parameter $(x)$ with respect to cylinder (i) at time (j). Consider the inertial force imparted to the fluid by cylinder (n) in one unit of time (Figure 4.5). The flow through the cylinder (n) at time ( $t-1)$ was known (QTHRD) from the previous geometry of the cylindrical shells. The flow through cylinder (n) changed from time $(t-1)$ to time $(t)$ by $Q(n, t)$;

$$
Q(n, t)=\pi \Delta y\left(r(n, t-1)^{2}-r(n, t)^{2}\right) / \Delta t
$$

where $\Delta t=$ time $(t)$-time $(t-1)$.

Now,

$$
\begin{gathered}
\frac{\partial v}{\partial t}=(v(n, t)-v(n, t-1)) / \Delta t \\
v \frac{\partial v}{\partial y}=v(n, t)(v(n-1, t)-v(n, t)) / \Delta y
\end{gathered}
$$




$$
\begin{gathered}
v(n, t)=\frac{\text { QTHRU }+Q(n, t)}{\pi r(n, t)^{2}} \\
v(n, t-1)=\frac{Q T H R U}{\pi r(n, t-1)^{2}} \\
v(n-1, t)=\frac{Q T H R U+Q(n, t)}{\pi r(n-1, t)^{2}} \\
m=\rho \cdot Q(n, t) \cdot \Delta t
\end{gathered}
$$$$
\text { and, }
$$

where $\rho=$ density of blood.

So, combining equations (4-33) through (4-40), an expression for the inertial force generated by cylindrical shell (n) during the time interval from $(t-1)$ to $(t)$ is obtained:

$$
\begin{aligned}
& F_{I}(n, t)=\rho \cdot Q(n, t) \cdot \Delta t\left[\left(\frac{Q T H R U+Q(n, t)}{\pi r(n, t)^{2}}-\frac{Q T H R U}{\pi r(n, t-1)^{2}}\right) / \Delta t\right. \\
& \left.+\frac{Q T H R U+Q(n, t)}{\pi r(n, t)^{2}}\left(\frac{Q T H R U+Q(n, t)}{\pi r(n-1, t)^{2}}-\frac{Q T H R U+Q(n, t)}{\pi r(n, t)^{2}}\right) / \Delta y\right]
\end{aligned}
$$

The pressure developed $(P(n, t))$ as a result of the inertial force is 


$$
P(n, t)=\frac{F_{I}(n, t)}{\pi r(n, t)^{2}}
$$

Viscous forces generated within the ventricular chamber were determined by applying the Hagen - Poiseuille equation to each cylindrical shell (44). A pressure gradient $(\Delta P)$ must be maintained in the direction of flow to overcome frictional forces. For laminar motion of a Newtonian fluid in a round cylinder,

$$
\Delta P=\frac{8 \mu_{f} A_{A} l}{r_{0}^{2}}
$$

where $\mu_{f}=$ viscosity of the fluid

$$
\begin{aligned}
v_{A}= & \text { average velocity in a plane } \\
& \text { perpendicular to the flow path } \\
1= & \text { length of the cylinder } \\
r_{0}= & \text { inside radius of the cylinder. }
\end{aligned}
$$

In the notation of the model, the pressure gradient required to overcome frictional forces in cylinder ( $n$ ) at time ( $t$ ) is

$$
P_{v}(n, t)=\frac{8 \mu v(n, t) \Delta y}{r(n, t)^{2}}
$$




$$
=\frac{8_{\mu}(Q T H R U+Q(n, t)) \Delta y}{\pi r(n, t)^{4}}
$$

where $\mu=$ viscosity of blood.

5. Model Termination

The model was terminated at the aortic valve using data from the literature for canine aortic input impedance (Table 4.2). Aortic input impedance is defined as

$$
Z A O(\omega)=\frac{P A O(\omega)}{Q A O(\omega)}
$$

or,

$$
P A O(\omega)=Z A O(\omega) Q A O(\omega)
$$

Where $\mathrm{ZAO}=$ aortic input impedance

$$
\begin{aligned}
& \text { PAO = aortic root pressure } \\
& \text { QAO = flow into the aorta } \\
& \omega=\text { angular frequency. }
\end{aligned}
$$

The flow produced by the model was converted from the time 
domain to the frequency domain by Fourier transform;

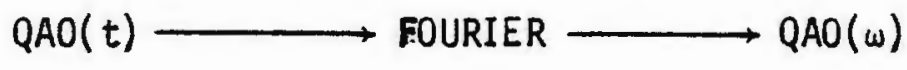

where $t=t i m e$.

The complex frequency domain components of aortic pressure were found from equation (4-45) and the data for aortic input impedance using phasor mathematics. That is, the magnitudes of the D.C. value and ten harmonics of aortic pressure vere determined by taking the product of the magnitudes of the corresponding harmonics of flow and impedance. The phase angles of the ten harmonics of aortic pressure were determined by taking the sum of the phase angles of the corresponding harmonics of flow and impedance. The frequency domain aortic pressure was then converted to the time domain by inverse Fourier transform;

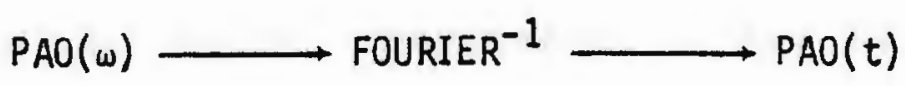

6. Simulated Myocardial Infarction

To simulate a left ventricle containing local areas of myocardial infarction, provision was made in the model to 
page 89

have designated segment/segments retain passive material characteristics throughout contraction. These segments do not contract during the isovolumic contraction period.

C. Results

The model was tested utilizing ten cylindrical segments. Parameters for the model were taken from the literature for a canine left ventricle $(4,9,28,38,45-48)$. All experimental results used for comparison with model results were obtained from dogs unless otherwise specified. The constants for the end-diastolic geometry of the left ventricle were specified as shown in Table 4.1. Other specifications for the model were: left ventricular end-diastolic pressure, $6.0 \mathrm{~mm}$ Hg; cardiac output, 1.8 liters/min.; heart rate, 141 beats/min.; duration of isovolumic contraction, .050 sec.; and duration of ejection. .125 sec..

Figure 4.6 shows the shape of the left ventricle at end-diastole. It also shows the cylindrical shell approximation.

The diastolic compliance of the left ventricular model was studied. The model of the left ventricle, assumed to retain diastolic material properties, was given various internal static pressures. The resulting stress in the wall of each shell was determined from the pressure-stress relationship (equation (4-20)). The strain to the 
page 90

myocardium was found from the stress-strain relationship (equation (4-21)). This strain was applied to various radial locations of the shell wall and, assuming conservation of volume of the shell wall, the resulting internal volumes were calculated. The pressure-volume relationships obtained for the left ventricle model are displayed in Figure 4.7.

Due to the asynchronous contraction of the cylindrical shells, the course of the radius and thickness of each shell is different over the simulated cardiac cycle. Figure 4.8 displays the variation of inside diameter with time at four locations of the left ventricle. The corresponding changes of wall thickness are also displayed. The percent change of radius and thickness with respect to end-diastolic radius and end-diastolic thickness for the same four locations are listed in Table 4.3. The percent changes were determined for the maximum dimension change during the isovolumic contraction period, for the change at the end of the isovolumic contraction period, and for the change at the end of the ejection period. It should be noted that an internal diameter at the apex of the left ventricle did not increase during the isovolumic contraction phase of the simulated cardiac cycle. This is because the apex is the first area of the left ventricle to be excited after the onset of contraction. As a result of excitation early in the heart cycle, by the beginning of ejection the diameter at the apex was smaller than the end-diastolic 
diameter. The blood mass expelled from the apex by the decrease in apical diameter over the isovolumic contraction period was moved toward the base of the left ventricle.

Figure 4.8 also shows that an internal diameter at the midpoint of the left ventricle increased slightly during the isovolumic contraction period, indicating that some of the blood mass expelled by the apex during this period was temporarily accomodated here. However, contraction began in this area a short time after contraction began at the apex, resulting in a net decrease in diameter by the end of the isorolumic contraction period (Table 4.3).

An internal diameter at the equator of the left ventricle began contracting later in the cardiac cycle than a diameter at the midpoint of the left ventricle. Hence, as illustrated in Figure 4.8 and Table 4.3 , a diameter at the equator increased a greater percentage than one at the midpoint during isovolumic contraction accomodating more blood mass expelled by contracting segments. Also, the late initiation of contraction resulted in a net increase in internal equatorial diameter during the isovolumic contraction period (Table 4.3).

An internal diameter at the base of the left ventricle (the last section of the left ventricle to begin contracting) expanded the greatest percentage during isovolumic contraction (Figure 4.8, Table 4.3).

The variation of the outside diameter over the simulated cardiac cycle at the equator of the left ventricle 
appears in Figure 4.9. Also shown in Figure 4.9 are the percent changes of outside diameter with respect to end-diastolic outside diameter at the end of isorolumic contraction and at the end of ejection.

The outline of the left ventricular chamber at three instances of the simulated cardiac cycle is displayed in Figure 4.10. Left ventricular flow and aortic pressure produced by the model are shown in Figure 4.11.

The pressure distribution throughout the ventricular chamber was determined for different instances in the cardiac cycle. As the myocardium in the vicinity of the ventricular apex began contracting, pressures due to the active stress in the myocardium were developed in the apical area while pressures due to the compliance of the myocardium were generated in all the passive segments. As contraction progressed from the ventricular apex towards the aortic valve, additional segments developed active stress and fewer segments generated compliant stress. The pressure distribution immediately before the opening of the aortic valve is displayed in Figure 4.12. During the ejection phase of the cardiac cycle, pressures vere generated due to the viscous and inertial forces within the left ventricle (Figure 4.13).

To study the function of a left ventricle containing an area of myocardial infarct, a cylindrical shell near the apex of the left ventricle (segment number 7) was constrained to display only passive characteristics of 
myocardium throughout the cardiac cycle. This segment did not contract auring the isovolumic contraction period. The resulting pressure distribution and geometric configuration at the end of the isovolumic contraction period is shown in Figure 4.14 .

D. Discussion

This representation of the left ventricle was developed by simulating the aynamics of the left ventricle through the cardiac cycle. The model emphasizes the synergism of the cardiac muscle mass by considering the mass divided into discrete sections. The constraints imposed on the dynamics of the sections and on the relationship between the sections are supported or indicated by physiologic observations. The pressure and flow waveforms produced by the model are similar to those measured experimentally (Figure 4.11). The pressure distribution in the left ventricular chamber throughout the cardiac cycle is such that blood tends to move towards the aortic valve (Figures 4.12, 4.13). The timing and sequence of cardiac contraction assumed in this model and the resulting geometric changes are responsible for establishing and maintaining the observed pressure distribution within the chamber. 
page 94

1. Model Assumptions and Constraints

The end-diastolic constraints presented in Table 4.1 for the Dieudonne and streeter left ventricular models were obtained from measurements on canine left ventricles. The values used for the model presented here vere chosen in the range of the Dieudonne and Streeter values. However, the values of end-diastolic volume used by Dieudonne and Streeter differ significantly; 35.0 and 52.4 cc.. respectively. In the present model an end-diastolic volume of $35.0 \mathrm{cc}$. was chosen. This value is in agreenent with data from other investigators $(9,46)$.

The muscle fibers in the wall of the left ventricle are mostly oriented circumferentially. The proportion of fibers angled less than 22.5 degrees from the circumference to those angled more than 22.5 degrees from the circumference is $10: 1$. The ratio is smaller at the apex of the left ventricle. (5) Hence, circumferential stress predominates over longitudinal stress in $80 \%$ of the left ventricular wall (49).

In the model, stress is assumed to be $100 \%$ circumferential. The dynamics of the model are affected in two ways by this assumption. First, due to the lack of longitudinally oriented muscle fibers, there occurs no shortening of the left ventricle along the longitudinal axis during the simulated cardiac cycle. The constraint that the left ventricle does not shorten along its longitudinal axis during contraction is a close approximation to the action of 
page 95

the left ventricle in-vivo. The left ventricle incurs no change in length during isovolumic contraction $(9,50-53)$ and a small shortening during the ejection phase of the cardiac cycle (7\% (9), 5-7\% (54), 4.7\% (55), 4. 4\% (53), <1\% (42,51). To allow a longitudinal shortening of this left ventricular model would complicate the analysis. The small shortening of the left ventricle found in-vivo does not seem to justify that complication.

The circumferentially oriented muscle fibers encompass a smaller radius than longitudinally oriented fibers. Therefore, by the law of Laplace circumferentially oriented fibers generate higher chamier pressures than longitudinally oriented fibers. Hence, the second effect of the assumption of $100 \%$ circumferentially oriented muscle fibers could be exaggerated ventricular chamber pressures produced by the model. This effect is discussed further in the section on Chamber Pressure Distribution.

Conservation of myocardial volume during contraction was assumed in the model. The volume change reported for skeletal muscle undergoing contraction was less than .01\% (56). It is likely that the volume of cardiac muscle is similarly conserved during contraction.

Contraction by the cylindrical shells was assumed to be sequential, beginning at ventricular apex. As indicated by the application of epicardial leads onto the left ventricle, the spread of excitation is upward and toward the left (57). BY insertion of intramural 
page 96

electrodes, it was shown that the epicardial excitation pattern reflects the movement of the intramural excitation wave (58). The above tests were performed on human left ventricles. Intramural excitation patterns are similar in human and canine hearts (59). The result of this excitation pattern is that a "peristalticlike" wave of contraction begins at the apex of the left ventricle and moves toward the outflow tract $(60)$. A peristalticlike wave of contraction is simulated in the model by the sequential contraction of the shells.

The Laplace relationship was derived assuming conditions of static equilibriun, which is not correct for a beating rentricle. That is, the forces on either side of equation (4-19) are not equal, but differ by the force required to accelerate the ventricular wall. However, it has been shown that the forces due to inertia of the ventricular wall are less than $1 \%$ of the wall force developing static pressure (61). In the present model, the force required to accelerate the myocardium during contraction was determined. This was accomplished by calculating the product of the mass of the shell wall and the acceleration of the center of mass of the shell wall for each instant in the simulated cardiac cycle (see Appendix E). The inertial force due to acceleration of the myocardium was always less than $1.9 \%$ of the force generating static pressure. Therefore, the laplace relationship appears to be a good approximation in analysis of the left 
ventricle.

The pressure-volume relationship derived from using the midwall strain to relate pressure and volume is displayed in Figure 4.15. Also displayed in Figure 4.15 is a left ventricular pressure-volume relationship obtained experimentally on excised canine hearts (45). The similarity of these data indicate that the strain at the midwall of the shell can be used in this model to relate pressure and volume within the ventricular chamber.

The radius of each shell changes sinusoidally. Results from numerous investigators who used various techniques to monitor left ventricular diameter indicate that the change in left ventricular diameter during contraction is approximately sinusoidal (Figure 4.16). The radius of each cylindrical shell changes in proportion to the end-diastolic radius of the shell. The ventricular wall is composed essentially of a ring of sarcomeres, hence a percentage change in sarcomere length will be reflected by the same percentage change in circumference (46). Por a specific state of cardiac contractility, therefore, it does not seem unreasonable to assume that the sarcomeres in different cylindrical shells contract the same percentage and this is reflected by the radii of the shells shortening the same percentage of their respective end-diastolic radii. The rationale to the radii of the cylindrical shells contracting a given percentage of their respective end-diastolic radii has been discussed. It should be noted 
page 98

that the radii do so regardless of events during the isorolumic phase of the cardiac cycle, during which geometric changes to the left ventricle occur. In support of this characteristic of the model, there is evidence that, at a particular cardiac contractility, the left ventricle returns to the same end-systolic dimensions regardless of end-diastolic dimensions (62). This property of the left ventricle may be a reflection of a property of isolated cardiac muscle. For isolated cardiac muscle the relation between length and tension at maximum contraction is largely independent of initial muscle length (63).

The constraint that any shell reaching its end-systolic radius remains in active tension until contraction in all the shells is completed is justified by consideration of physiologic data. It has been shown on dogs that duration of cardiac action potential varies with heart rate, ranging from $250 \mathrm{msec}$. at a heart rate of 60 beats/min. to 150 msec. at a heart rate of 300 beats/min. (64). The fall of tension in the myocardium is more or less coincident with the end of the action potential (65). Hence, in the model, if the duration of isovolumic contraction plus the duration of ejection were chosen to be less than duration of action potential at a specific heart rate, tension would not cease in the myocardium of any shell before ejection was completed. Herein, the heartrate was specified at 141 beats/min.. This corresponds to duration of an action potential (and maintainance of an active state) 
page 99

of $200 \mathrm{msec}$. (64). The sum of the specified duration of the isovolumic phase and the specified duration of the ejection phase of the simulated cardiac cycle is 175 msec.. Accordingly, tension would not fall in any shell until after ejection is complete.

Abnormal left ventricular function could be caused by local areas of malfunctioning myocardium interacting with other areas of completely normal muscle (26). An area of damaged (infarcted) myocardium could result from occlusion to the coronary artery supplying blood to the area. The muscle may be structurally normal but unable to contract due to interference with the excitation-contraction linkage (i.e. changes to the sarcotubular system of the cells or changes to the myofilaments in the sarcomeres) (26). The infarcted tissue interacts with healthy tissue in a passive manner. To simulate local myocardial infarction in the model, a cylindrical section was constrained to retain passive material properties during contraction. The cylindrical sections adjacent to the infarcted segment exhibited normal contractile activity.

In developing the present model, it was assumed that blood mass displaced during isovolumic contraction by contracting shells was distributed in the passive shells in such a way that the passive shells were equally strained. This assumption is not supported by physiologic evidence and hence, may be a basic source of inaccuracy in the model. 
page 100

2. Changes in Left Ventricular Diameter

As shown in Table 4.3, the end-systolic internal diameter of the left ventricular model is $20.4 \%$ smaller than the end-diastolic internal diameter. This value is very close to values obtained experimentally (20.3\% (55) . $20.2 \%$ (66)). The time course of left ventricular internal diameter at four locations in the left ventricle is displayed in Figure 4.8 .

Figure 4.8 shows that an internal diameter at the midpoint of the left ventricle increased slightly during the isovolumic contraction period. However, a diameter at the midpoint sustained a net decrease by the beginning of ejection (Table 4.3). This is in agreement with experimental results obtained by application of various dimensional monitoring techniques to the left ventricle. Implantation of radiopaque markers on the endocardium and subsequent cinefluorographic studies showed a net decrease in the internal diameter at the midpoint of the left ventricle during isovolumic contraction (Figure 4.17) $(50,62)$. A catheter tip instrument for monitoring left ventricular internal diameter demonstrated a net decrease in internal diameter at the midpoint of the left ventricle during isovolumic contraction (67). Implantation of ultrasonic transducers on the endocardium and measurements with a sonomicrometer revealed a net decrease in internal diameter at the midpoint of the left ventricle during isovolumic contraction (Figure 4.17) (66). 
page 101

As illustrated in Figure 4.8 and Table 4.3, an internal diameter at the equator of the left ventricle increased a greater percentage than one at the midpoint during isovolumic contraction. An equatorial diameter sustained a net increase by the beginning of ejection. The similarity of model results to experimental results obtained using ultrasonic techniques is demonstrated in Figure 4.18 $(68) \cdot$

An internal diameter at the base of the left ventricle sustained the greatest expansion during isovolumic contraction (Figure 4.8, Table 4.3). Similarity of these results to experimental results obtained utilizing ultrasonic techniques is shown in Figure 4.19 (48). The basal "bulge" was shown to disappear when the normal excitation pattern of the left ventricle was disturbed by spontaneous rentricular pacing (ectopic focus) $(48,69)$. This indicates that the increase in left ventricular basal diameter during the isovolumic contraction period may be a result of the normal asynchrony of contraction in the left ventricle.

The percent change of the equatorial outside diameter from end-diastole to end-systole as determined by the model was $7.1 \%$ (Figure 4.9). This is significantly less than the percent change of the equatorial inside diameter, 20.4. The difference is due to thickening of the left ventricular wall during contraction. Percent changes of the equatorial outside diameter obtained experimentally (7.3\% 
page 102

(55) and $7.0 \%$ (70)) were remarkably similar to those obtained in the model. Experimental results and model results are also similar regarding the pattern of contraction of outside equatorial diameter (Figures 4.9, $4.20)$.

\section{Changes in Mural Thickness}

The time course of left ventricular wall thickness corresponding to the left ventricular diameter changes described above is displayed in Figure 4.8. It can be seen from Pigure 4.8 and Table 4.3 that the wall thickness changed inversely to the respective diameter changes. This is necessary to conserve wall rolume.

percent changes of wall thickness with respect to end-diastolic wall thickness are displayed in Table 4.4 for model results and experimental results. The tabulations are for changes incurred over the isovolumic contraction period and for changes incurred over the entire cardiac cycle at three locations of the left ventricle. Most of the experimental results reported in Table 4.4 were obtained by tests, utilizing strain gages placed through the heart wall. These gages had to be adjusted to the end-diastolic thickness of the wall manually or by use of spring tension. If the myocardium (relaxed and flaccid during diastole) is indented by the gage, at the onset of contraction (when the myocardium becomes stiff) an inadrertent thickness change is 
page 103

recorded before any change occurs $(40,48)$. The initial rapid increase in thickness seen in some experimental results (Figure 4.21 ) could be an example of this experimental artifact. This could explain why some of the experimental values for percent change of wall thickness obtained by strain gage measurements are higher than model values (Table 4.4). Aside from the experimental results that may be exaggerated due to this experimental artifact, experimental and model results regarding overall percent change in wall thickness are similar: at the apex, 10.7 and 11.9. respectively; at the midpoint of the left ventricle, 10.0 and 13.7 , respectively; at the base, 9.3 and 13.7 respectively.

The percent change in wall thickness at the apex of. the left ventricle obtained from the model (11.9) falls within the range of the standard error of experimental results $(10.7+/-2.1)(71)$. It should be noted that these experimental results were obtained from pigs.

The experimental results reported for percent wall thickness change at the midpoint of the left ventricle $(10.0,9-12 \%)$ (72) were obtained by strain gage measurements. Der Meer notes that the percent change obtained in the experiments was found to be dependent on the force with which the gage was applied to the heart. These results are smaller than the corresponding change indicated by the model (13.7). During the experiments, it is possible that the gage was not set with enough tension during 
page 104

diastole. This would cause the results obtained in the experiments to be too small.

The experimental results for percent change in wall thicknes at the base of the left ventricle were obtained from implanted ultrasonic transacers on the epicardiun and endocardium. The corresponding model results (13.7) do not fall within the range of the standard error of experimental results $(9.3+/-1.0)(48)$. One reason for the discrepancy could be that different left ventricular basal locations were considered in obtaining the model and experimental results. The pattern of basal wall thickness change is similar in the model and experimental results (Figure 4.19).. More recent results by Rankin (55), obtained utilizing similar techniques, showed a percent change in wall thickness at the equator of the left ventricle greater than the model results (29.0\% vs. 13.7\%). Rankin notes that there are large differences in percent change of wall thickness obtained by different investigators, and suggests "methodological peculiarities" as a possible explanation for the differences. However, using similar experimental techniques Guntheroth obtained a smaller change than model results and Rankin obtained a larger change. This may indicate that an assymetric shift of myocardial mass occurs during contraction in-vivo which is not obtained as a result of this cylindrical shell model. 
page 105

4. Chamber Pressure Distribution

The geometric configuration developed during the simulated isovolumic contraction phase of the cardiac cycle established a pressure gradient within the ventricular chamber clearly conducive to ejection (Figure 4.12). The potential energy distribution in the left ventricular chamber just prior to ejection has been used as an index of ejection efficiency. It is desirable that the direction of the gradient within the ventricle just prior to ejection be similar to Figure 4.12. Such a distribution has been shown to be absent in certain myocardial dysfunctions (73). The magnitudes of the pressure gradient obtained in the model for this instant in the cardiac cycle seem to be exagerated. Several factors may be responsible for this exageration. The value used for active isometric stress was $2.00 \mathrm{gr} / \mathrm{mm}$, obtained from studies on papillary muscles (43). The applicability of results obtained from isolated papillary muscle preparations to the ventricular myocardium in-situ may be questioned. Howerer, in studies on dog hearts in-vivo a value for total isovolumic tension in the left ventricle of $2.35 \mathrm{gr} / \mathrm{mm}$ was obtained (47). In addition, in experiments utilizing a strain gage applied to the left ventricle peak wall stress, corrected for wall thickness changes and coupling of the gage to the myocardium, averaged $1.92 \mathrm{gr} / \mathrm{mm}(74)$. Peak wall stress usually occurs at the beginning of ejection (75). Hence, the value of stress used here does not seem unreasonable. 
page 106

A characteristic of the model which may be responsible for the large pressure magnitudes displayed by the model is the assumption that equal, circumferential stress is developed in all the myocardium just prior to ejection. According to the model, the part of the ventricular chamber containing the greatest pressure magnitudes is the apical region (Figure 4.12). This region of the left ventricle has the greatest proportion of longitudinally oriented muscle fibers compared to circumferentially oriented fibers (5). Longitudinally oriented fibers would contribute to chamber pressure less effectively than circumferentially oriented fibers by the law of Laplace. Hence, consideration of apical fiber orientation may correct the exagerated chamber pressure magnitudes. It is interesting to note that consideration of some longitudinally oriented muscle fibers in the apex of the left ventricle may explain the small shortening the left ventricle incurs during contraction in-vivo.

The results also show that the pressure gradients during the ejection phase of the cardiac cycle are small (Figure 4.13). This indicates that the viscous and inertial forces generated within the left ventricle during ejection are small in comparison to the forces producing static pressure.

It should be noted that pressures within shells number 1 and number 10 are not displayed in Figures 12 and 13. As mentioned previously, shell number 1 is at the point 
of fixation of the left ventricle to the cardiac skeleton and is constrained in motion. Therefore, an internal pressure was not obtained for this shell.

The accuracy of representing segment number 10 by a cylindrical shell was questioned. That segment is more hemispherical or conical. Hence, an internal pressure was not obtained for segment number 10 to aroid producing inaccurate or confusing results at that segment.

\section{Myocardial Infarction}

Local myocardial infarction can occur subsequent to occlusion of a coronary artery. The damaged portion of myocardium may not be able to contract and interacts with healthy tissue in a passive manner. In the model passive material characteristics were assigned to portions of the left ventricle to simulate myocardial infarction. The simulation of local myocardial infarction shows two alterations to healthy left ventricular function (Figure 4.14). First, the ventricular pressure distribution is not conducive to flow toward the aortic valve in the vicinity of the infacrt. Chamber pressure distribution not conducive to ejection in the vicinity of infarct was found for the human left ventricle. The infarcted myocardium was found not to contribute to the potential energy in the ventricular chamber. Furthermore, some of the energy produced by the healthy myocardium was dissipated in producing deformation 
page 108

of the infarcted portions. As a result a pressure distribution was found in the area of the infarct which was not conducive to flow toward the aortic valve. In addition, the pressure distribution was shown to become more favorable to ejection after circulation to the infarcted area was improved by coronary bypass surgery (73)

The second result from the simulation of an infarcted left ventricle is that the area of infarct bulges outward during contraction. outward motion of the ventricular wall (dyskinesis) is known to occur in some cases of left ventricular myocardial infarct $(26,76)$. A correlation between declining myocardial perfusion and the development of aneurysmal bulging during isovolumic contraction has been shown. In adition, it was shown that normally perfused myocardium adjacent to the ischemic area displays some dyskinesis. The normally perfused tissue may passively follow the abnormal motion of the ischemic area. (77)

It should be stressed that although the results shown by the model for a left ventricle containing myocardial infarct are consistent with some characteristics of the infarcted left ventricle in-vivo, the model presently does not provide an accurate physical representation of a left ventricle containing local areas of myocardial infarct. That is, in the model a whole cylindrical segment is used to represent the infarcted portion. In-vivo, coronary occlusion in the left ventricle is not likely to result in 
page 109

damage to the myocardium along a circumference of the ventricle. Future refinements of the model should have the capacity to simulate myocardial infarction in portions of the cylindrical segments. It should be noted that the model assumption concerning unidirectional flow along the longitudinal axis of the left ventricle must be changed in future refinements if flow is allowed to occur from a healthy portion of a cylindrical shell into an infarcted portion of the same shell.

E. Summary of Results

A mathematical model of the left ventricle is presented which simulates the dynamics of the left ventricle through the cardiac cycle. Ventricular wall motion and the time course of ventricular wall thickness in the model are similar to those observed in-vivo. Left ventricular flow and aortic pressure produced by the model are similar to those measured experimentally.

The left ventricular model shows that a pressure distribution exists in the chamber of the healthy left ventricle throughout the cardiac cycle which is conducive to flow toward the aortic valve. Results from the model suggest that this pressure distribution is altered by myocardial infarction and is not conducive to ejection in the vicinity of the infarct. In addition, the model 
page 110

displays that dyskinesis of the ventricular wall occurs in the infarcted area. 
Table 4.1. Left ventricular end-diastolic constraints (see Figure 4.1). RATIO, THICK, TRONC and the end-diastolic volume are specified for the model. C results from equation $(4-3)$. (B-b) results from the confocal constraint. (Dieudonne (28), Streeter (4)) 


\begin{tabular}{|c|c|c|c|c|c|c|}
\hline & $\begin{array}{l}\text { PATIO } \\
\text { (b/a) }\end{array}$ & $\begin{array}{l}B-b \\
(c m)\end{array}$ & 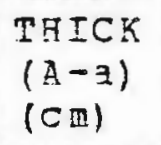 & $\begin{array}{c}\text { TRUNC } \\
7_{3}\end{array}$ & $\begin{array}{c}C \\
(C \mathbb{R})\end{array}$ & $\begin{array}{c}\text { END- } \\
\text { DIASTOLIC } \\
\text { TOLDUE (mI) }\end{array}$ \\
\hline DIEODONNE & 3.1 & 0.40 & 0.97 & 50.0 & 4.35 & 35.0 \\
\hline$A R E N A$ & 2.5 & 0.49 & 1.00 & 52.2 & 3.59 & 35.0 \\
\hline STREETRP & 2.2 & 0.59 & 1.09 & 50.0 & 3.70 & 52.4 \\
\hline
\end{tabular}

Table 4.1 
page 113

Table 4.2. Canine aortic input impedance (38). 


\begin{tabular}{|c|c|c|}
\hline HARMONIC & $\begin{array}{c}\text { MAGNITUDE } \\
\text { (MM HG SEC/CC) }\end{array}$ & $\begin{array}{c}\text { PHASE } \\
\text { (degrees) }\end{array}$ \\
\hline D.C. & 3.260 & - \\
\hline 1 & 0.261 & -58.0 \\
\hline 2 & 0.179 & -45.0 \\
\hline 3 & 0.163 & -32.0 \\
\hline 4 & 0.155 & -18.0 \\
\hline 5 & 0.176 & -25.0 \\
\hline 6 & 0.121 & -30.0 \\
\hline 7 & 0.196 & -36.0 \\
\hline 8 & 0.156 & -4.0 \\
\hline 9 & 0.189 & -30.0 \\
\hline 10 & 0.254 & -50.0 \\
\hline
\end{tabular}

rable 4.2 
page 115

Table 4.3. Percent change of model dimensions with respect to end-diastolic dimensions.

MAX - maximum increase in diameter or decrease in thickness during isovolumic contraction

ISOVOL - percent change at the end of isovolumic contraction

EJECT - percent change at the end of ejection 


\begin{tabular}{|c|c|c|c|c|c|c|c|c|c|c|c|c|}
\hline \multicolumn{2}{|c|}{$\begin{array}{l}\text { LV } \\
\text { LOCATION: }\end{array}$} & \multicolumn{2}{|c|}{ BASE } & \multicolumn{3}{|c|}{ FQUATOR } & \multicolumn{3}{|c|}{$\begin{array}{l}\text { HALEWAY BETWEEN } \\
\text { APEX AND BASE }\end{array}$} & \multicolumn{3}{|c|}{ A PEX } \\
\hline \multirow[t]{2}{*}{$\begin{array}{l}\text { SEGMFNT } \\
\text { NUMBER: }\end{array}$} & & 2 & & & 4 & & & 6 & & & 9 & \\
\hline & $\begin{array}{l}\text { M } \\
A \\
X\end{array}$ & $\begin{array}{l}J \\
S \\
O \\
V \\
0 \\
L\end{array}$ & $\begin{array}{l}E \\
J \\
E \\
C \\
T\end{array}$ & $\begin{array}{l}M \\
A \\
X\end{array}$ & $\begin{array}{l}\mathrm{T} \\
\mathrm{S} \\
\mathrm{O} \\
\mathrm{V} \\
\mathrm{D} \\
\mathrm{L}\end{array}$ & $\begin{array}{l}\mathbf{P} \\
\mathbf{J} \\
\mathrm{R} \\
\mathrm{C} \\
\mathrm{T}\end{array}$ & $\begin{array}{l}M \\
\Lambda \\
X\end{array}$ & $\begin{array}{l}I \\
S \\
0 \\
V \\
0 \\
L\end{array}$ & $\begin{array}{l}E \\
J \\
E \\
C \\
T\end{array}$ & $\begin{array}{l}M \\
A \\
X\end{array}$ & $\begin{array}{l}\mathrm{I} \\
\mathrm{S} \\
0 \\
\mathrm{~V} \\
0 \\
\mathrm{I}\end{array}$ & $\begin{array}{l}E \\
J \\
E \\
C \\
T\end{array}$ \\
\hline $\begin{array}{l}\text { INS IDE } \\
\text { DIAM. } \\
\frac{r-r(e d)}{r(e d)}\end{array}$ & +7.0 & +7.0 & -20.4 & +1.0 & +0.6 & -20.4 & +0.3 & -1.7 & -20.4 & 0.0 & -5.9 & -20.4 \\
\hline $\begin{array}{l}\text { WALI. } \\
\text { PHICK, } \\
\frac{h-h(e d)}{h(e d)}\end{array}$ & -4.1 & -4.1 & +12.0 & -0.6 & -0.4 & +13.8 & -0.2 & +1.0 & +12.0 & 0.0 & +3.2 & +11.8 \\
\hline
\end{tabular}

Table 4.3 
Table 4.4. Percent change in wall thickness with Iespect to the end-diastolic value; model and experimental results.

ISOVOI - percent change at the end of isovolumic contraction

EJECT - percent change at the end of ejection 


\begin{tabular}{|c|c|c|c|c|c|c|c|}
\hline \multicolumn{2}{|l|}{ LV LOCATION: } & \multicolumn{2}{|l|}{$B \cap S F$} & \multicolumn{2}{|c|}{$\begin{array}{l}\text { HALFWAY BETWEEN } \\
\text { APEX AN DASE }\end{array}$} & \multicolumn{2}{|c|}{ A PEX } \\
\hline SOURCE & $\begin{array}{c}\text { FXPERIMENTAL } \\
\text { METHOD }\end{array}$ & I SOVOL & EJECT & ISOVOL. & EABCI & ISOVOL & EJEC? \\
\hline MODET. & - & $-4 \cdot 1$ & 12.0 & 1.0 & 12.0 & 3.2 & 11.8 \\
\hline rothran 1967 & Strain Gage & & & 6.0 & 15.0 & & \\
\hline Mc Hale 1972 & Strain Gage & & & $\begin{array}{l}\text { Increase } \\
\text { boserved }\end{array}$ & 16.0 & & \\
\hline Dor Meer 1973 & Strain Gaqe & & & 3.0 & 10.0 & & \\
\hline Eeigl 1964 & Strain Gage & & & 10.0 & 20.0 & & \\
\hline Goldstein ${ }_{2} 1974$ & Strain fage & & & & & $\begin{array}{l}\text { Increas? } \\
\text { Observed }\end{array}$ & $\begin{array}{r}10.7 \\
+2.7\end{array}$ \\
\hline Guntheroth 1971 & $\begin{array}{l}\text { Ultrasonic } \\
\text { Transducers }\end{array}$ & \begin{tabular}{|l} 
Decrease \\
phserved
\end{tabular} & $\begin{array}{r}8.5 \\
t-1.2\end{array}$ & & & & \\
\hline Guntheroth 1974 & $\begin{array}{l}\text { Ultrasonic } \\
\text { Transducers }\end{array}$ & $\begin{array}{r}-2.0 \\
y-0.3\end{array}$ & $\begin{array}{r}9.3 \\
+1.0 \\
\end{array}$ & & & & \\
\hline
\end{tabular}

1 - Horse Left Ventricle

2 - Piq left Ventricle

Table 4.4 
page 119

Figure 4.1. Confocal ellipses.

(see text for description of variables.) 
page 120

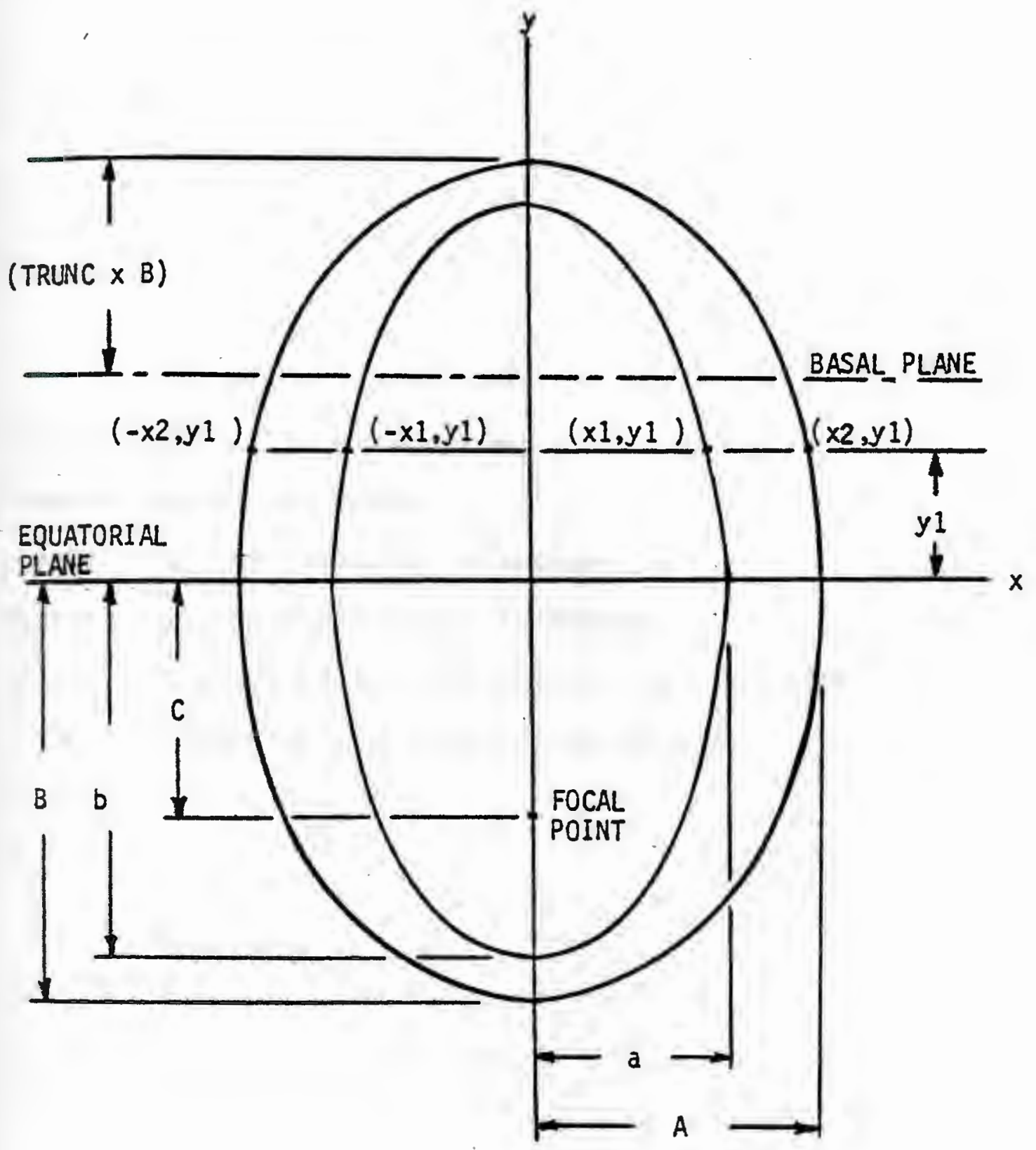

Figure 4.1 
Figure 4.2. Determination of end-diastolic dimensions of the model.

r(ed) - inside radius at end-diastole

h(ed) - end-diastolic wall thickness

I(ed) - Y location of the midpoint of the shell

$\Delta y$ - height of the cylindrical shells 


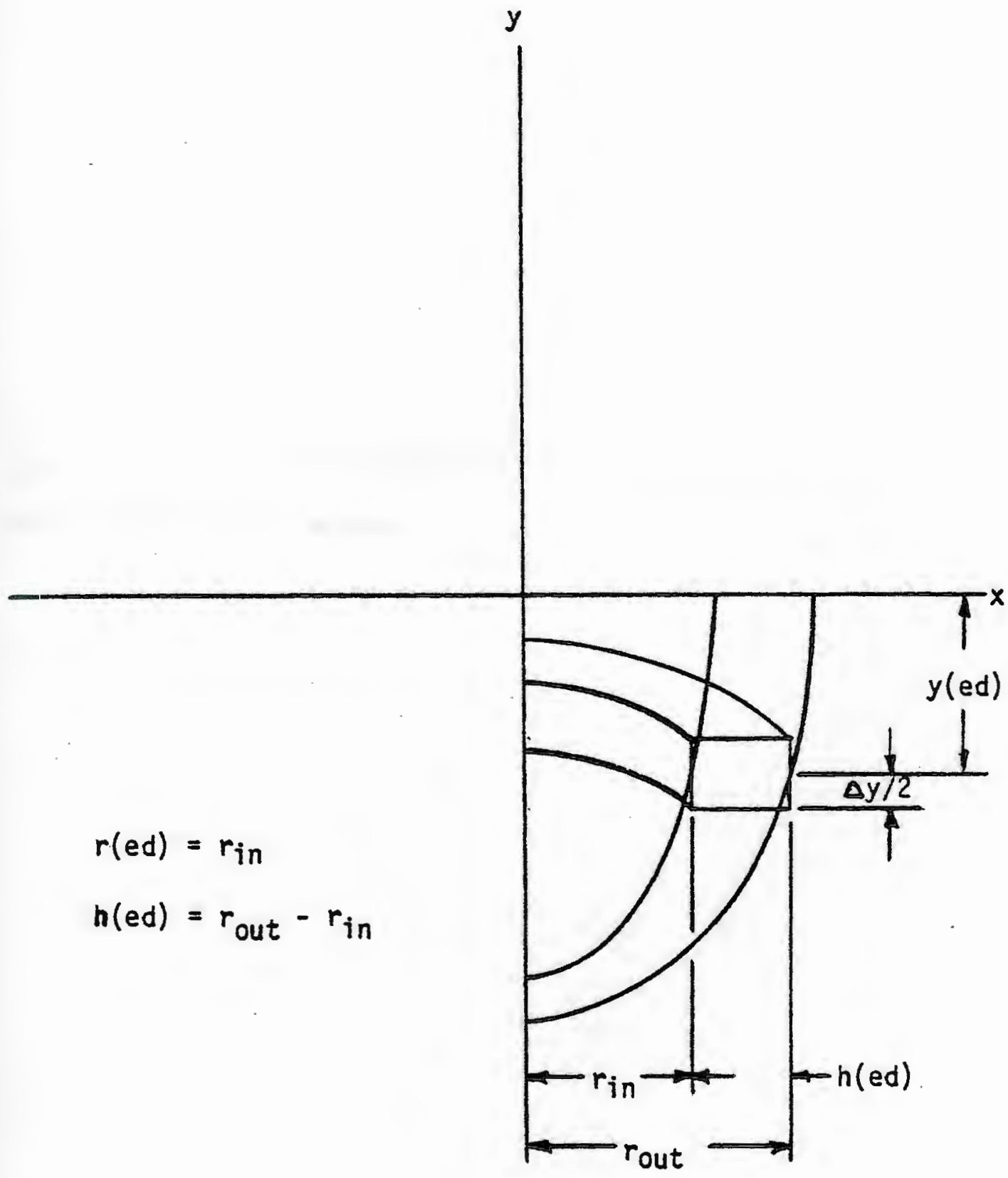

Figure 4.2 
page 123

Figure 4.3. End-diastolic configuration of the left ventricular model. 
page 124

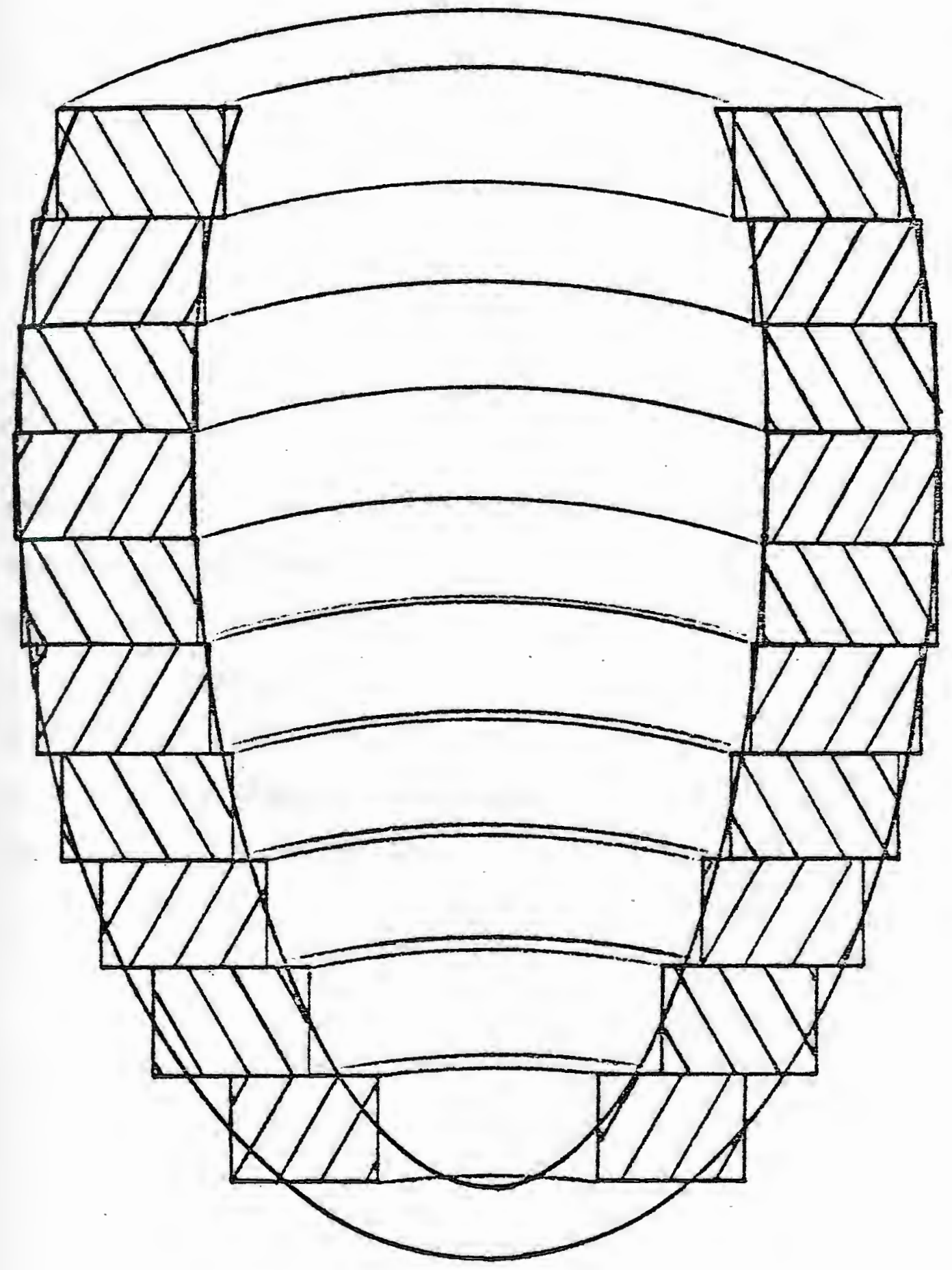

Figure 4.3 
page 125

Figure 4.4. Pressure-stress relationship of the cylindrical shells.

P - chamber pressure

$\sigma$ - wall stress

I - inside radius of the shell

h - wall thickness of the shell

$\Delta Y$ - height of the shell 
page 126

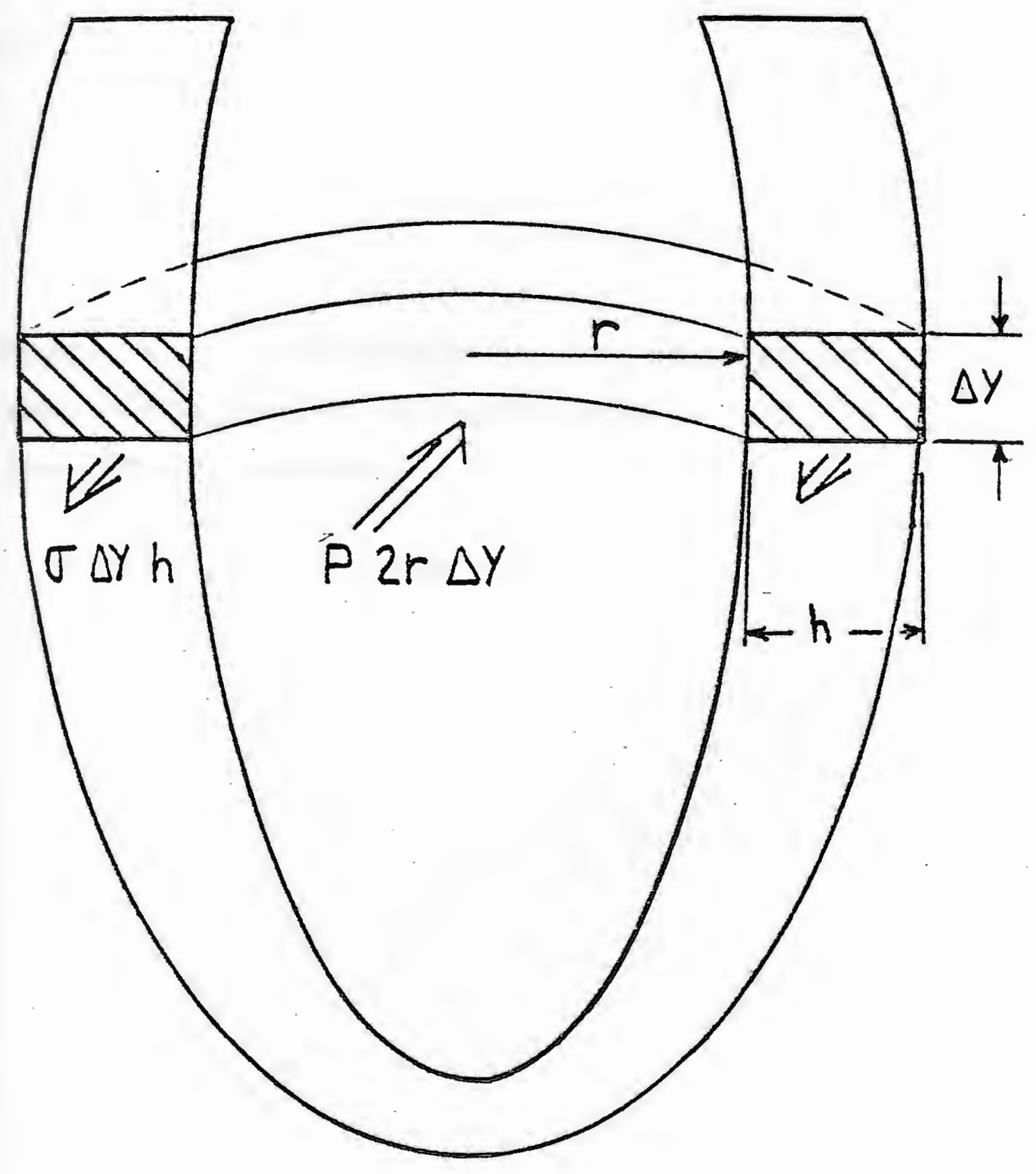

Figure 4.4 
page 127

Figure 4.5. Determination of inertial forces generated by the left ventricular model. (See text for notation.) 
$\operatorname{IIME}(t-1):$
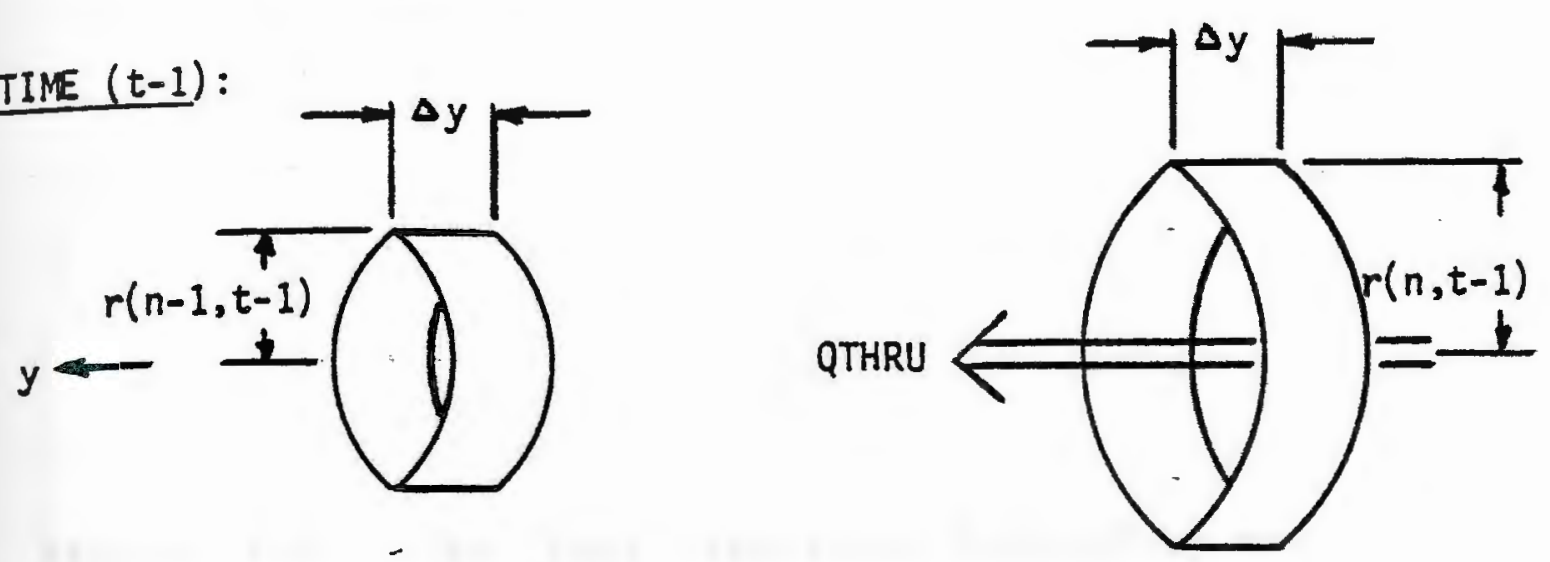

\section{$\operatorname{IIME}(t):$}
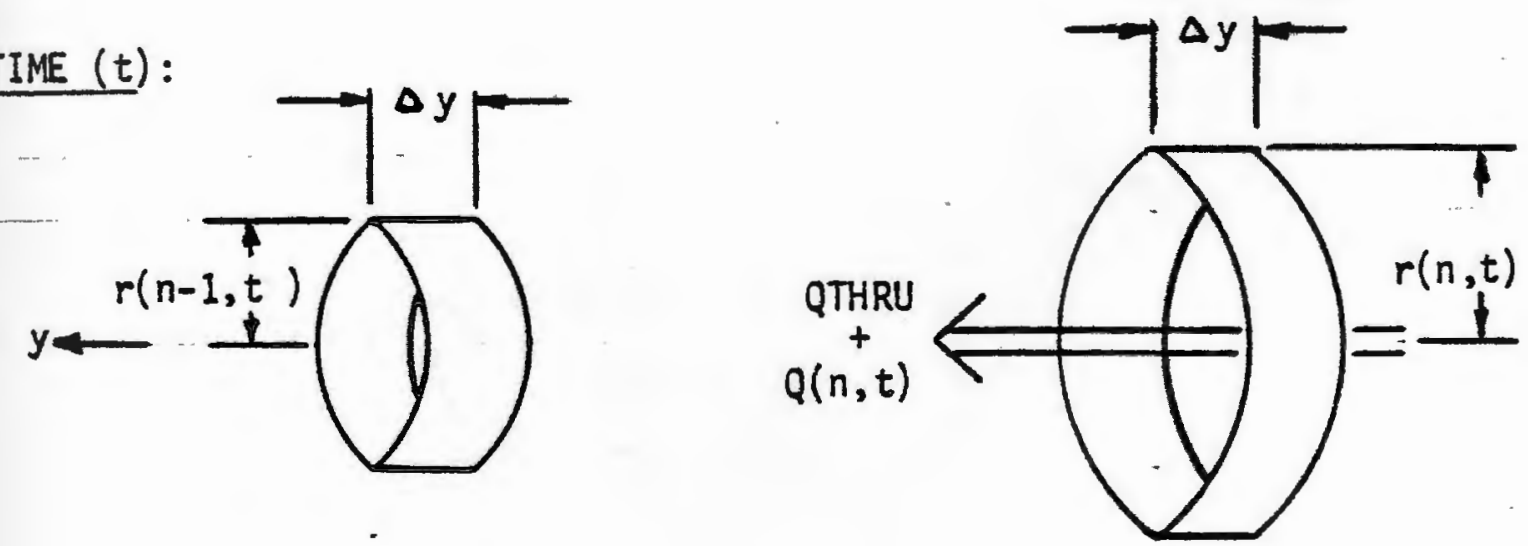

Figure 4.5 
page 129

Figure 4.6. The left ventricle modeled by ten cylindrical shells. 


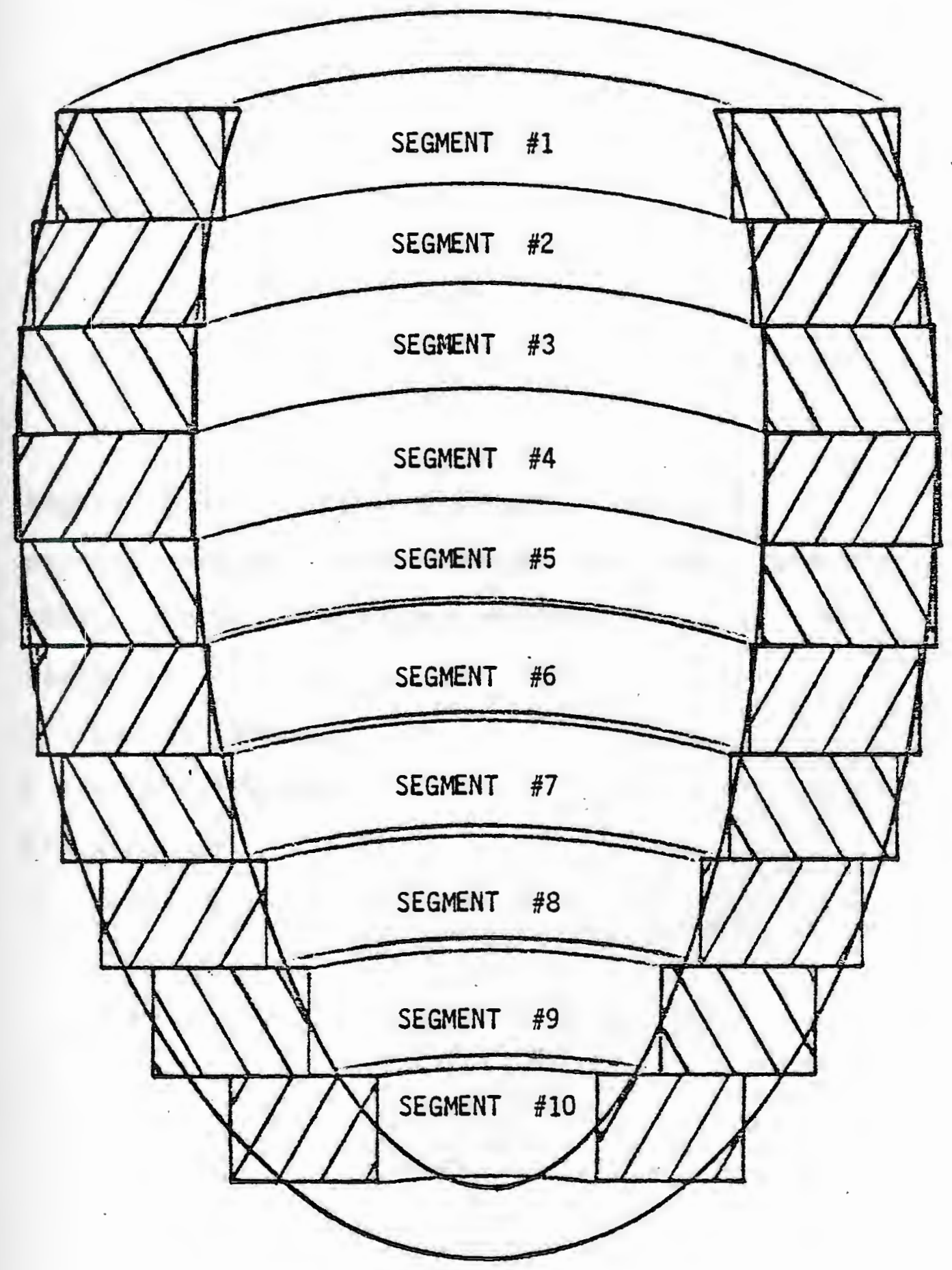

Figure 4.6 


\section{page 131}

Figure 4.7. Left ventricular diastolic pressure-volume relationships obtained from the model. Strain is figured at the radius $(I+k h)$, where;

I - inside radius

h - wall thickness

$k: 0.00(x)$

$0.25(+)$

$0.50(0)$

$0.75(*)$ 


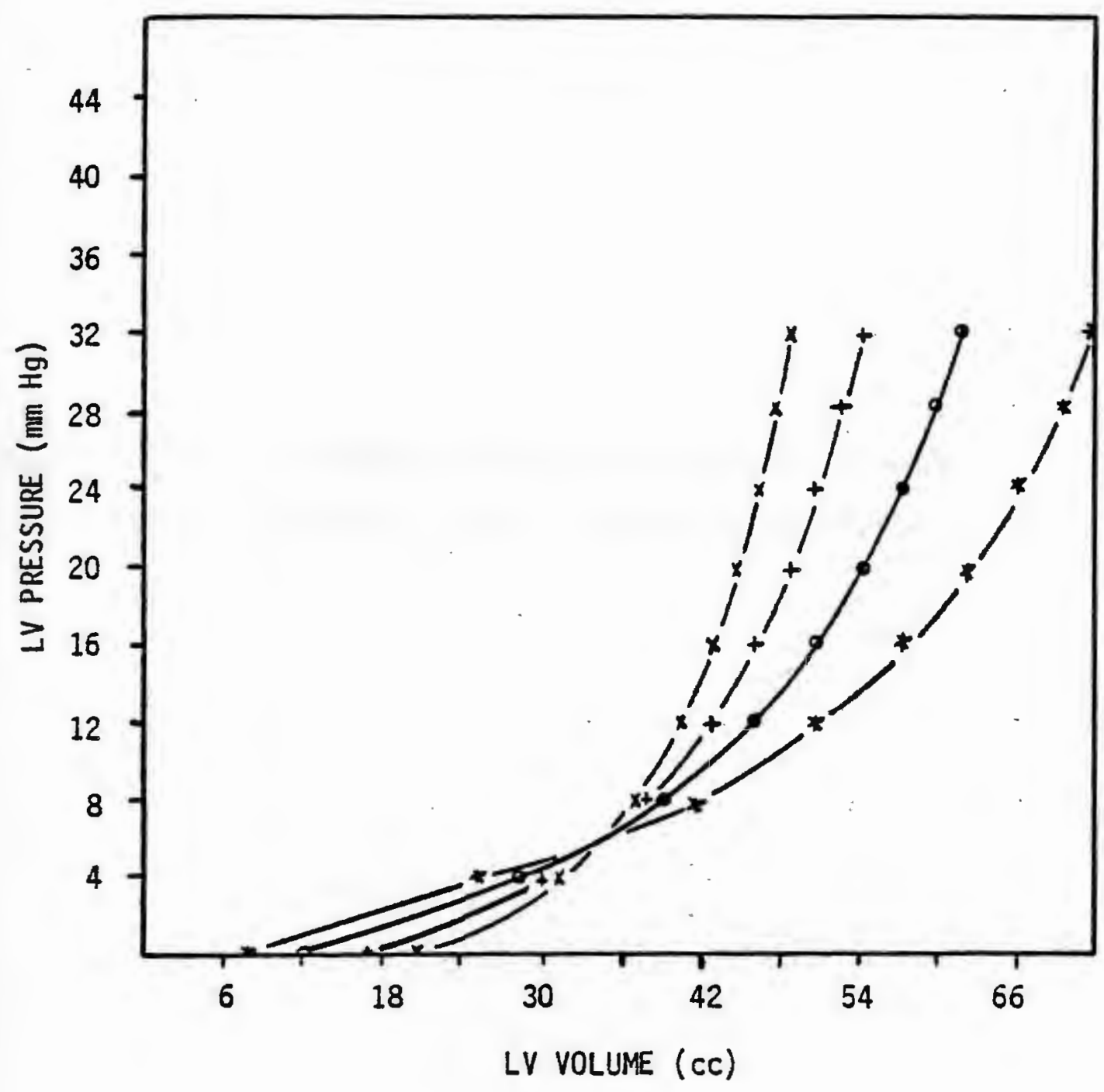

Figure 4.7 
page 133

Figure 4.8. Diameter and wall thickness changes

of the left ventricular model during contraction. 


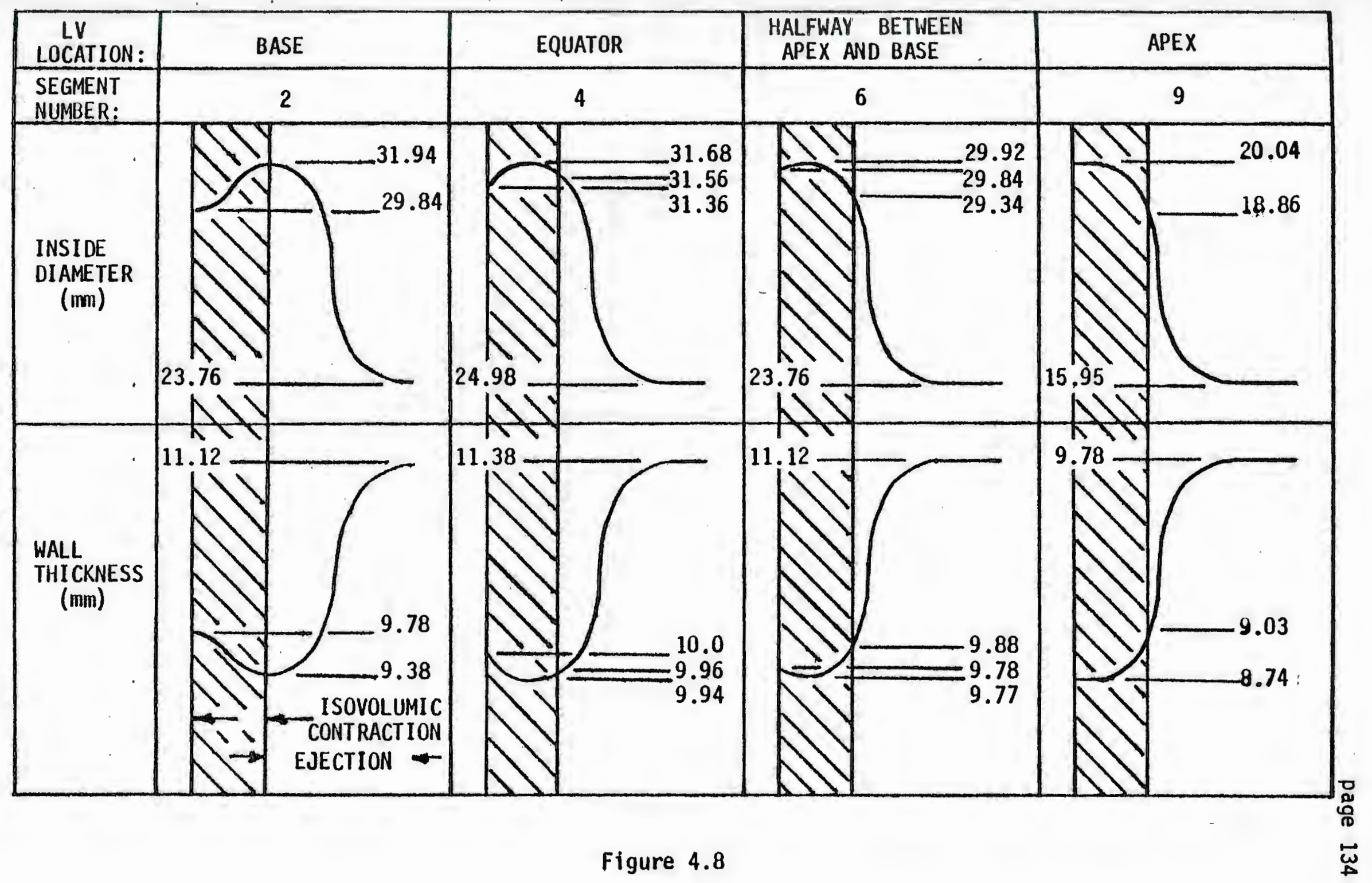


Figure 4.9. Outside diameter change at the equator of the left ventricular model during contraction.

$D(e d)$ - end-diastolic diameter

$D(m) \quad-$ maximum diameter

$D(0)$ - diameter at the beginning of ejection

$D(e)$ - diameter at the end of ejection 


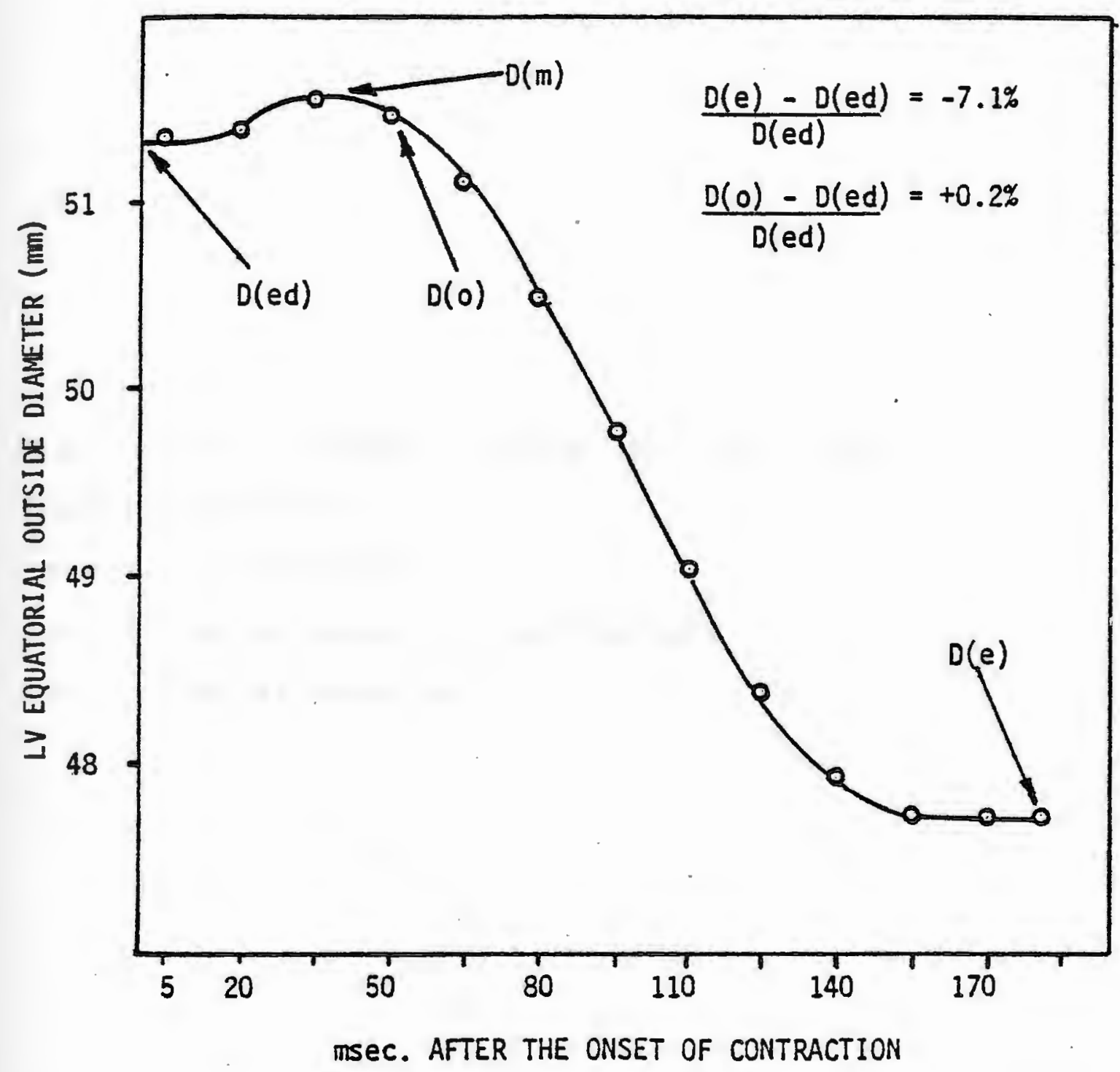

Figure 4.9 
page 137

Figure 4.10 Chamber outline of the left ventricular model at:

- end-diastole

- - - end of isovolumic contraction

- - - end of ejection 
page 138

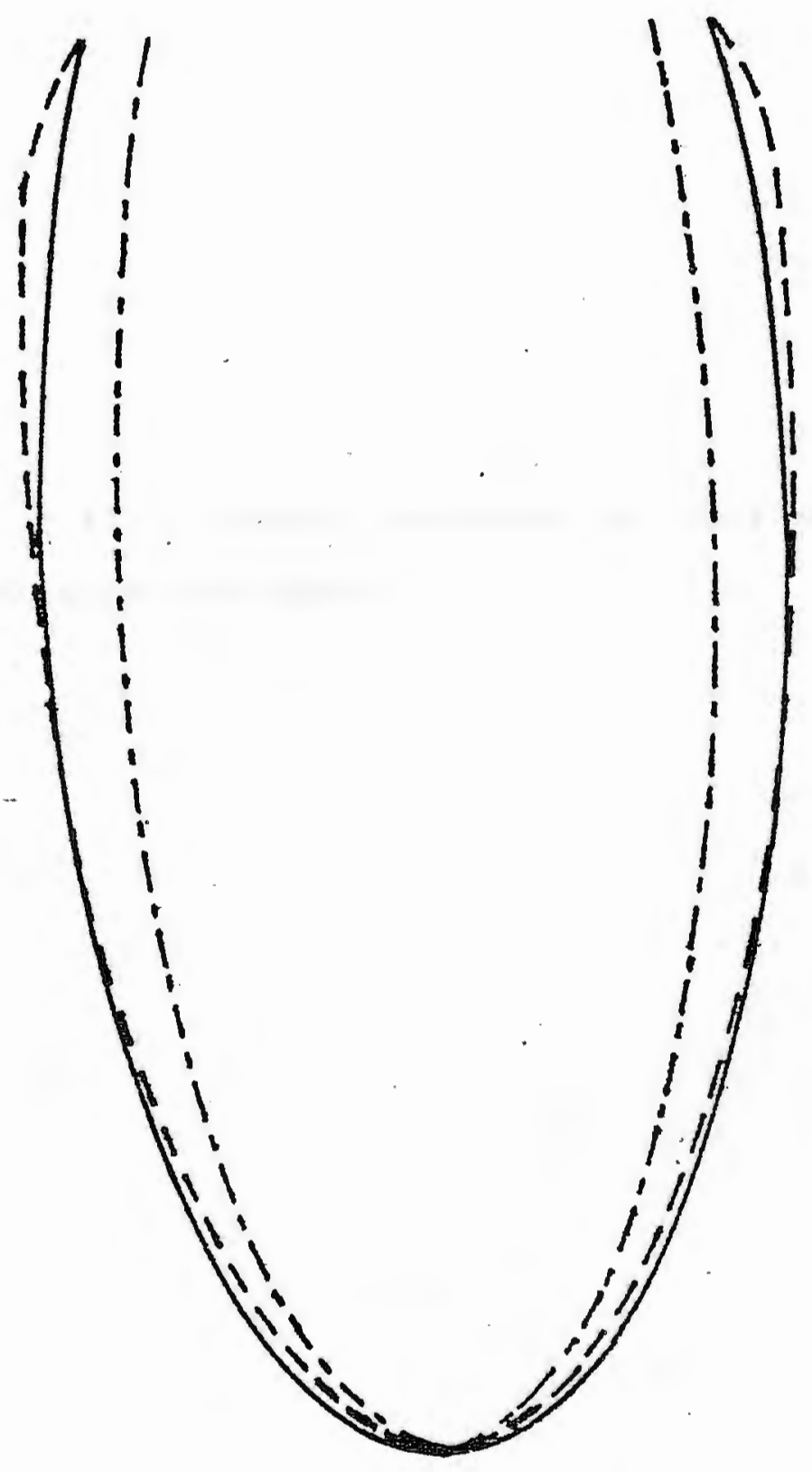

Figure 4.10 
page 139

Figure 4.11. Output pressure and flow waveforms obtained from the model. 


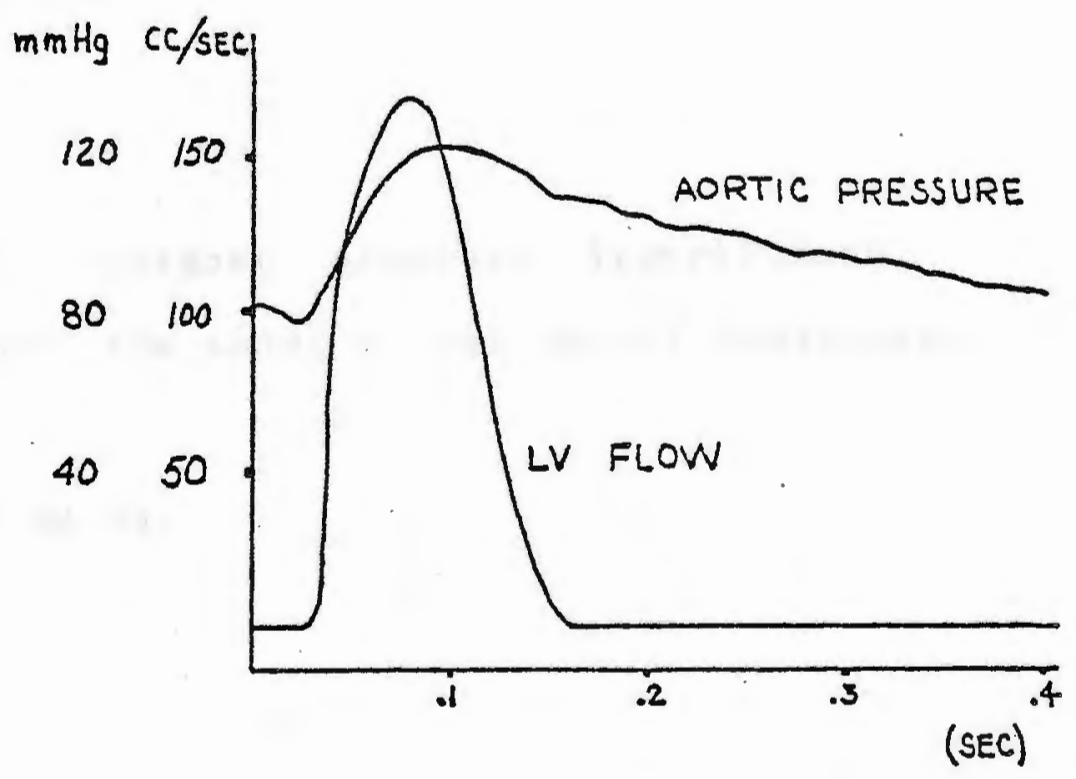

Figure 4.11 
page 141

Figure 4.12. Chamber pressure distribution

obtained from the model at the end of isorolumic contraction.

Pressures in mm $\mathrm{Hg}$. 


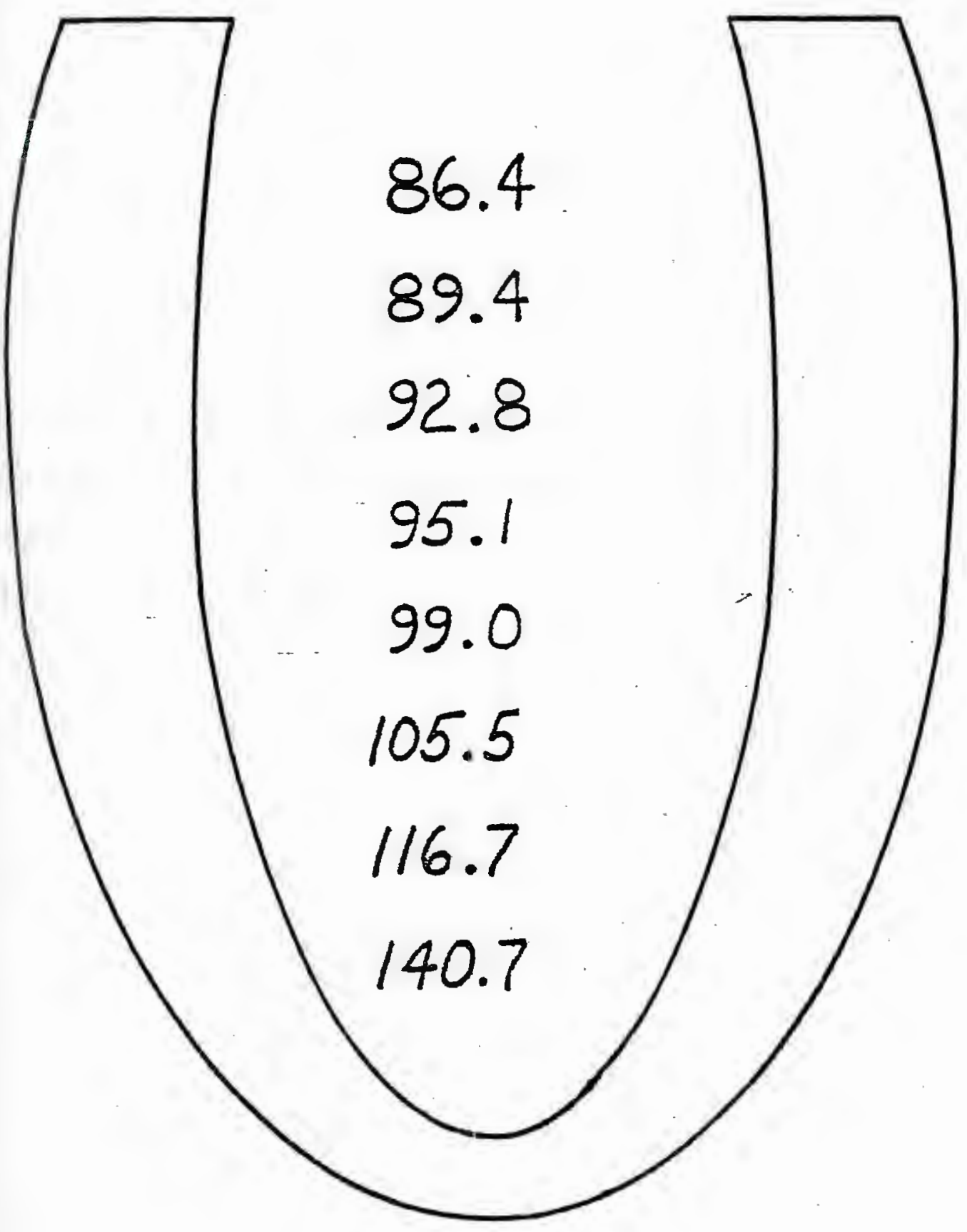

Figure 4.12 
page 143

Figure 4.13. Chamber pressure distribution obtained from the model at an instant during ejection.

Pressures in $\mathrm{mm}$ Hg. 
page 144

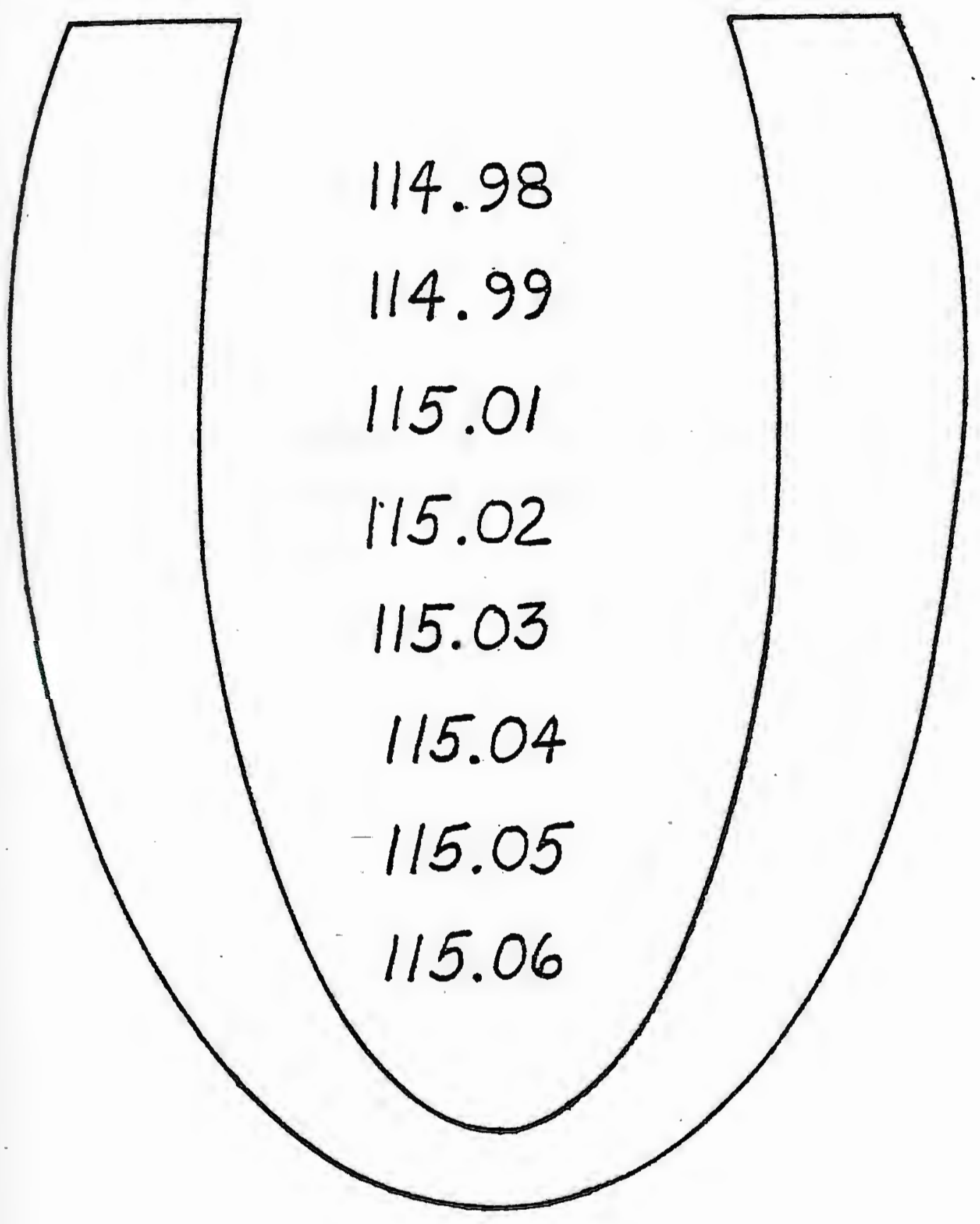

Figure 4.13 
page 145

Pigure 4.14. Results of the simulation of a myocardial infarcted left ventricle. Pressures in ma $\mathrm{Hg}$. 
page 146

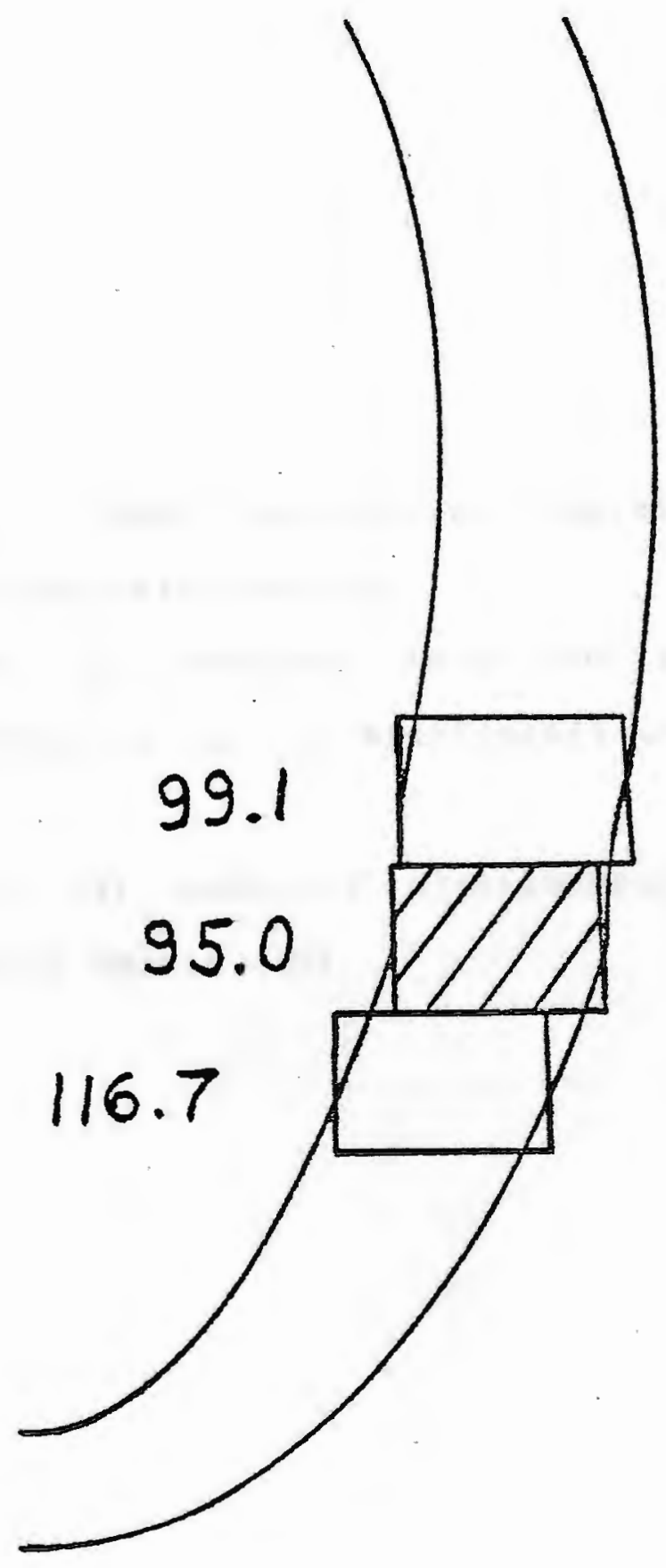

Figure 4.14 
Figure 4.15. Left ventricular diastolic pressure-volume relationship;

- and (0) obtained from the model with strain calculated at the midcircumference of the shells;

-. - - and (x) obtained experimentally using excised canine hearts (45). 


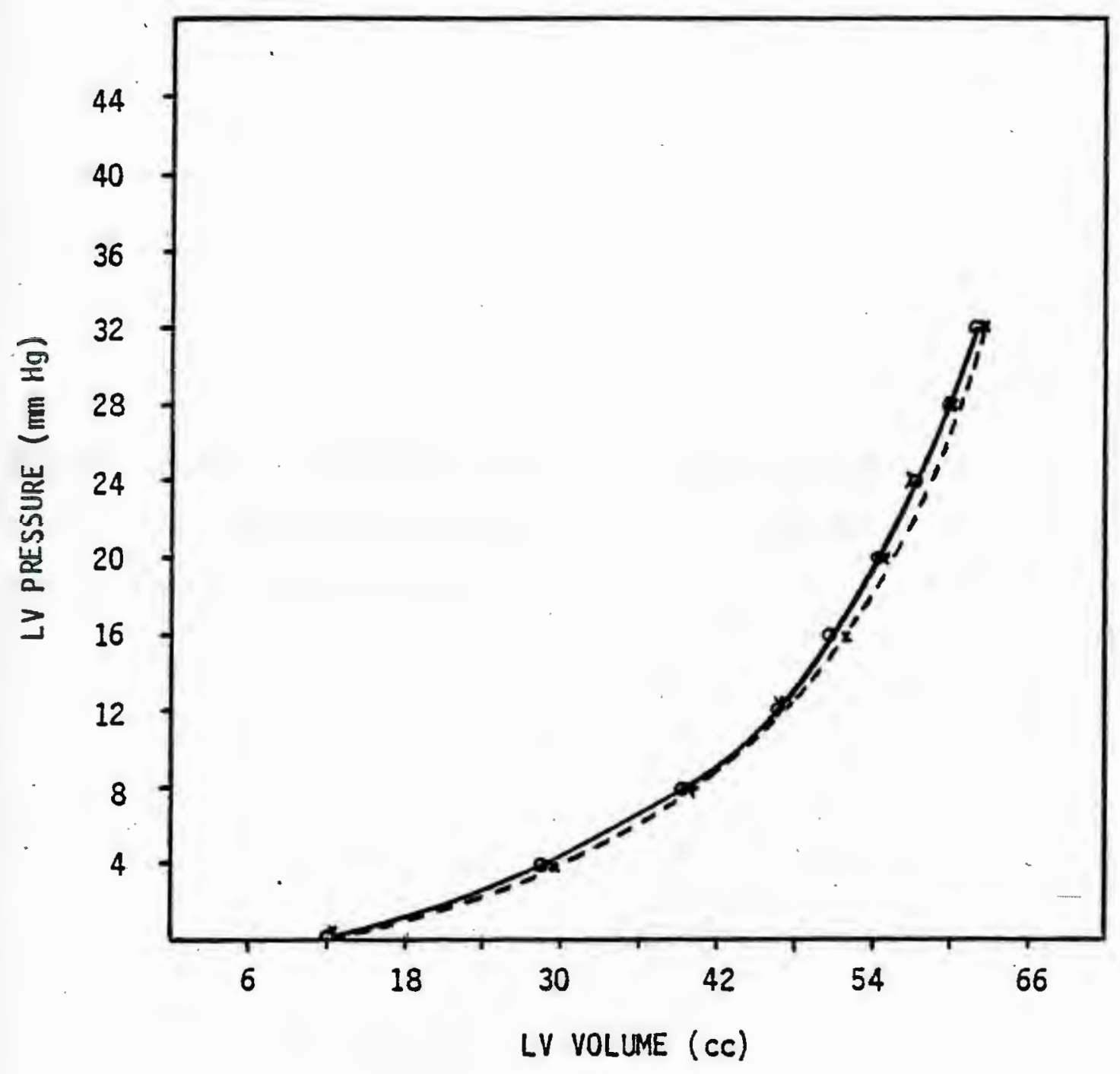

Figure 4.15 
page 149

Figure 4.16. Inside diameter change of the left ventricle during ejection. Data obtained experimentally from dogs. 


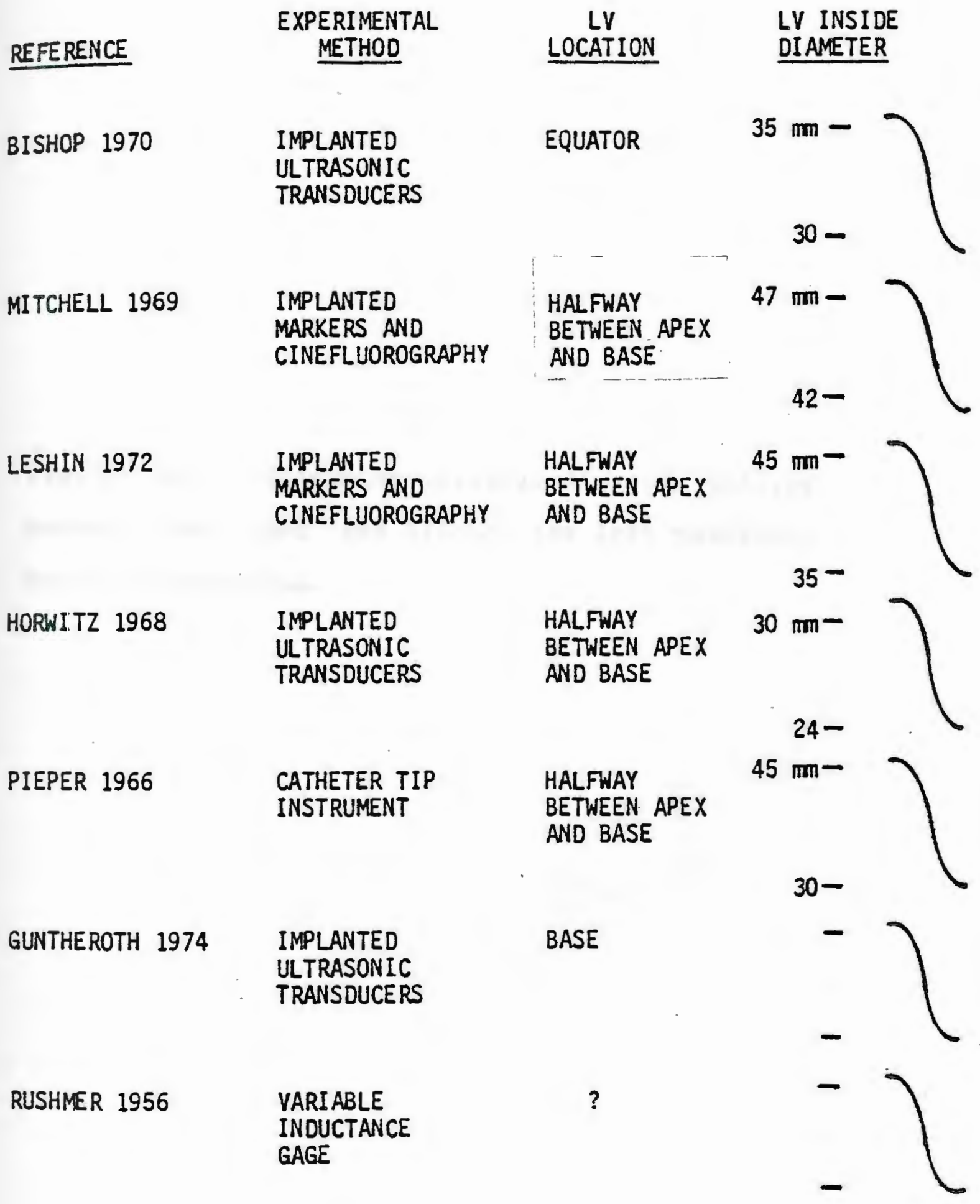


page 151

Pigure 4.17. Course of internal diameter halfway between the apex and base of the left ventricle during contraction. 
EXPERIMENTAL RESULTS (MITCHELL 1969):

EXPERIMENTAL RESULTS (LESHIN 1972):

EXPERIMENTAL RESULTS (HORNITZ 1968):

MOOEL RESULTS:

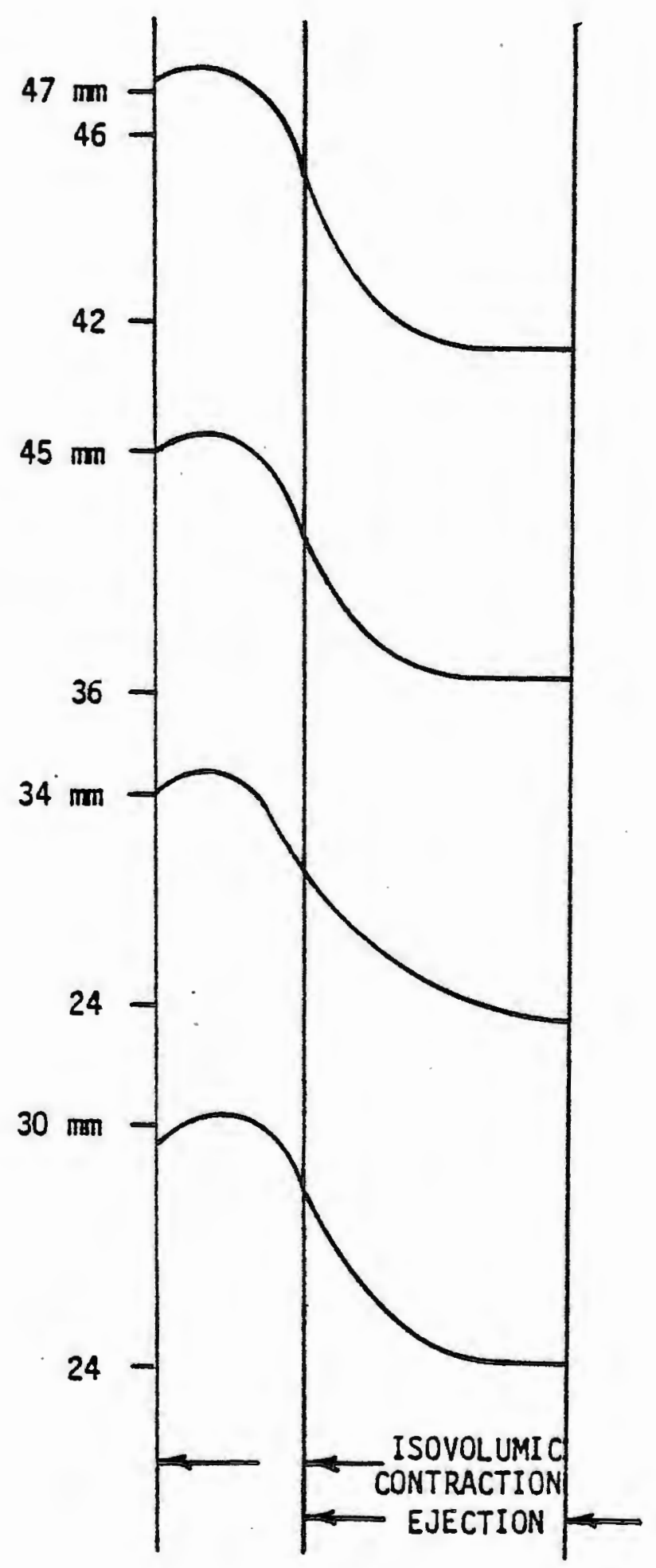

Figure 4.17 
page 153

Figure 4.18. Course of internal diameter at the equator of the left ventricle during ejection. 
EXPERIMENTAL RESULTS (BISHOP 1970):

MODEL RESULTS:

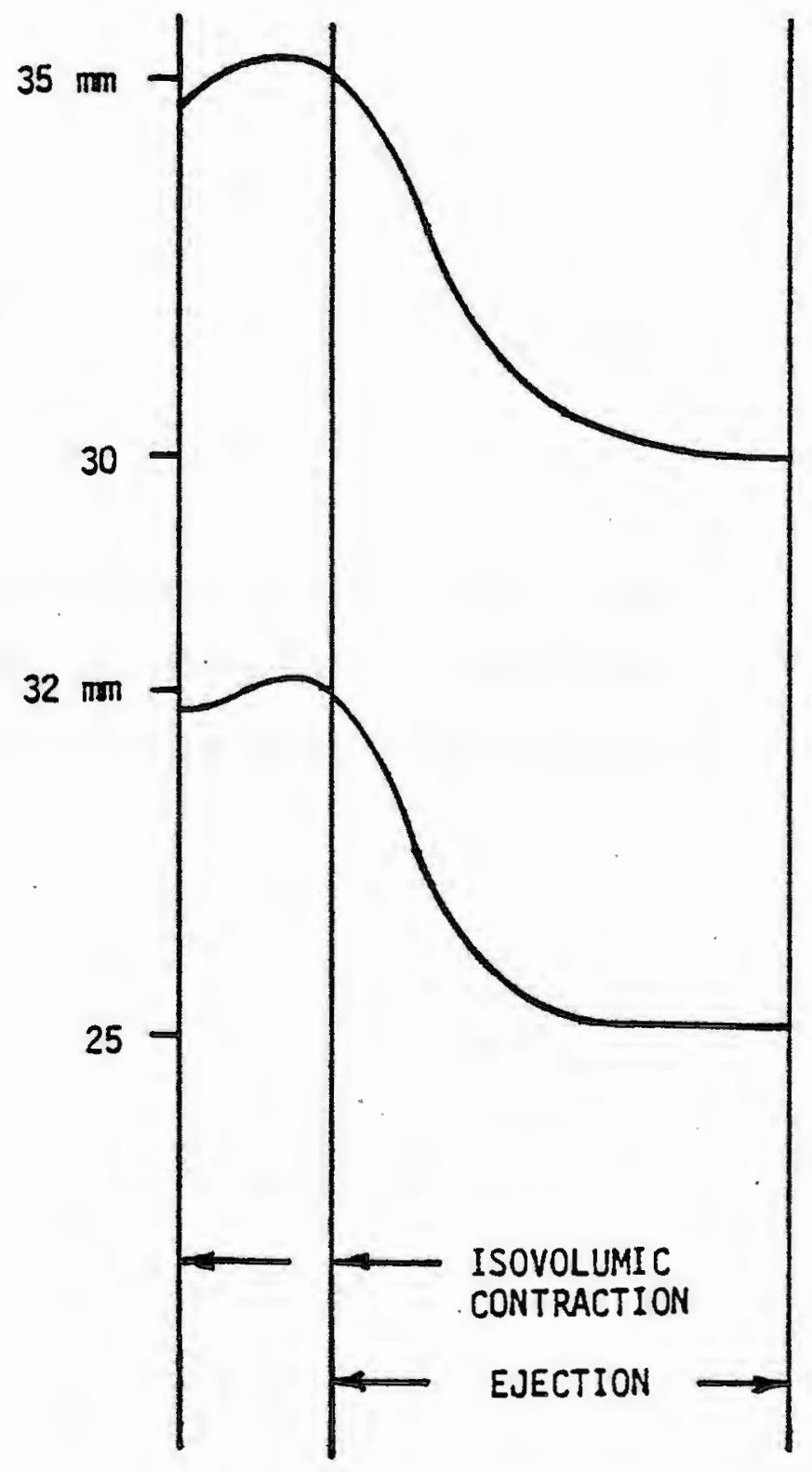

Figure 4.18 
page 155

Figure 4.19. Dimension changes at the base of the left ventricle during contraction. The aortic pressure waveform and the electrocardiogram are also shown. 
MODEL RESULTS

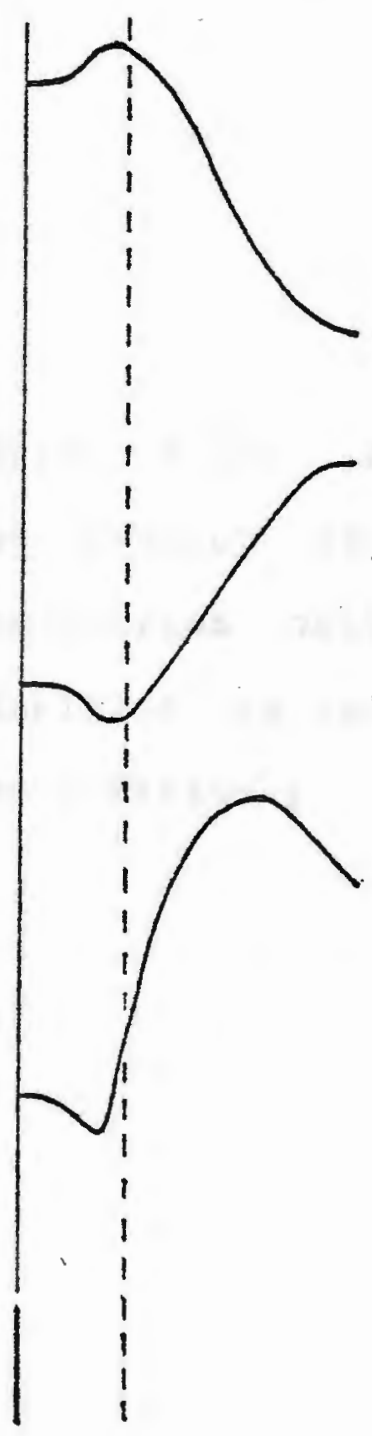

EXPERIMENTAL RESULTS

(GUNTHEROTH 1974)

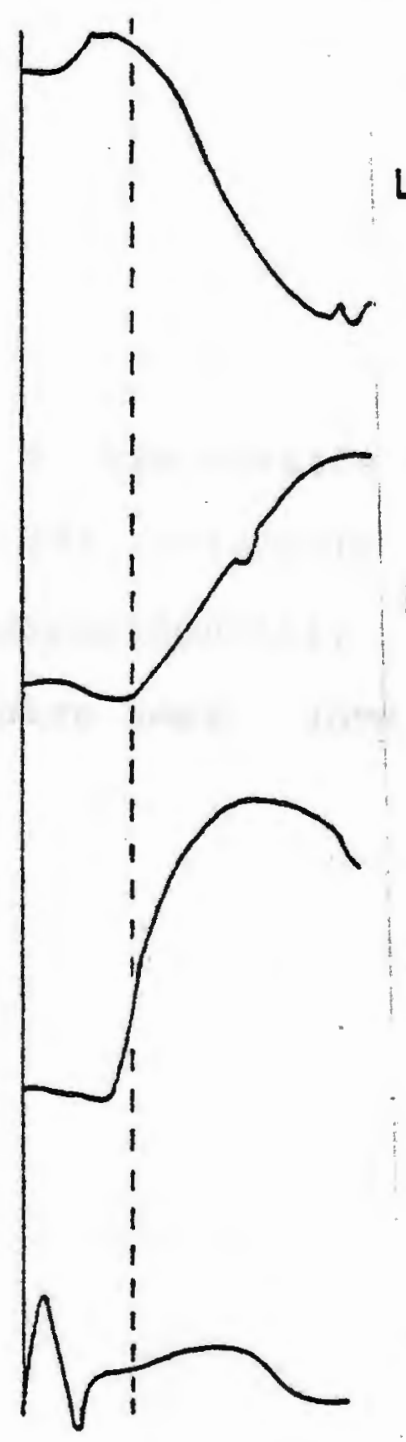

LV INTERNAL DIAMETER

LY WALL THICKNESS

AORTIC PRESSURE

\section{ELECTROCARDIOGRAM}

Figure 4.19 
page 157

Figure 4.20. Course of the outside diameter at the equator of the left ventricle during contraction obtained experimentally (70). Data displayed is for reclining dogs. (see Figure 4.9 for notation.) 


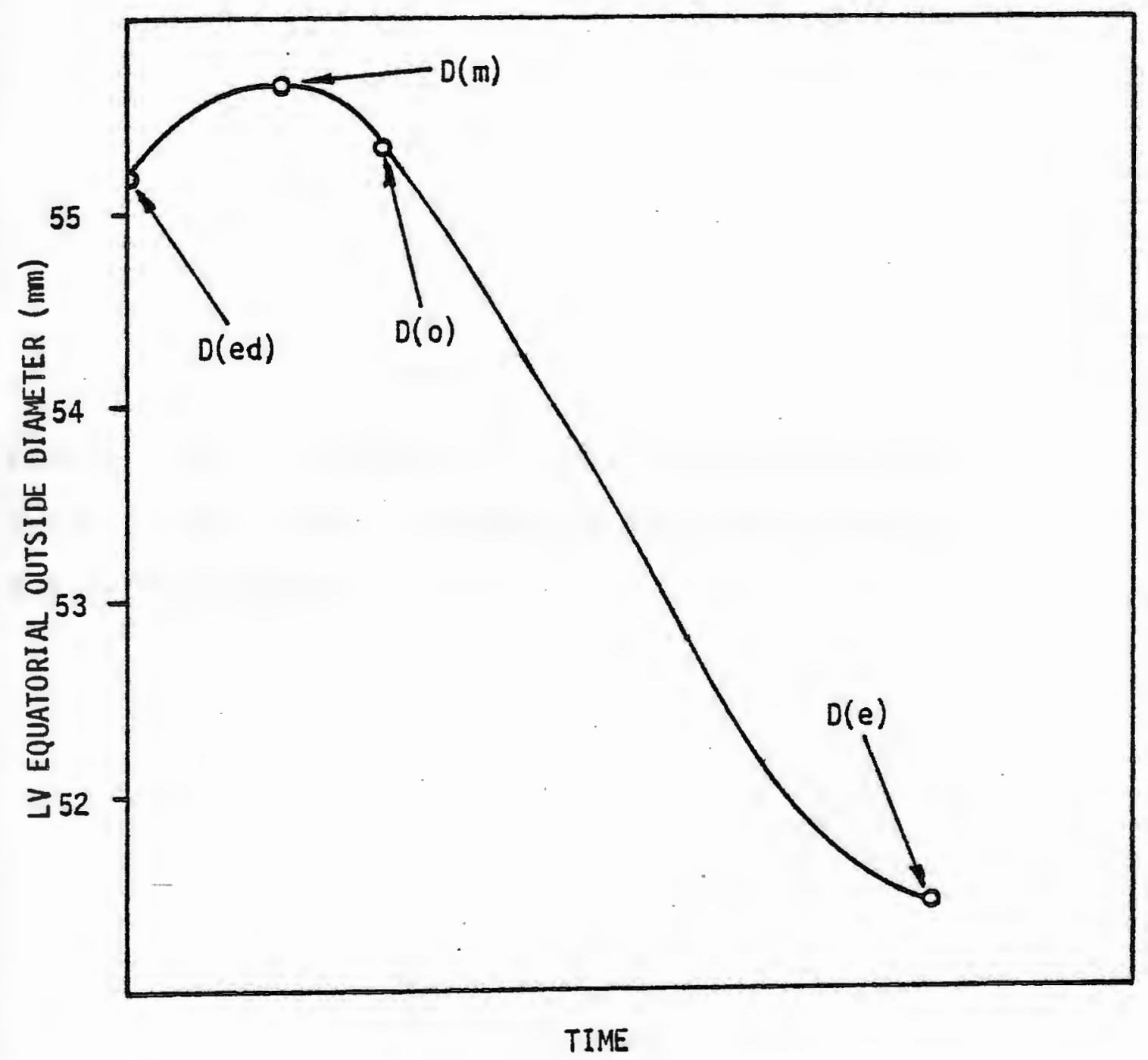

Figure 4.20 
page 159

Pigure 4.21. Course of wall thickness halfway between the apex and base of the left ventricle during contraction. 
page 160

EXPERIMENTAL RESULTS

(FEIGL 1964):

$$
10.0 \mathrm{~mm}-
$$

MODEL RESULTS:

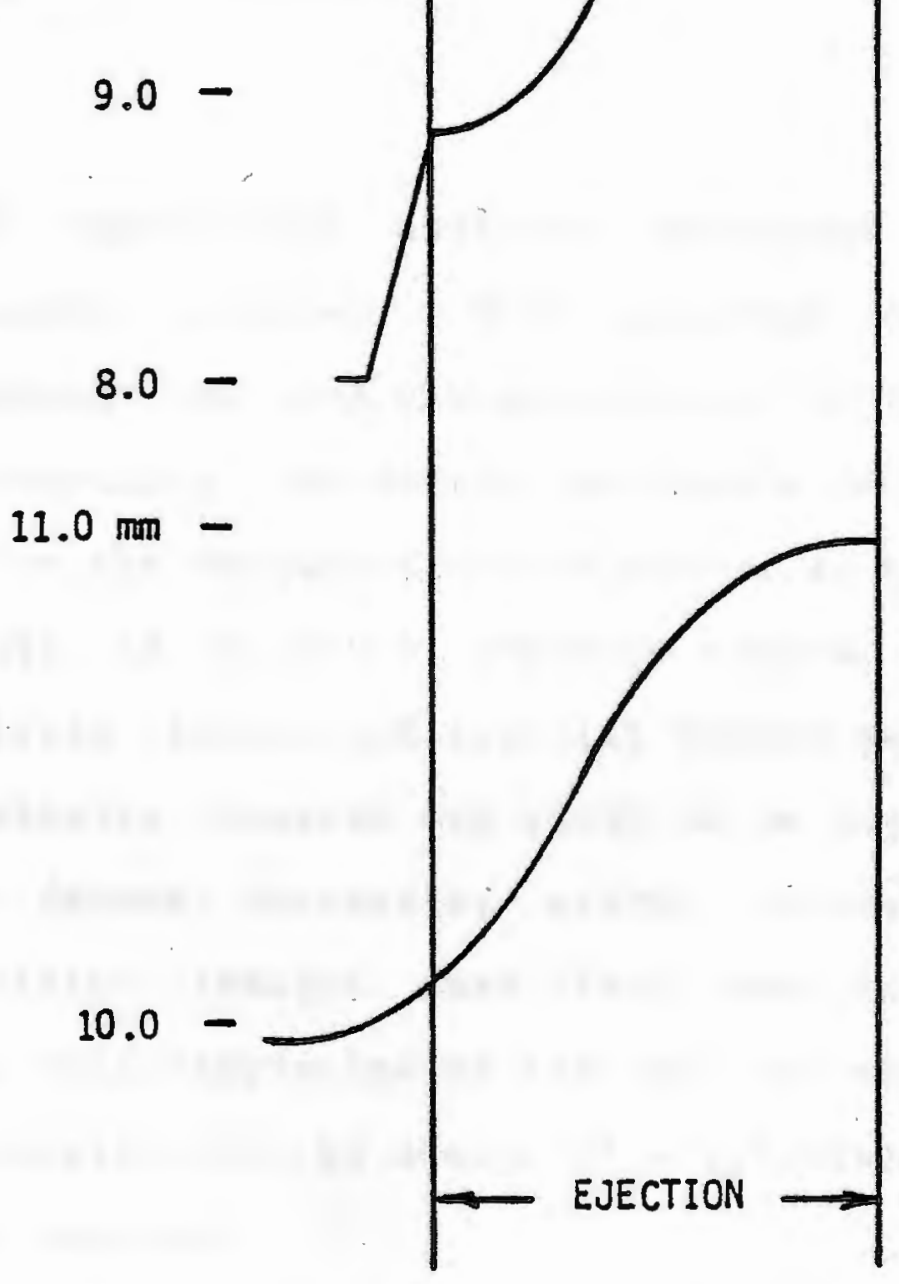

Figure 4.21 


\section{CHAPTER V}

\section{DISCOSSION}

The left ventricular analyses presented herein serve several useful purposes. Both analyses provide information regarding the pump characteristics of the left ventricle. By comparing the source resistance and aortic input resistance in the frequency domain analysis, the left ventricle is shown to be a D.C. pressure source. In the time domain analysis viscous and inertial forces generated within the ventricular chamber are shown to be negligible compared to the forces generating static pressure. In addition to providing insight into left ventricular function, the pump characteristics of the left ventricle are of primary consideration in the design of artificial hearts and cardiac assist devices.

These left ventricular analyses could provide tools for diagnosing heart disease from hemodynamic measurements. By measuring left ventricular pressure and aortic flow under two different left ventricular afterload conditions, the source pressure and source impedance of the heart could be determined. The frequency domain analysis shows that these 
page 162

parameters may be useful in diagnosing myocardial infarct. However, the hemodynamic measurements required for the frequency domain analysis are much more extensive than data which could be provided by a standard cardiac catheterization. One difficulty is collecting data under two different left ventricular afterloads. An intraaortic balloon could be utilized for this purpose as it was used in the experiments.

Results from the time domain analysis of a healthy left ventricle indicate that the pressure distribution in the ventricular chamber throughout the cardiac cycle is such that blood tends to move toward the aortic valve. These results should be tested by experiments. For example, an open chest canine preparation could be used.

Several pressure catheters installed in the left ventricle to determine the chamber pressure distribution may interfere with ventricular function. A more feasible way of determining the chamber pressure distribution may be to use one pressure catheter carefully placed at different locations within the ventricular chamber. Placement could use fluoroscopic techniques. Using the one catheter method pressures from different heart cycles would be compared. Therefore, the preparation would have to be carefully controlled at a steady state during placement of the catheter. Corresponding moments of different heart cycles could be compared in subsequent data analysis by coordinating the cycles by their QRS complexes. 
page 163

The pressure distribution in the ventricular

chamber just prior to ejection has been used as a cardiac index (73). It may be instructive to investigate the pressure distribution at this moment of the cardiac cycle experimentally. For this purpose, the experimental protocol should include installation of an electromagnetic flow probe at the root of the aorta. Pressures at different chamber locations could be recorded as described above. Flow data could be simultaneously recorded. In subsequent data analysis, the moment of the heart cycles corresponding to end-isovolumic contraction could be determined using the aortic root flow data.

The time domain analysis indicates that large pressure magnitudes exist in the apical area of the ventricular chamber at end-isovolumic contraction. Experimental results may show that large gradients do not exist in-rivo. The time domain analysis can be refined by considering muscle fiber orientation in the model. As discussed previously; this addition to the model should result in lower pressure magnitudes in the apical region. The time domain analysis indicates that the pressure distribution in the ventricular chamber at end-isovolumic contraction is not conducive to ejection in the vicinity of myocardial infarction. The model is presently capable of analyzing a myocardial infarction occurring along a circumference of the left ventricle. As discussed previously, the model should be refined to allow 
analysis of a left ventricle containing myocardial infarction in arbitrary portions of the myocardium.

Experimental investigation of the pressure distribution of an infarcted left ventricle could be included in the protocol of the experimental procedure described above. In the experiment, myocardial infarction could be induced in the left ventricle by ligating branches of the coronary arteries. The pressure distribution could be investigated as described previously. Comparison of model and experimental results may lead to correlation between the nature of chamber pressure distribution and the location and severity of myocardial infarction. 
APPENDICES 
APPENDIX A

PHYSIOLOGIC BACKGROUND APPENDIX

A. Cellular and Subcellular Structure of Myocardium

Mocardial tissue consists of long, striated muscle fibers. Groups of fibers are enclosed by connective tissue forming muscle fiber bundles. Branching frequently occurs between parallel fibers. (Figure 1)

Each fiber consists of a series of myocardial cells joined by a specialized structure (intercalated disc). The intercalated disc allows transmission of the electrical depolarization impulse and contractile forces from cell to adjacent cell.

Each cell is bounded by a membrane (sarcolemma) and contains: a centrally located nucleus; a large concentration of mitochondria (sarcosomes); an intracellular tubular network (sarcotubular system); and the contractile structures (myofibrils). (Figure 2)

The sarcosomes are the sites of oxidative phosphorylation. That is, molecules produced by the life

*

Parts of this material were recently reviewed by Dr. Clara Franzini- Armstrong in "Muscle Membranes and ExcitationContraction Coupling", presented at the Friday Evening Lectures series, Woods Hole, Massachusetts, August 19, 1977. 
processes of the organism are oxidized in the sarcoscmes. The energy released by the oxidation is used to generate adenosine triphosphate (ATP), the energy storage unit of the ce11. The sarcosomes comprise 25-30 percent of the myocardial mass (29).

The sarcotubular system which pervades the muscle fiber is composed of two components. One component, the transverse tubular system, consists of invaginations of the sarcolemma. This system provides an extension of the extracellular space into the muscle fiber. The transverse tubules are usually transverse to the fiber but often run longitudinally (80). A second component, the sarcoplasmic reticulum (SR), is a network of tubules and cisternae surrounding the myofibrils. The SR is not continuous with the extracellular space. The tubules of the SR terminate in terminal cisternae which are apposed to transverse tubules. The complex consisting of the transverse tubule and two cisternae of the $S R$ is referred to as the "triad". (Figure 2)

Hyofibrils extend the length of the cell and insert onto the intercalated discs. Myofibrils comprise about 50 percent of the cell mass (29). Each myofibril consists of a series of sarcomeres, the fundamental contractile units of striated muscle (Figure 2). The ends of all the sarcomeres in adjacent myofibrils are in the same plane. This allignment gives the muscle fiber its striated appearance. The structure of the sarcomere is illustrated in 
page 168

Figure 3. Each sarcomere is bounded longitudinally by the $Z$ lines. Between the $\mathrm{z}$ lines are thick and thin filaments (myofilaments) composed primarily of the proteins myosin and actin, respectively. The myofilaments are responsible for contraction of the sarcomere.

The thin filaments extend from the $z$ lines toward the center of the sarcomere where they interdigitate with the thick filaments at the myosin cross bridges (Figure 3).

The portion of the sarcomere spanned by the thick filaments is referred to as the A band. Thin filaments extend partially into this band. The central portion of the A band which contains only thick filaments is referred to as the M-I Complex, or the pseudo $B$ zone. The portion of the sarcomere extending from the $z$ line to the $A$ band which consists only of thin filaments is referred to as the I band.

Both types of myofilaments are a fixed length. Contraction of the sarcomere occurs by an increase in the amount of overlap between the actin and myosin filaments. That is, through a series of making and braking of bonds between actin and the myosin cross bridges, the actin and myosin filaments "slide" over one another drawing the $Z$ lines together. Hence, during contraction the pseudo $B$ zone, I band, and the distance between the $z$ lines are reduced while the A band (representing the length of the thick filaments) remains constant. 
page 169

B. The Mechanism of Contraction

Myocardial cells are specialized for electrical impulse formation, electrical impulse conduction, or contraction.

The cells specialized for impulse formation are located in the sinoatrial and in the atrioventricular nodes of the heart. These are pacemaker cells which initiate the heartbeat by periodically depolarizing. Hence, the heart is myogenic since muscle activity arises in the muscle itself. The cells specialized for conduction are the Purkinje cells. These cells constitute the Purkinje fibers and allow rapid conduction of the depolarization impulse.

The bulk of cardiac cells are specialized for contraction.

The heart is a functional syncitium; once depolarization begins in the myocardium it spreads throughout the entire myocardium crossing cell boundaries at the intercalated discs. (A syncitium is an aggregate of cells with no intracellular membrane. Hence, a syncitium functions as a unit. The heart is not a syncitium, but since the intercalated discs allow transmission of the depolarization impulse and contractile forces, the heart functions as a syncitium.)

Calcium ion appears to be the mediator between excitation of a myocardial cell and contraction of the sarcomere. Depolarization of the cell passes from the cell surface to the interior of the muscle fibers via the 
transverse tubular system. The depolarization reaches the terminal cisternae of the $S R$ and triggers release of calcium ions from the $S R$ (29). The calcium ions diffuse into the myofibrils. The reaction between actin and myosin which causes shortening of the sarcomere is inhibited in the resting state by the presence of modulating proteins, tropomyosin and troponin. The influx of calcium into the myofibrils upon cell depolarization releases the inhibition and contraction results (31). The force of contraction in the sarcomere is expressed as a longitudinal force of contraction by the muscle fiber.

subsequent to contraction, reaccumulation of calcium ions by the SR results in inhibition of the actin-myosin interaction (in the presence of the modulating proteins) and the sarcomeres return to their resting length (31)

A relationship between the concentration of calcium ions on the sarcotubular membrane and the tension developed by cardiac muscle has been shown (81). It was suggested that regulation of the amount of calcium ion released to the contractile apparatus may be a method of regulating myocaraial contractility (inotropic state) (31).

(Lee proposed an interesting theory regarding the uptake of calcium by the SR. The hydrolysis of ATP to adenosine diphosphate (ADP) and inorganic phosphate provides the energy necessary for the reaction to occur between actin and myosin filaments during contraction. In-vitro 
page 171

experiments showed that the uptake of calcium ions by the SR is greatiy accelerated in the presence of inorganic phosphate. Hence, a product of the contraction process (inorganic phosphate) may act in a feedback system by accelerating uptake of calcium ion by the $S R$ and relaxation of the muscle fiber. (33)) 
page 172

Figure 1. Muscle fiber bunde. 


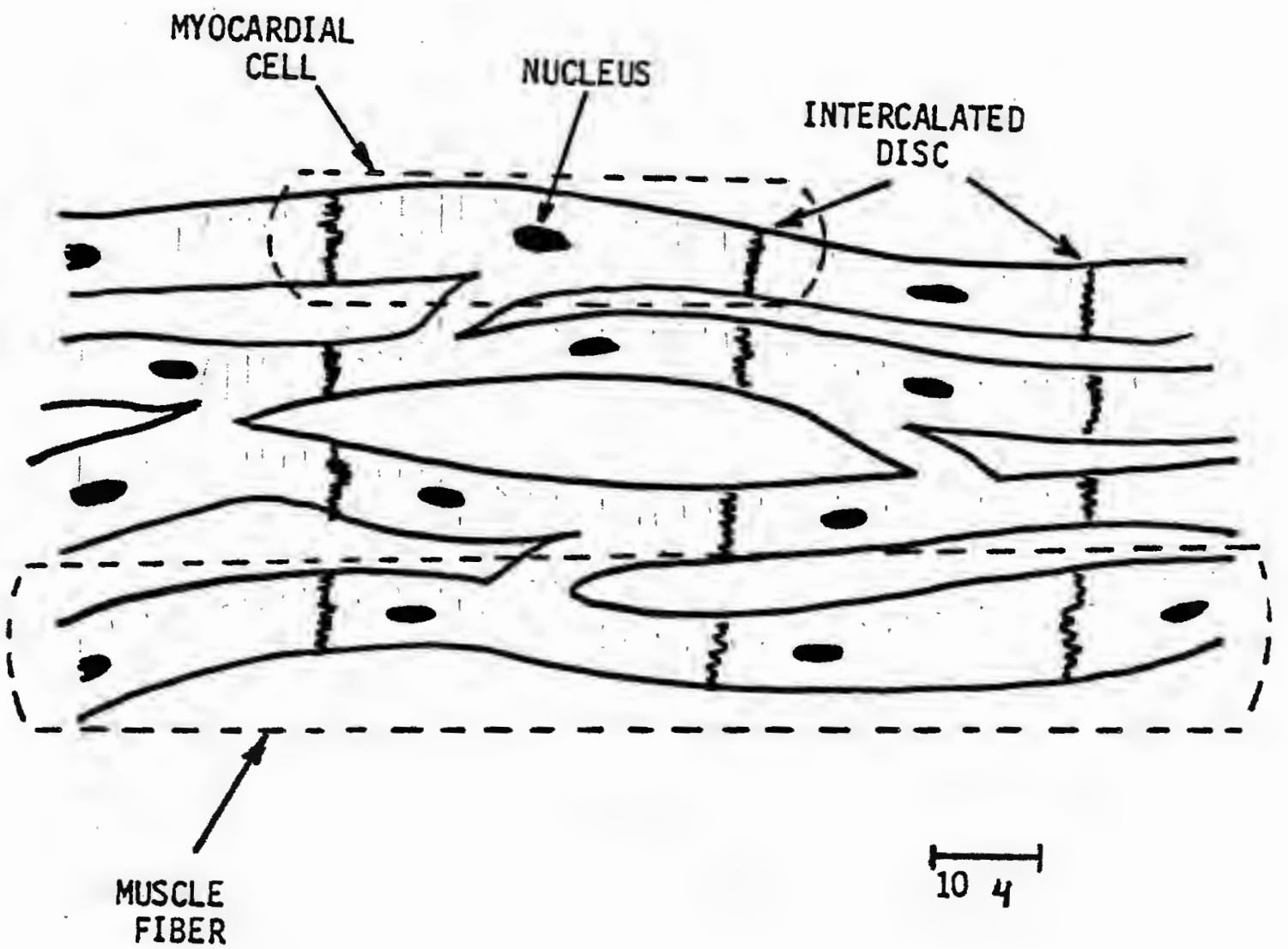

Figure 1 
page 174

Figure 2. Myocardial cell. 


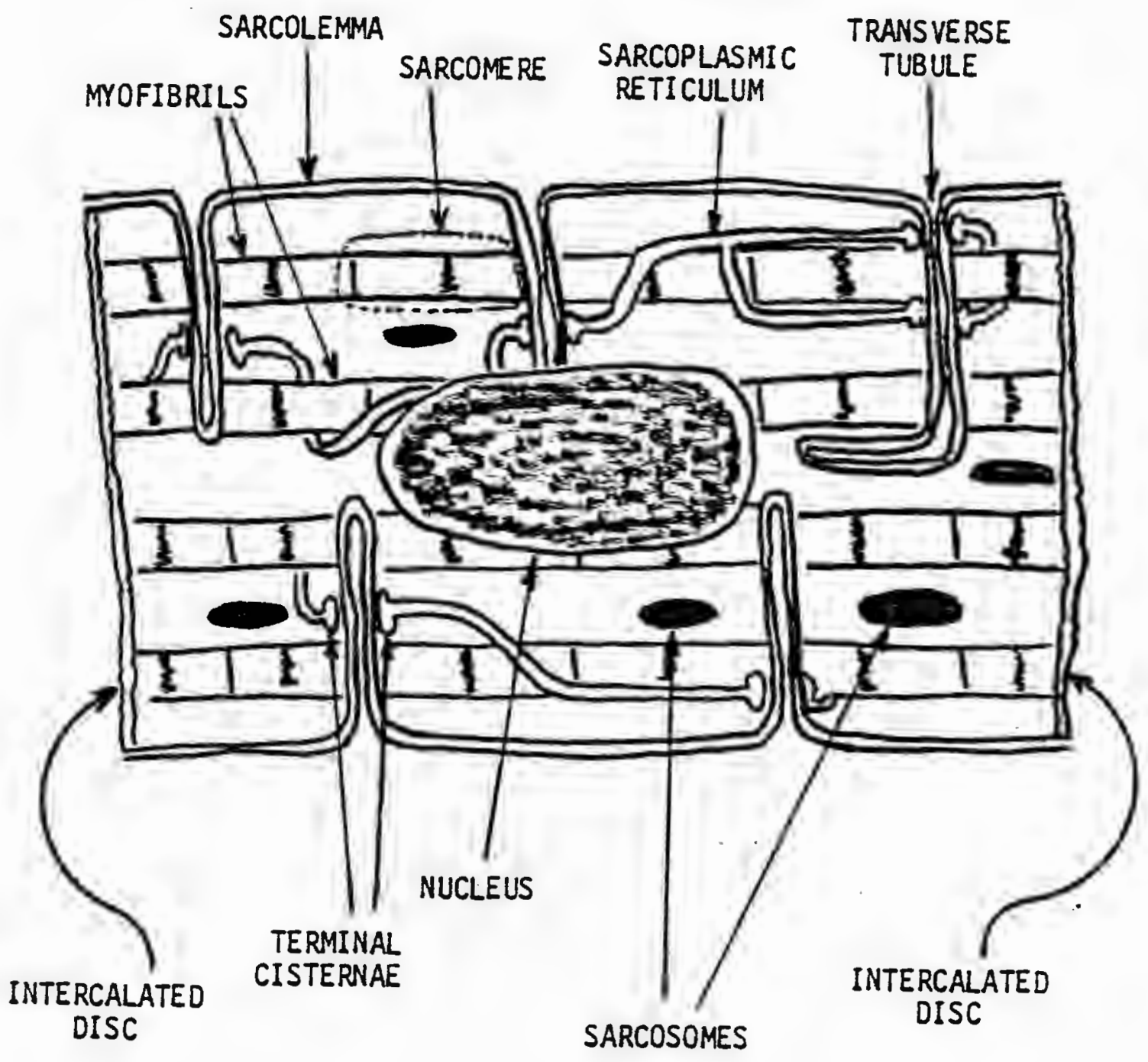

Figure 2 
page 176

Figure 3. The sarcomere. (3) 


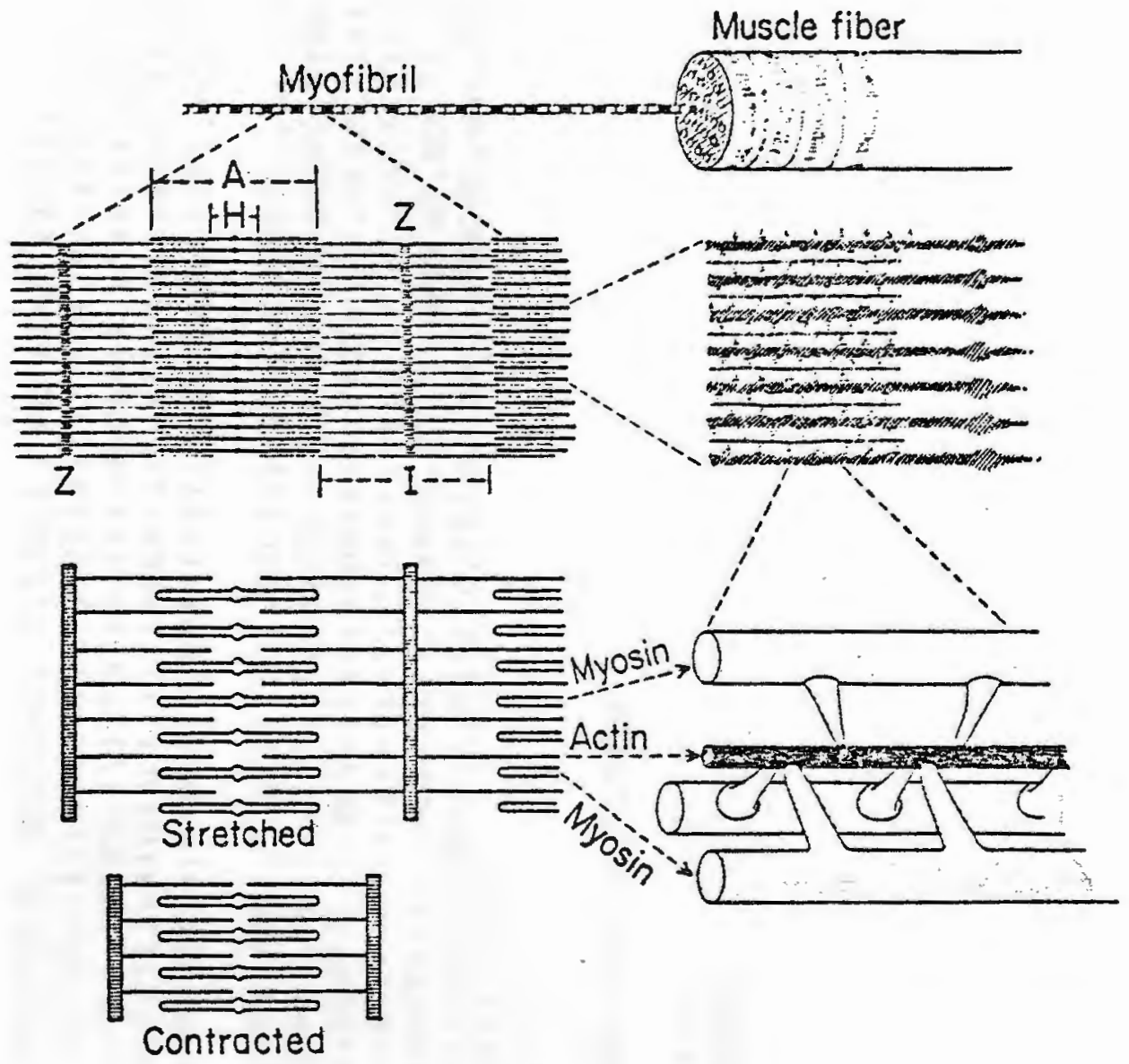

Figure 3 
APPENDIX B

C PROgRam to CALCULATE SOURCE PRESSURE AND SOURCE ImpedanCE

C

C

C HEART1

C (CYCLES BEGINNING AT DIASTOLE, NDIAS=1; SYSTOLE, NDIAS=0 (192)

DIMENS ION A1 $(20,11), B 1(20,11), A 2(20,11), B 2(20,11), A 3(20,11), B 3(20$, *11), $\operatorname{SMP}(20,11), C_{1}(20,11), C 2(20,11), C 3(20,11), A C 1(1), B C 1(1), A C 2(1)$ * 1$), B C 2(11), A C 3(11), B C 3(11), A T O T A L(11), A A V G E(11), A S O(11), A M I N(1), A$ *MAX $(11)$, BTOTAL $(11), \operatorname{BAVGE}(11), B S D(11), B M I N(11), B M A X(11), C(11), P H I(1)$ * 1$), A C(11), A P H I(11)$

COMMCN ILVP(1200), IAOP(1200), I AOF(1200), IZO(4), IFS(4), ZRFST,FACT $(4$ *) , NSMP $(20)$, JNO, I RDC AL (5), I I, I I, I I I , S $(20)$, TOL, LMN, NCYCLE, SAMP 1 , STDE *V(6),EPG $(11), E Z G(11), A L V P(11)$, BLVP $(11), A A O F(11), B A O F(11), A L V P C(1))$ *, ELVPC $(11), A A O F C(11), B A O F C(11), C P G(1)$, PHIPG $(11), C Z G(1), P H I Z G(1)$ *, AAOP(11), BAOP $(11)$, A AOPC $(11), B A O P C(11)$, IEXPNO, I CEXP, IPR INT, NDA TA,N *DOG, NRUN, NF I XIT, NDOG I, NDI A S, NPR ES S, NSTA TE, FREQ, NAWAY, NUMC YC, NOFFON

*, I PRESS $(3,129)$, I STATE $(3,129)$

CALL ERRSET $(215,256,-1)$

CALL MOMENT

2 READ ( $8, E N D=3)$ NDOG, NRUN, NPRESS, NSTATE $N D O G=N D O E-50$

IPRESS (NDGE, NRUN) = NPRESS

I STATE (NDCE, NRUN) = NSTATE

GO TO 2

3 NDIAS $=0$

NCYCLE $=2$

I CEXP $=0$

I PF INT $=18$ 
TCLCYC $=0.1$

TOL SMP $=0.05$

$N D O G=1$

$N D O G 1=1$

IFINCI AS .EQ. IIREADI9INDATA

IF INDIAS . EQ. OIREAD (4) INCATA

5 IF INDIAS.EQ, IIREAD $(9$, END $=120)$ I EXPNO, I $1, I$ I , I I I

IF (NDIAS .EQ. O) READ (4, END $=1201$ IEXPNO, I 1, I I I I I

IF (ICEXP . EQ. IEXFNOIGO TO 9

IFIICEXP. . T. IEXPNOIGO TO 6

WRITE $(6,107)$ IEXPNO

GO TO 5

6 CALL ARRAYS

ICEXP $=1$ CEXP+1

IFIICEXP. LT. IEXPNOIGO TO 6

7 NFIXIT $=0$

IFIIEXPNO .LT. 114 . AND. IEXPNO .GT. 77INFIXIT=1

IFINDATA .EQ 2 .OR. IEXPNO , GE, 191 INFIXIT=1

CALL CYCLES

9 DO $10 \quad I=1,20$

$S|I|=0.0$

10 CONTINUE

DO $20 \quad I=I 1, I I$

$S(I)=1.0$

20 CCNT INUE

$T C L=T O L C Y C$

$L M A=1$

CALL GEDATA(ILVP, A1, $1, A C 1, B C 1$ )

CALL GEDATAIIAOP,A2,B2, AC $2, B C 21$

CALL GEDATA(IAOF, A3,B3,AC $3, B C 3)$ 
DO $23 \quad j=1,2$

DO $22 I=I 1, I I$

C $1(I, J)=\operatorname{SQRT}(A 1(I, J) * * 2 * B 1(I, J) * * 2)$

$C 2(I, J)=S O R T(A 2(I, J) * * 2+B 2(I, J) * * 2)$

$C 3(1, J)=\operatorname{SQRT}(A 3(I, J) * * 2+B 3(1, J) * * 2)$

22 CONT INUE

23 CONT INUE

CALL AVRAGE $(\mathrm{Cl}, 1)$

IFILNN .EQ. OIGO TO 100

CALL AVRAGE $(C 2,1)$

IFILMN .EQ. OIGO TO 100

CALL AVRAGE $(C 3,1)$

IF ILMN .EO. OIGO TO 100

DO $25 I=I 1, I I$

$\operatorname{SMP}(I, 2)=N \operatorname{SMP}(I)$

25 CONT INUE

$T C L=T O L S M P$

CALL AVRAGE(SMP, 2$)$

IFILMN .EQ. OIGO TO 100

SAMP $=0.0$

COUNT $=0.0$

DC $30 \quad I=11,11$

IFISII) .EC. 0.0$)$ GO TO 30

SAMP $=$ SAMP +N SMPII

COUNT $=$ COUNT +1.0

30 CONTINUE

SAMP $1=$ SAMP $/$ CCUNT

SAMP $2=$ NSMP (III)

CALL TALLYIAI, S, ATOTAL, AAVGE, ASO, AMIN, AMAX, 20,11, IER, 2201

CALL TALLY(B1,S, BTOTAL, BAVGE, BSD, BMIN, BMAX, 20,11, IER, 220) 


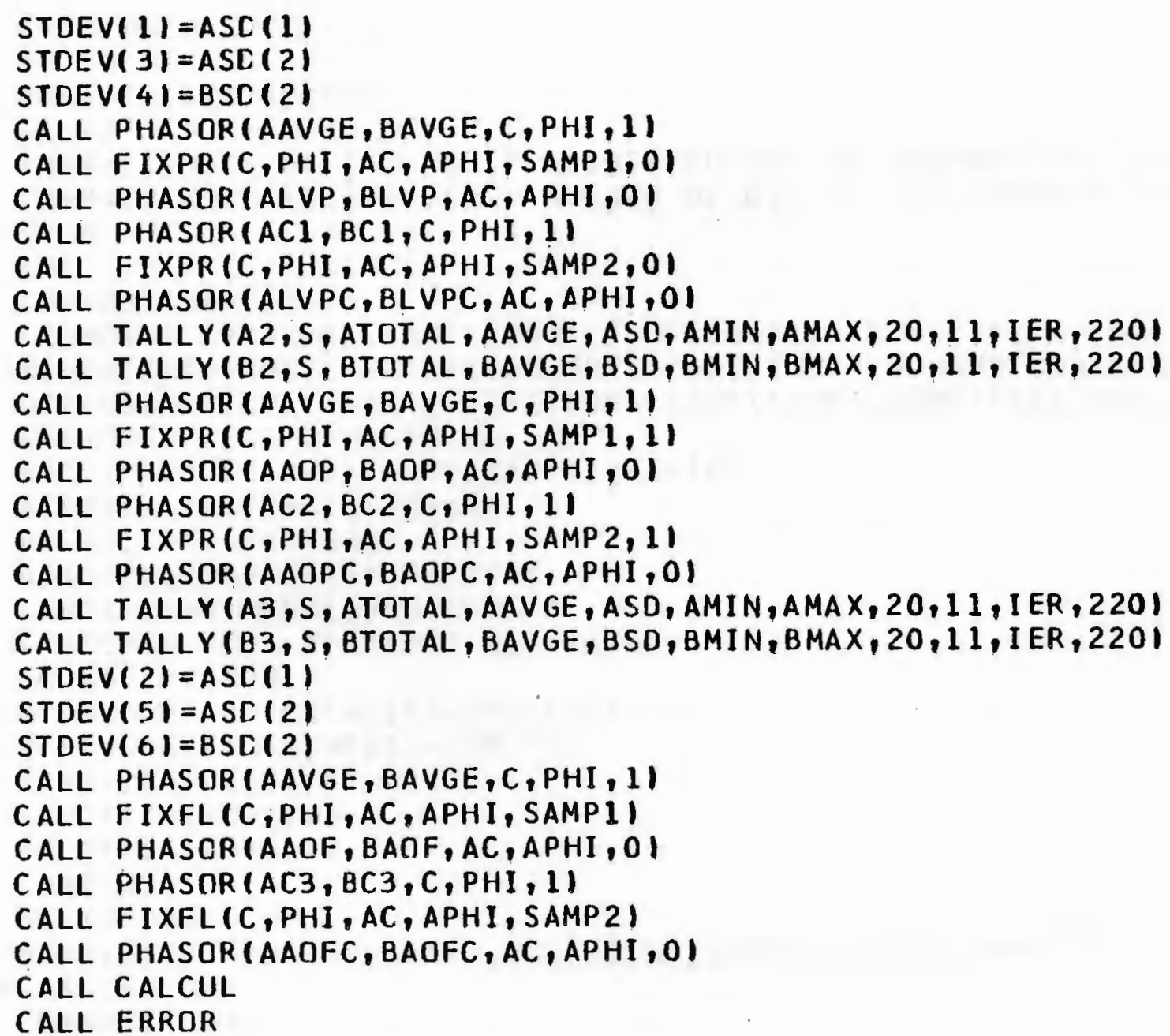




\section{CALL PRINT \\ GO TO 5}

100 WRITE $(6,110)$ IEXPNO

GC TO 5

107 FORMAT (IHO/ FILE \#",I3,' REQUESTED OUT OF SEQUENCE-NO ANALYSIS')

110 FORMAT $(1 \mathrm{HO} /$ ' FILE \#',I3,' NUMBER OF CYCLES VIOLATED-NO ANALYSISII

120 STOP

END

SUBROUTINE ARRAYS

COMMON ILVP (1200), I AOP (1200), IAOF $(1200)$, I Z0 (4), IFS(4),ZRFST,FACT(4

*), NS MP ( 20$)$, JNO, IRDCAL ( 5$)$, DUMMY 1 (232), IC EXP, DUMMY2, NDATA, NDOG, NRUN

DIMENS ION ILVPI(600), IAOP I(600), IAOF $1(600)$, NSMP $1(10)$, IRDCA $1(3)$

IFINDATA . EQ. 2160 TO 20

READ $(1,199)$ ILVP1, IAOP1, I ACF1, IZ0, IFS

READ (1,198) ZRFST, FACT(1)

READ (1,197 IFACT (2)

READ ( 1,198 ) FACT (3), FACT (4)

READ (1,199 INSMP 1, JNO, IRCCA 1

IF(ICEXP .EQ. 7)READ $(1,199)$ IBADOY

DO $10 \quad I=1,600$

IF ( I LE, I) IRCCAL ( I ) =IRDCA I I)

IF (I -LE. 101 NSMP $(I)=N S M P I(I)$

$I L V P(I)=I L V F 1(I)$

$I A O P(I)=I A O P I(I)$

I AOF (I )=I AOF I I I )

10 CONT INUE

GO TO 200

20 READ ( 3 INDCG, NRUN, LETTER, ILVP, I AOP, IAOF, IZO, IFS, ZRF ST, FACT, NSMP, JNO

*, IRDCAL

197 FORMAT IF5.3) 


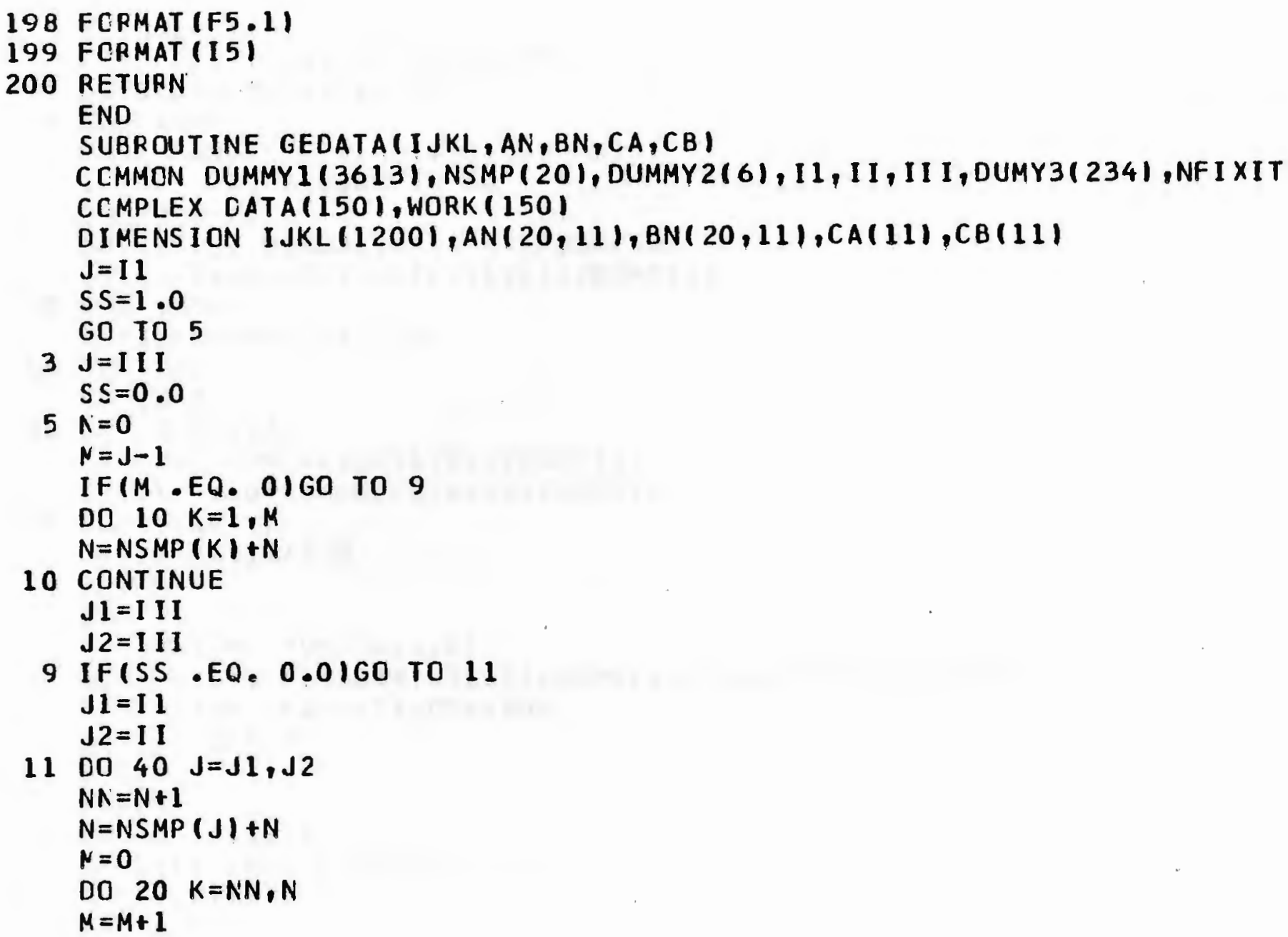




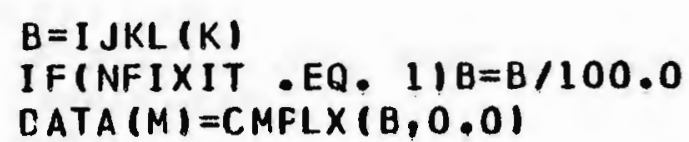

20 CONT INUE

CALL FOURT (CATA, $M, 1,-1,0$, WORK)

IF ISS.EQ. 0.01G0 TO 50

DO $30 \mathrm{~K}=1,11$

$\operatorname{AN}(J, K)=2.0 * R E A L(C A T A(K)) / N S M P(J)$

$B N(J, K)=-2.0 * A I M A G(C A T A(K) / / N S M P(J)$

30 CCNT INUE

$\operatorname{AN}(J, 1)=A N(J, 1) / 2.0$

40 CONTINUE

GO TE 3

50 DO $60 \quad K=1,11$

$C A(K)=2.0 * R E A L(D A T A(K) / / N S M P(J)$

CB $(K)=-2.0 * A I M A G(C A T A(K) / / N S M P(J)$

60 CONTINUE

$C A(1)=C A(1) / 2,0$

RETURN

END

SUBROUTINE AVRAGE $(C, N)$

COMMCN DUMMY1(3639), I1, I I, DUMMY 2, S 120$), T O L, L M N, N C Y C L E$

DIMENS ION $C(20,11)$, DEV (20)

DO $110 \mathrm{~J}=\mathrm{N}, 2$

$X=0.0$

$Y=0.0$

CO $20 \quad I=I 1, I I$

IF(S(I) .EQ. 0.0$) G 0$ TO 20

$X=C(I, J)+X$

$Y=Y+1.0$ 
20 CCNT INUE

45 IFINCYCLE .GT. YIGO TO 100

CAVRGE $=X / Y$

$N=0$

DO $50 I=I 1, I I$

IFISII). EQ. 0.0160 TO 50

DEV $(I)=A B S($ (CAVRGE-C $(I, J)) /$ CAVRGE $)$

IFIDEV II) -LE. TOLIGO TO 50

$N=1$

50 CONTINUE

IF IM.EQ. O)GO TO 110

GRAD $=0.0$

DO $601=11,11$

IFISII.$E Q \cdot 0.0) G 0$ TO 60

IFIGRAD . GE. DEVII)IGO TO 60

GRAD $=D E V(I)$

$L=I$

60 CCNTINUE

$S(L)=0.0$

$Y=Y-1.0$

$X=X-C(L, J)$

GO TO 45

100 LMN $=0$

GO TO 120

110 CONTINUE

120 RETURN

END

SUEROUTINE PHASOR $(A, B, C, P H I, L)$

DIMENS ION A(11), B $(11), C(1), P H I(1))$

DO $90 I=1,11$ 
IFIL . EQ. $01 \mathrm{GO}$ TO 70

IF (BII), GE, 0.01G0 TO 50

IF ( A I I.$G T \cdot 0.0160$ TO 55

$A D C=-180.0$

GO TO 60

50 IFIAII) EE. 0.0)GO TO 55

$A D D=180.0$

GO TO 60

$55 \quad A D D=0.0$

$60 \mathrm{PHI}(I)=-($ ATAN $(B(I) / A(I) \mid * 180,0 / 3,1416+A D D)$

$C(I)=S Q R T(A)(I) * * 2+B(I) * * 2)$

GC TO 90

$70 \mathrm{~A}(\mathrm{I})=\mathrm{C}(\mathrm{I}) * \operatorname{COS}(\mathrm{PHI}(\mathrm{I}) * 3.1416 / 180.0)$

$B(I)=-C(I) * S I N(P H I(I) * 3.1416 / 180.0)$

90 CONT INUE

RETURN

END

SUBROUT INE FIXPR (CMEAS, PMEAS, C, P, SAMP, L I

CCMMON DUMMY $1(3609)$, FACT (4), DUMMY $2(260)$, NDATA

DIMENS ION CMEAS $(11)$, PMEAS $(11), C(11), P(11), X(11), Y(11), 2(1)$, RATIOI

*11), PHI(11)

DO $10 \mathrm{~J}=1,11$

$I=\mathbf{J}-\mathbf{1}$

$X(J)=I * F A C T(1) / S$ AMP

$Y(J)=1 \cdot 0-|X| J \mid * * 2 / F A C T(3) * 2)$

$Z(J)=2.0 * F A C T(2) * X(J) / F A C T(3)$

10 CONT INUE

CALL PHASOR $(Y, Z, R A T I O, P H I, 1$ !

PHID $=0.0$

CO $20 \mathrm{~J}=1,11$ 
IF (NDATA.EQ.2) RATIO $(J)=1,0$

I F (NCATA.EQ.2 I PHI ( J) =0.0

IFIL.EQ. $0.0 R, X(J) \cdot L E \cdot 3.0)$ GO TO 15

PHID $=-1.45 * x(\mathrm{~J})$

$15 \mathrm{C}(\mathrm{J})=\operatorname{CMEAS}(\mathrm{J}) *$ RAT IO(J)

P $(J)=$ PMEAS $(J)-P H I(J)-P H I D$

20 CONT INUE

RETUAN

END

SUBROUT INE FIXFL (CMEAS, PMEAS, C, P, SAMP)

COMMON DUMMY 1 (3609), FACT (4)

DIMENS ICN CMEAS $(11)$, PMEAS $(11), \mathrm{C}(11), \mathrm{P}(11)$

$C(1)=C M E A S(1)$

$P(1)=$ PMEAS $(1)$

CO $300 \mathrm{~J}=2,11$

$I=J-1$

$X=I * F A C T(1) / S A M P$

IF (FACT $(4)-50.0) 100,150,200$

100 RATIO=.8373255E-10*X**5-.3208667E-07*X**4*.4018683E-05*X**3+.58360

* $16 \mathrm{E}-04 * X * 2+.2039687 \mathrm{E}-01 * X+.9437819$

$\mathrm{PHI}=.4540262 \mathrm{E}-08 * X * * 5-.1595053 \mathrm{E}-05 * X * 4 * .2809963 \mathrm{E}-03 * X * * 3-.3286052$

$* E-01 * X * * 2+.3821838 E+01 * X-.3325348$

GO TO 250

150 RATI $0=.1960143 E-09 * x * * 5-.7961717 E-07 * x * * 4+.1120121 E-04 * x * * 3-.48866$

*12E-03*X**2+.1772314E-01*X+.9475231

PHI $=-.4024513 E-10 * X * * 6+.2762906 E-07 * x * * 5-.55055$ C4E-05*X**4*.443625

$* 3 E-03 * x * * 3-.1913939 E-01 * x * * 2+2.721911 * x-.2531528$

GO TO 250

200 RATI $O=-.534419 E-10 * X * * 5+.2637328 E-07 * X * * 4-.4172151 E-C 5 * X * * 3 * .29391$

$* 47 \mathrm{E}-03 * X * * 2-.3801871 \mathrm{E}-02 * X+.100734 \mathrm{E}+01$ 
$\mathrm{PHI}=.3576522 \mathrm{E}-07 * X * * 5-.9758594 \mathrm{E}-05 * X * * 4+.8799024 \mathrm{E}-03 * X * * 3-.2932322$ $* E-01 * X * * 2+.2120712 E+01 * X-.5154968$

$250 \mathrm{C}(\mathrm{J})=\mathrm{CMEAS}(\mathrm{J}) * \mathrm{R}$ AT IO

$P(J)=P M E A S(J)+P H I$

300 CONT INUE

RETURN

END

SUBROUTINE CALCUL

COMMON DUHMY I (3609), FACT(4), DUMMY $2(26), 11,11,111,5(20), D U M M Y 3(3), S$ *AMP1,DUMMY 4 (28), ALVP (11), BLVP(1), AAOF $(11), B A O F(11), A L V P C(11), B L V P$

*C(11), AAOFC $(11), B A O F C(1)$, CPG $(11), P H I P G(1)), C Z G(1)$, PHI ZG $(11), D U M M$ * Y $5(48)$, NDCG, NRUN, DUMMY 6 ( 3 ), NPRESS, NSTATE, FREQ, NAWAY, NUMCYC, NOFFON,

*IPRESS $(3,129)$, I STATE $(3,129)$

DIMENS ION APG $(11), B P G(11), A Z G(11), B Z G(1)$

COMPLEX PLV1,PLV2,QA1, QA2,PG, ZG

DC: $40 \quad I=1,11$

PLVI $=C M P L X(A L V P(I), E L V P(I))$

PLV2 $=C M P L X(A L V P C(I), E L V P C(I) !$

$Q A 1=C M P L X(A A O F(I), B A O F(I))$

QA2 $=$ CMPLX $(A A D F C(I), B A O F C(I))$

$P G=(P L V 1 * Q A 2-P L V 2 * Q A 1) /(Q A 2-Q A 1)$

$Z G=(P G-P L V I) / Q A I$

$\triangle P G(I)=R E A L(P G)$

$B P G(I)=A I M A G(P G)$

$A Z G(I)=\operatorname{REAL}(Z G)$

$B Z G(I)=A I M A G(Z G)$

40 CCNT INUE

CALL PHASCR (APG,BPG,CPG,PHIPG, 1 )

CALL PHASOR (AZG,BZG,CZG,PHIZG, 1$)$

DO $50 \quad I=1,11$ 
CZG (I) $=$ CZG (I)*1333.2894

50 CONTINUE

$I D C G=N D O G-50$

NPRESS = I PRESS (IDOG, NRUN )

NSTATE = I ST ATE (I DOG, NRUN)

FREQ $=F A C T(1) /$ SAMP 1

NAWAY $=$ I I I - I I

NUMC YC $=0$

DO $60 I=I 1, I I$

IF (SII) .EQ.0.0 160 TO 60

NUNCYC $=$ NUMCYC +1

60 CONTINUE

IF (ALVPC ( 1$) \cdot L E \cdot A L V P(1)$ INOFFON=0

I F ( ALVPC ( 1$), G T, A L V P(1)$ INOFFON=1

RETURN

END

SUEROUT INE MOMENT

WRITE $(6,5)$

5 FORMAT (93X," "HEART1"!)

CALL IDATE (IYEAR, IDAY)

WR I TE $(6,10$ I IDAY, IYEAR

10 FCRMAT $(90 X, I 3,1$ DAY DF 191,121

CALL TIME (IHOUR, IMIN, ISEC)

WR I TE $(6,20)$ I HOUR, IMIN, I SEC

20 FORMAT $(93 X, A 2,1: 1, A 2,1: 1, A 2)$

RETURN

END

SUBROUTINE ERROR

COMMON DUMMY $1(3672)$, EPG $(11), E Z G(11)$, ALVP $(11), B L V P(11), A A O F(11), B A O$

*F(11), ALVPC $(11), B L V P C(1)$, AAOFC $(1)), B A D F C(1))$ 
OIMENS ION PLV1(11),PLV2(11),Q1111),02(11),PHI(11)

CALL PHASOR(ALVP, BLVP, PLVI,PHI, 1 )

CALL PHASOR (ALVPC,BLVPC,PLV2,PHI, 11

CALL PHASOR (AAOF, BAOF,Q1,PHI, 1 )

CALL PHASOR (AAOFC, BAOFC, Q2,PHI, 1 )

DO $10 \quad I=1,11$

$A=A B S(02(I) /(Q 2(I)-Q 1(I) * .01 * P L V 1(I))$

$B=A B S(-Q 1(I) /(Q 2(I)-Q 1(I)) * .01 * P L V 2(I))$

$C=A B S(Q 2(I) *(P L V 1(I)-P L V 2(I)) /((Q 2(I)-Q 1(I)) * * 2) * .05 * Q 1(I))$

$D=A B S(Q 1(I) *(P L V 2(I)-P L V 1(I) /(102(I)-Q 1(I) * * 2) * .05 * 02(I))$

$E P G(I)=A+B+C+D$

$A=A B S(1.0 /(02(I)-Q 1(I) * .01 * P L V 1(I))$

$B=A B S(-1.0 /(02(I)-Q 1(I)) .01 * P L V 2(I))$

$C=A B S((P L V I(I)-P L V 2(I)) /((02)(I)-Q 1(I)) * * 2) * .05 * Q 1(I))$

$D=A B S((P L V 2(I)-P L V I(I)) /(102(I)-Q 1(I) * * 2) * .05 * Q 2(I))$

$E Z G(I)=(A+B+C+D) * 1333.2894$

10 CONTINUE

RETURN

END

SUEROUTINE CYCLES

DIMENS ION NTEST $(1200)$, NHOLO (40), NHOL D $1(40)$, NSMP $1(40)$

CCMMCN ILVP $(1200)$, I AOP (1200), DUMMY $1(1213)$, NSMP( 20$)$, JNO, DUMMY $2(242)$

*,NFIXIT, DUNNY3,NDIAS

$\angle S N P=0$

DO $10 \mathrm{I}=1$, JNO

LSMP $=$ L SMP +NSMP (I)

10 CONT INUE

DO $201=1$, LSNP

NTEST (I) I ILVP (I)

IFINFIXIT .EQ. 1 INTEST (I)=NTEST (II/100 
20 CONT INUE

$J N O 1=J N O$

$\mathrm{JNC}=0$

$\mathrm{NSWICH}=1$

DC $50 \mathrm{~J}=1,40$

IF INSWICH .EO, OIGO TO 50

$N G R A D=0$

DO $30 \quad I=1$, LSMP

IFINGRAD .GE. NTESTIII)GO TO 30

NGRAD $=$ NTEST ( I )

$L=I$

30 CCNTINUE

NHOLD $(J)=L$

IF(NTEST (L) , GE, 60)GO TO 35

$N$ SWICH $=0$

GO TO 50

$35 \mathrm{JNC}=\mathrm{JNO}+1$

$L 1=L-20$

IFILI $\cdot L T \cdot 1 / L 1=1$

$L 2=L+20$

IF IL 2 .GT . LSMPIL $2=L S M P$

CO $40 \mathrm{~K}=\mathrm{L} 1, \mathrm{~L} 2$

NTEST $(K)=0$

40 CONTINUE

50 CONTINUE

DO $90 \quad I=1, J N O$

$N=$ NHOL $C(I)$

NSWI T $=1$

70 IF INDI AS EEC. OIM=N-1

IFINDIAS,EQ. $11 M=\mathrm{N}+1$ 
IFIM.GT . OIGO TO 75

$\Lambda=M$

GO TO 80

75 IFIM . GT. LSMPIGO TO 80

IF I I AOP (M) ITT, I AOP (N) INSWIT =0

IF(IAOP(M) GE. IAOP(N).AND, NSWIT,EQ, OIGO TO 78

77 IFINDIAS. EQ. OIN=N-1

IFINDIAS,$E Q \cdot 1 \mid N=N+1$

GO TO 70

78 IFINDIAS EQ E 1 .OR. N ILE. $31 G 0$ TO 80

$\mathrm{NCHK}=\mathrm{N}-1$

$M C H K=N-2$

$\mathrm{KCHK}=\mathrm{N}-3$

IF(I AOP (MCHK) -LT I IAOP(NCHK) AAND. IAOP(KCHK) -LT. IAOP(NCHK) IGO * TO 77

79 LCHK $=N+1$

IF( I IADP(LCHK)-IAOP(N) ).GT • 100)GO TO 80

$N=N+1$

IFIN ELT. NHOLDIIIIGC TO 79

$N=N-10$

WR I TE $(6,200$ II , N

80 NHOLD(I $)=N$

90 CCNTINUE

DO $100 I=1, J N O$

NHOLDI (I) =NFOLD(I)

100 CCNT INUE

DO $120 \quad I=1, \mathrm{JNO}$

NGRAD $=1201$

DO $110 \mathrm{~J}=1, \mathrm{JNO}$

IF(NGRAO .LE. NHOLDI(J))GC TO 110 
NGRAD $=$ NHOLD $1(J)$

$L=J$

110 CONTINUE

NHOLD(I) =NHCLDI(L)

NHOLDI ( L) $=1201$

120 CONT INUE

NSMP $1(1)=$ NHCLD(1)

DO $130 I=2$, JNO

$J=I-1$

IF (NHOLD 11$)$.NE, O)NSMP I I I)=NHOLD(I)-NHOLD(J)

IF (NHOLD ( 1$)$. EQ. O) NSMP $1(J)=$ NHOLD(I)-NHOLD $(J)$

130 CONTINUE

IFINHOLDI 1$), E Q \cdot 0) \mathrm{JNO}=\mathrm{JNO}-1$

IF ( JNO GT .20$)$ JNO $=20$

DO $160 I=1$, JND

NSMP(I $)=N S M P I(I)$

IF (NSMP (I ) . GT • 150) WRITE(t, 155) I, NSMP(I)

155 FORMAT $(' 1$ ' $5 X$, 'CYCLE NO.', 12, ' HAS ', I3,' SAMPLES' $)$

160 CONTINUE

C

IF ( JNO - NE. JNDI IWRI TE $(6,180)$ JNOI, JNO

180 FORMAT $11,5 \times$, NUMBER OF CYCLES CHANGED FROM $1,12,1$ TO $1,12,1: 11$

200 FCRMAT $11 \%$ ' CYCLE NO.' I I,' REQ-D AN ARBITRARY BEGINNING AT', I4) RETURN

END

SUBROUTINE PRINT

COMMCN DUMMY $1(3641)$, II I, S $(20)$, DUMMY $2(4)$, STDEV $(6), E P G(1), E 2 G(1)$, A *LVP( 11$)$, BLVP(11), AAOF $(11), B A O F(11), A L V P C(11), B L V P C(11), A A O F C(1)), B$ *AOFC $(11)$, CPE $(11)$, PHIPG $(11), C Z G(11), P H I Z G(11)$,DUMMY3 (46), IPR INT, NDA

*TA, NDOG, NRUN, DUMMY $4(2)$, NDI AS, NPRES S, NSTATE, FR EQ, DUMNYG( 2$)$, NOFF CN

2 FORMAT $(1,270 X, '$ (CYCLES BEGINNING AT DIASTOLE) $)$ 
4 FOFMAT $(11,70 X, '(C Y C L E S$ BEGINNING AT SYSTOLEI')

6 FORMAT $171 \times, 1$ (BALLOCN PRESSURE $1,13,1$, HEART STATUS 1,111

8 FORMAT $(71 \mathrm{X}, 11$ =NORMAL, $2=$ =DENERV, $3=0 \mathrm{CCL} U \mathrm{D}, 4=$ DENOC $) 1$ ')

15 FORMAT IIHO/16X, DOG ', I3,' RUN I, I3,9X, 'S.S. CHANGED AV FREQ ON*OFF' I

25 FORMAT IIHO/16X,'DOG ', 13,' RUN ', I3,9X,'S.S. CHANGED AV FREQ CFF *-CN')

30 FORMAT $(40 x, 12,5 x, 12,5 X, F 5.2)$

40 FORMAT $(40 X, 12)$

50 FCRMAT I $1 H 0 / 29 X$, 'LVP',6X, 'AOF',30X, 'SOURCE PRESSURE',12X,'SOURCE IM *PECANCE' I

60 FORMAT (27X' (MM HG) (CC/SC)',13X,'HARMONIC MAGNITUDE PHASE ER *ROR MAGNITUDE PHASE ERRORII

70 FORMAT $(15 X, 1$ DC: $, 49 X, 1$ (MM HG) (DEG) (MAG) (DY*S/CM**5) (DEG)

* (MAG) $)$

80 FOFMAT $15 X$, S.S. AVG ',F7.3,2X,F7.3,16X, DC , 7X,F6.1,10X,F6,1,5 $* X, F 6.0,10 X, F 6.01$

90 FORMAT I I5X,' S.D.', 7X,F 7.3,2X,F 7, 3,17X,'1',7X,F $6.1,2 X, F 6,1,2 X, F 6,1$ * $5 X, F 6.0,2 X, F 6.1,2 X, F 6.01$

100 FORMAT $115 \mathrm{X}, 1$ CHANGED $, F 7,3,2 \mathrm{X}, \mathrm{F} 7,3,17 \mathrm{X}, 121,7 \mathrm{X}, \mathrm{F} 6,1,2 \mathrm{X}, \mathrm{F} 6.1,2 \mathrm{X}$, *F6.1,5X,F6,0,2X,F6.1,2X,FG.01

110 FORMAT $(60 X, 131,7 X, F 6,1,2 X, F 6,1,2 X, F 6,1,5 X, F 6,0,2 x, F 6,1,2 X, F 6,0)$

120 FORMAT (15X,' FUND: ', 39X, '4', 7X,F6, 1, 2X,F6.1, 2X,F6.1, 5X,F6.0,2X,F6. *1,2X,F6,01

130 FOFMAT $115 X$, A S.S. AVG $, F 7.3,2 X, F 7.3,17 X, 151,7 X, F 6,1,2 X, F 6,1,2 X$, *F6.1,5X,F6.0,2X,FG.1,2X,F6.01

140 FORMAT $(15 X, 1$ S.D. ', $7 X, F 7.3,2 X, F 7,3,17 X, 16,7 X, F 6.1,2 X, F 6,1,2 X, F 6,1$ *, $5 X, F 6,0,2 X, F 6,1,2 X, F 6.01$

150 FORMAT (15X, A CHANGED $, F 7.3,2 X, F 7,3,17 X, 171,7 X, F 6,1,2 X, F 6,1,2 X$, *F6.1,5X,F6.0,2X,F6.1,2X,F6.01 
160 FORMAT I $15 X$, B S.S. AVG ',F7.3,2X,F7.3,17X, '8 , 7X,F6.1,2X,F6.1,2X, *F6.1,5X,F6.0,2X,F6.1,2X,F6.01

170 FCRMAT (15X, S.D.' , 7X,F $7.3,2 X, F 7.3,17 X, 191,7 X, F 6.1,2 X, F 6.1,2 X, F 6.1$ $*, 5 X, F 6,0,2 X, F 6,1,2 X, F 6.01$

180 FORMAT $(15 X$, B CHANGED $1, F 8.3,2 X, F 7.3,16 X, 1101,7 X, F 6,1,2 X, F 6.1,2 X$, *F $6.1,5 X, F 6,0,2 X, F 6.1,2 X, F 6.01$

I PR INT = I PR INT +1

IF ( ( IPR INT/2)*2.NE.I PR INT • AND .NOI AS,EQ . 1 IWR I TE $(6,2)$

IF ( (IPRINT/2)*2.NE.IPR INT . AND.NDIAS,EQ.0) WRITE $(6,4)$

IF ( ( IPRINT / 2$) * 2$. NE. I PR INT I HRI TE $(6,6)$ NPRESS, NSTA TE

IF ( ( IPRINT/2)*2.NE. I PRINT IWRITE $(6,8)$

IF I NCF FON.EG.OIWRITE $(6,15$ INDOG, NRUN

IF ( NOF FON.EG. 1 IWRITE $(6,25$ INDOG, NRUN

$N=0$

CO $220 \quad I=1,20$

IFIS(I) .EC.0.01G0 TO 220

IF (M.EQ.1) GO TO 210

WR ITE $(6,30) 1$, I I I, FREQ

$M=1$

GO TO 220

210 WRITE $(6,40) 1$

220 CCNT INUE

WRITE $(6,50)$

WR I TE $(6,60)$

WRITE $(6,70)$

WRITE $(6,80)$ ALVP $(1), A A O F(1), C P G(1), E P G(1), C Z G(1), E Z G(1)$

WRITE $(6,90)$ STDEV $(1), \operatorname{STDEV}(2), \mathrm{CPG}(2), \operatorname{PHI} P G(2), \mathrm{EPG}(2), \mathrm{CZG}(2), \operatorname{PHI} Z \mathrm{G}(2$ *), EZG(2)

WRITE $(6,100)$ ALVPC $(1), A A O F C(1), C P G(3), P H I P G(3), E P G(3), C 2 G(3), P H I 2 G($ $* 31, E Z G(3)$ 
WRITE(6,1 10$)$ CPG (4), PHIPG (4),EPG (4), CZG(4), PHI ZG (4), EZG(4)

WRITE $(6,120)$ CPG $(5), P H I P G(5), E P G(5), C Z G(5), P H I Z G(5), E Z G(5)$

WRI TE $(6,130$ IALVP( 2$), A A O F(2), C P G(6), P H I P G(6), E P G(6), C Z G(6), P H I Z G(6)$

* EZG(6)

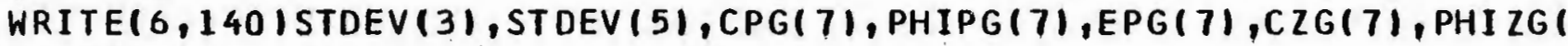

*7), EZG(7)

WRITE(6,150) ALVPC (2),AAOFC (2),CPG(8), PHIPG (8), EPG (8),CZG(8), PHIZG)

*8), EZG (B)

WRITE(6,160)BLVP(2), EAOF (2),CPG(9),PHIPG(9),EPG (9),CZG(9),PHIZG(9) *,EZG(9)

WRITE(6,170) STDEV (4),STDEV (6),CPG(10),PHIPG $(10), E P G(10), C Z G(10), P H$

*IZG(10), EZG(10)

WRI TE $(6,180)$ BLVPC $(2), B A O F C(2), C P G(1)$, PHIPG(1), EPG $(1),, C Z G(1), P H$

*IZG(11), EZG(11)

RETURN

END 
APPENDIX C

" program to test the diastolic COMPLiant properties of the

" L.V. TIME DOMAIN MODEL

"

11

11

\section{PASIVE}

"THIS PROGRAM TESTS THE COMPL IANT PROPERTIES OF 'MODEL"

" INPUT ARE THE DIASTOLIC PRESSURE AND THE FRACTION OF WALL THICKNESS

" FROM THE ENDOCARDIUM aT WHICH STRAIN IS CONSIDERED

DIMENSICN RO $(10), H O(10)$, RDIAS $(10)$, HDIAS $(10)$

$E D P=8.0$

$E=2.71828$

$F I=3.1416$

BET $A=5.0$

ALPHA $=3.0$

FACTCR $=0.01$

$Z=0.6032$

$\operatorname{RDIAS}(1)=1.3912$

$\operatorname{RDIAS}(2)=1.4921$

$\operatorname{RDIAS}(3)=1.5495$

$\operatorname{RDIAS}(4)=1.5682$

$\operatorname{RDIAS}(5)=1.5495$

$\operatorname{RDIAS}(6)=1.4921$

$\operatorname{RDIAS}(7)=1.3912$

$\operatorname{RDIAS}(8)=1.2361$

RDIAS $(9)=1.0020$

RDIAS $(10)=0.6032$

HCIAS $(1)=0.9516$

$\operatorname{HDIAS}(2)=0.9784$ 


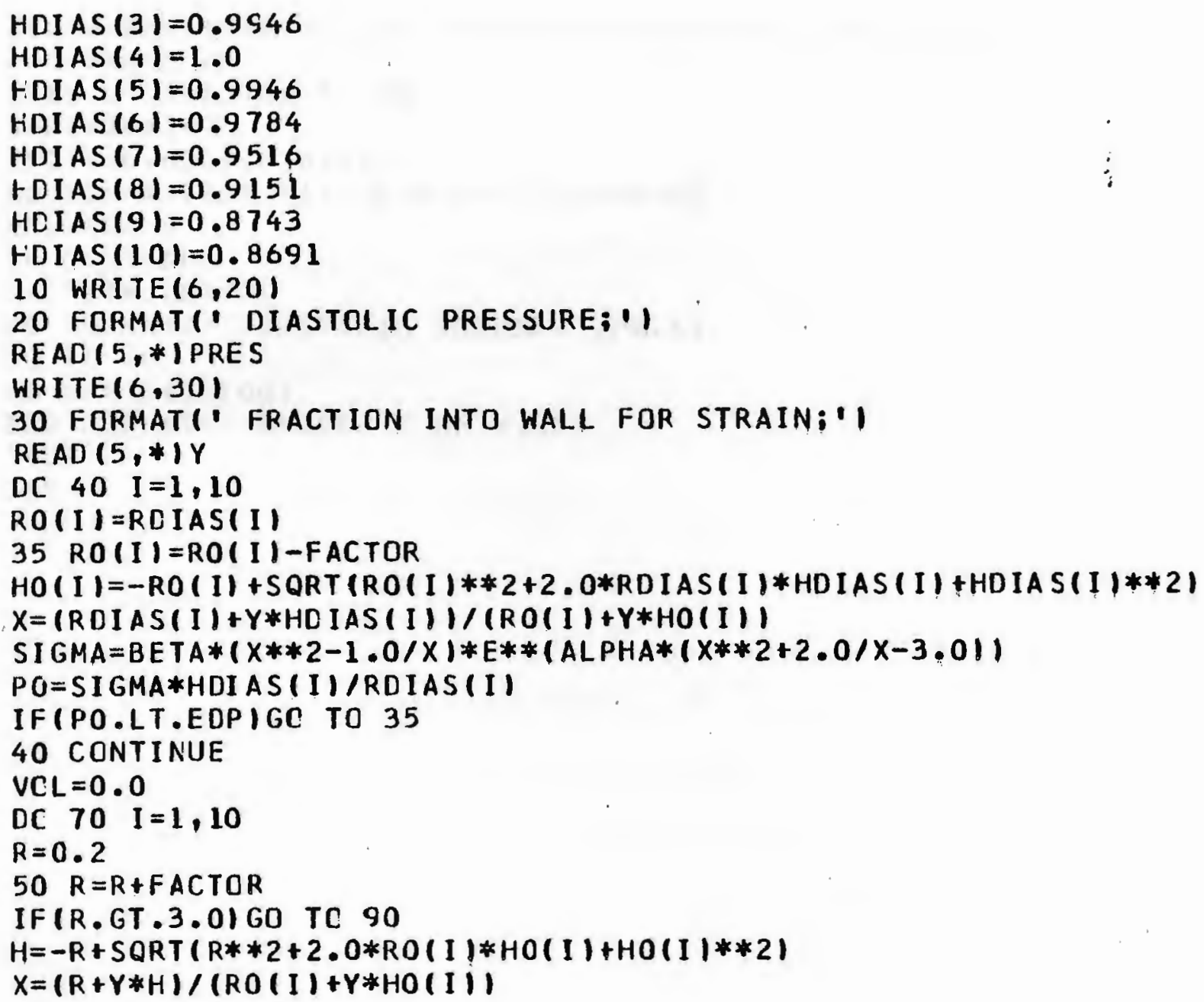


SIGMA $=$ BETA*(X**2-1.0/X)*E**(ALPHA*(X**2+2.0/X-3.0) $)$ $P=S I G M A * H / R$

IFIP.LT.PRESIGO TC 50

$V=P I * R * 2 * Z$

WRITE $(6,601 I, P, R, V, X$

60 FORMAT $(10 X, I I, P, R, V, X=1, I 2,4 F 8,4)$

$V C L=V C L+V$

70 CCNTINUE

WR ITE $(6,801$ VOL

80 FORMATI' DIASTOLIC VOLUME $=1, F 8.4$ !

GO TO 10

90 WRITE $(6,100)$

100 FORMATI, EXCEED R OF 3.01 !

STOP

EAD 


\section{APPENDIX D}

" PROgRAM analyzing the time domain l.V. MDdel

II

"MODEL

"THE MAXIMUM NUMBER OF SHELLS (NSEG) IS 10,

"THE MAXIMUM NUMBER OF PDINTS IN THE HEART CYCLE INCYCLE) IS 85.

"TO SIMULATE MYOCARDIAL INFARCT IN A SEGMENT DURING I SOVOLUMIC CONTRACTION,

" SEE LINE $4688^{\circ}$

DIMENSICN RAD $(85)$

COMMCN RADIUS $(10,85)$, J, NSEG, DEL $Z$, TOTVOL, NUMPT S, NCYCLE, FLOW( 85$),$ DELT, EDV, ESV,DIASP, TO, THICK $(10), N S W I T(10)$, SYSDUR, DELAY, AOP $(86), \operatorname{NOUT}(10), \operatorname{QSEG}(10,85)$ "I

"THE END-DIASTOLIC VOLUME (CC):

$E D V=35.0$

"THE STROKE VOLUME (CC):

$S V=12.77$

"THE END SYSTOLIC VOLUME:

$E S V=E D V-S V$

"THE EQUITORIAL THICKNESS OF THE L.V. WALL AT END DIASTOLE (CM):

$T 0=1.0$

"THE UNIFORM PRESSURE IN THE L.V. AT END DIASTOLE (MM HG):

CI ASP $=6.0$

"THE NUMBER OF CYLINDR ICAL SEgMENTS MODEL ING THE L.V.:

$N S E G=10$

"THE TIME DURATION OF THE CARCIAC CYCLE (SECI:

CYCDUR $=0.425$

"THE TIME DURATION OF EJECTION (SEC):

SYSTLE $=0.120$ 
"FROM GUYTCN, PAGE 164,

"THE DELAY OF CENTRACTION OVER THE L, V, FROM APEX TO VALVE (SEC):

DELAY $=0.066$

"THE DURATION OF SYSTOLE PLUS DELAY (SEC):

SYSDUR = SYSTLE+DELAY

"THE TOTAL NUMBER OF POINTS CONSIDERED IN THE CARDIAC CYCLE:

NCYCLE $=85$

"THE NUMBER OF POINTS CONSIDERED IN SYSTOLE:

NUMPT $S=S Y S D U R * N C Y C L E / C Y C D U R$

"THE TIME BETWEEN FOINTS:

DELT $=$ CYCDUR/NCYCLE

"I

"to PLot the RADII OF THE L.V. VS. TIME, NOUT(1)=1;

NOUT $(1)=1$

"TO PLOT THE OUTLINE OF THE L.V. VS. TIME, NOUT(2)=1:

NOUT $(2)=1$

"TO FLOT L.V. FLCW VS. TIME, NOUT $|3|=1$ :

$\operatorname{NCUT}(3)=1$

" TO PLOT AORTIC PRESSURE VS. TIME, NOUT (4)=1:

$\operatorname{NCUT}(4)=1$

"TO PRINT AOP, L.V. FLOW, AND L.V. INERTIAL, VISCOUS AND COMPLIANT PRESSURES, " NCUT (5) $=1$ : NCUT $(5)=1$

"TO PLOT THE L.V. PRESSURE DISTRIBUTION FOR EACH SEGMENT VS. TIME, NOUTI6I=1: NCUT $(6)=1$

" TO PLOT THE PRESSURE DISTRIBUTION IN THE L.V. FOR EACH POINT IN TIME, " NOUTIT) $=1$ :

NCUT $(7)=1$

"TO PRINT THE FLOW AND PRESSURe OF EACH SEgMENT WITH TIME, NOUT(8)=1:

NCUT $(B)=1$ 
" TO PRINT hall thICKNESS, R(EDP=0), R(I,J), SIGMA, PCOMP, NOUT(9)=1: NOUT $(9)=1$

"

CALL RADSET

CO $50 \mathrm{~J}=1$, NC YCLE

$\operatorname{FLOW}(\mathrm{J})=0.0$

IFIJ.LT.NSWIT 1 ) $/ G 0$ TO 50

DO $40 \quad I=1$, NSEG

FLOW $(J)=F \operatorname{LOW}(J)+\operatorname{CSEG}(I, J)$

40 CONTINUE

"WRI TE $(6,45) \mathrm{J}, F \operatorname{LOK}(\mathrm{J})$

45 FORMAT $(13$, F10,2)

50 CENT INUE

IF (NOUT ( I).NE. 1 )GO TO 80

DO $70 I=1$, NSEG

CO $60 \mathrm{~J}=1$, NUMPTS

$\operatorname{RAC}(J)=\operatorname{RADIUS}(I, J)$

60 CONT INUE

WR I TE $(6,65)$ I

65 FORMAT $(50 X$, 'RACIUSI', I2,')'1

70 CALL PLOTTIRAC,NUMPTS, 0.0,DELT)

80 IF (NOUT (2). NE. 1 IGO TO 140

$M S E G=N S E G+1$

$N=$ NUMPT $S+1$

$\Lambda=N U N P T S+2$

DC $130 \mathrm{~J}=1, \mathrm{~N}$

DO $90 \quad I=1$, NSEG

$90 \operatorname{RAC}(I)=\operatorname{RADIUS}(I, J)$

RAD (MSEG) $=10.0$

IF (J.LT.M)WRITE $(6,100) \mathrm{J}$ 


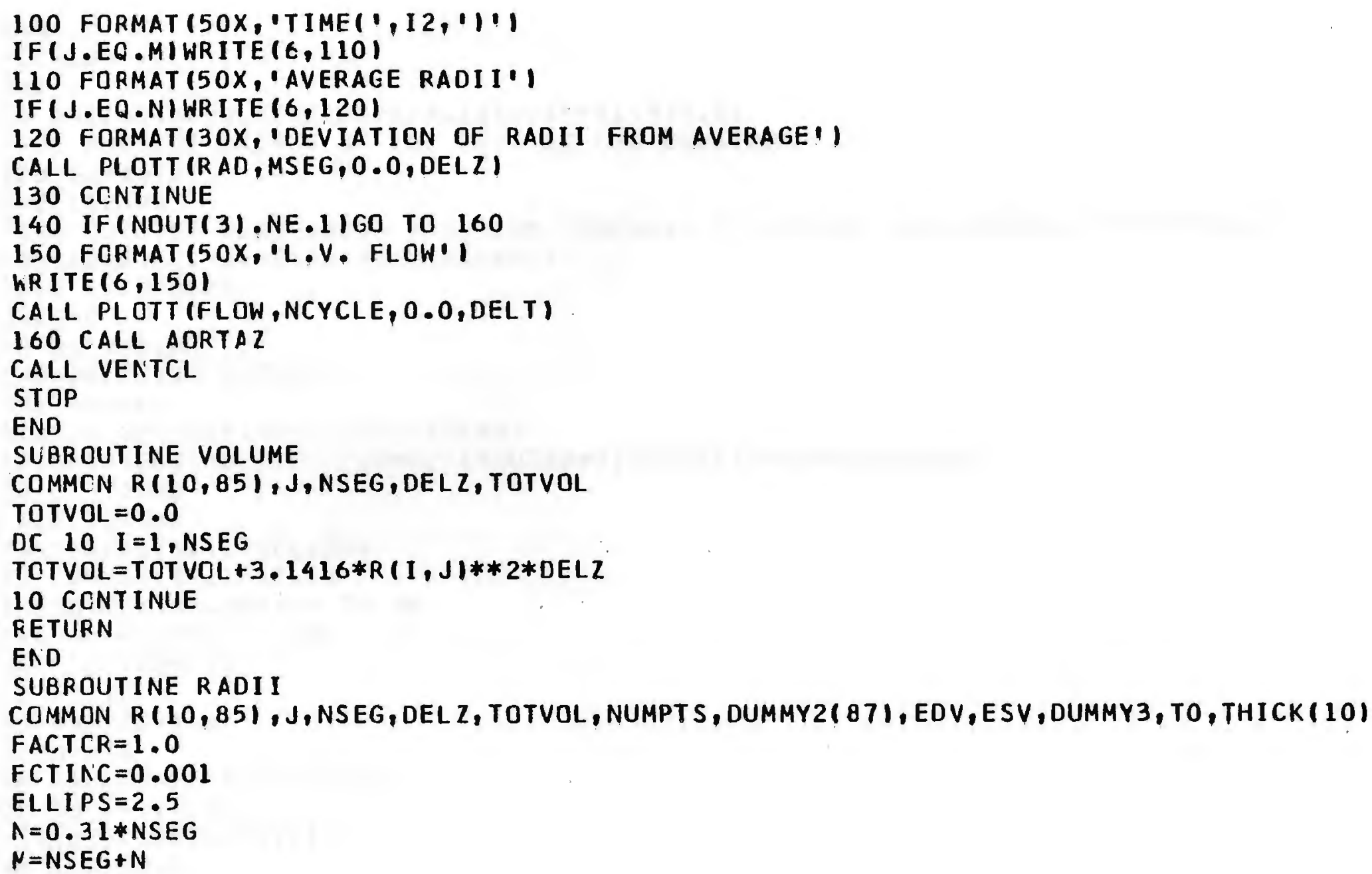


$N=N+1$

$V C L=E D V$

$J=1$

$10 A=(10.75 *$ VOL $) /($ ELLIPS*3.1416) $) * *(1.0 / 3.0)$

"THE OUTSIDE RADIUS OF THE L.V. AT THE EQUATOR:

ACUTER $=A+T O$

$B=E L L I P S * A$

"THE OUTSIDE SEMI-MAJOR AXIS FOR CONFOCAL ELLIPSOIDS (DIEUDONNE, STREETER):

$B O U T E R=S Q R T(-A * * 2+B * * 2+A O U T E R * 2)$

$D E L Z=(2 \cdot 0 * B) / M$

JSEG $=0$

DO $20 \quad I=N, M$

$Z=B+D E L Z / 2 \cdot 0-I * D E L Z$

$J S E G=J S E G+1$

$R(J S E G, J)=S Q R T(A * * 2-(A * Z / B) * * 2)$

$\operatorname{THICK}(J S E G)=S Q R T(A C U T E R * * 2-(A O U T E R * Z / B O U T E R) * 2)-R(J S E G, J)$

20 CONT INUE

CALL VOLUME

"WRITE $(6,25)$ TOT VCL, EDV

25 FORMAT $(1 X, 2 F 10.4)$

IF (TOTVCL. GE . EDVICO TO 30

FACTOR $=F A C T O R+F C T I N C$

$V O L=F A C T O R * E D V$

GE TO 10

30 FACTCR $=1.0$

$J=N U M P T S$

40 FACTOR=FACTOR-FCT INC

DC $50 \quad I=1$, NSEG

$R(I, J)=F A C T O R * R(I, I)$

50 CONT INUE 


\section{CALL VCLUME}

"WRI TE $(6,25)$ TOTVCL, ESV

IFITOTVOL.GT.ESVIGO TO 40

RETURN

END

SUBRCUTINE VENTCL

DIMENSICN XPLOT (85), PINERT $(10,85), P V I S C(10,85), P L V(10,85), P C O M P(10,85), P I S O(10)$

CCMMCN R(10,85), DUMMY 1 , NSEG, DELZ, DUMMY 2, NUMPT S, DUMMY3,Q(85), DELT, DUMMY 4(4),-

THICK(10), NSWIT (10), DUMMYS (2), AOP (86), NOUT $(10)$, QSEG $(10,85)$

$P I=3.1416$

$E=2.71828$

FCTINC $=0.001$

"VISCOUSITY OF BLCOD (POISE):

VI SC $=0.04$

"DENSITY OF BLOOD (GR/CC):

$\mathrm{RHO}=1.05$

"TO CONVERT DYNE/CM**2 TO MM HG:

CCNVER $=0.00076$

"THE CONSTANTS FOR THE STRESS-STRAIN RELATION FROM WEISS (LINE 26501,

" (ALPHA IN MM HE; BETA NC DIMENSION)

ALPHA $=5.0$

$B E T A=3.0$

"NUMPTS + 3 HOLDS THE RADII AT WHICH THERE IS NO COMPLIANT PRESSURE:

$N=$ NUMPT $S+3$

"MYOCARDIAL ACT IVE ISOMETRIC TENSION $(2$ GR/MM**2 CONVERTED TO MM HGIFROM TAYLOR:

SIGMAI $=2.0 * 73.54$

DO $20 \quad I=1$, NSEG

IF INOUT (9) .EQ. I) WR ITE $(6,3)$ I

3 FORMAT(IHO' SEGNENT', I3, J THICKNESS R(EDP=01 R(I,J) SIGMA PCOMPI)

DO $10 \mathrm{~J}=1$, NUMPT $S$ 


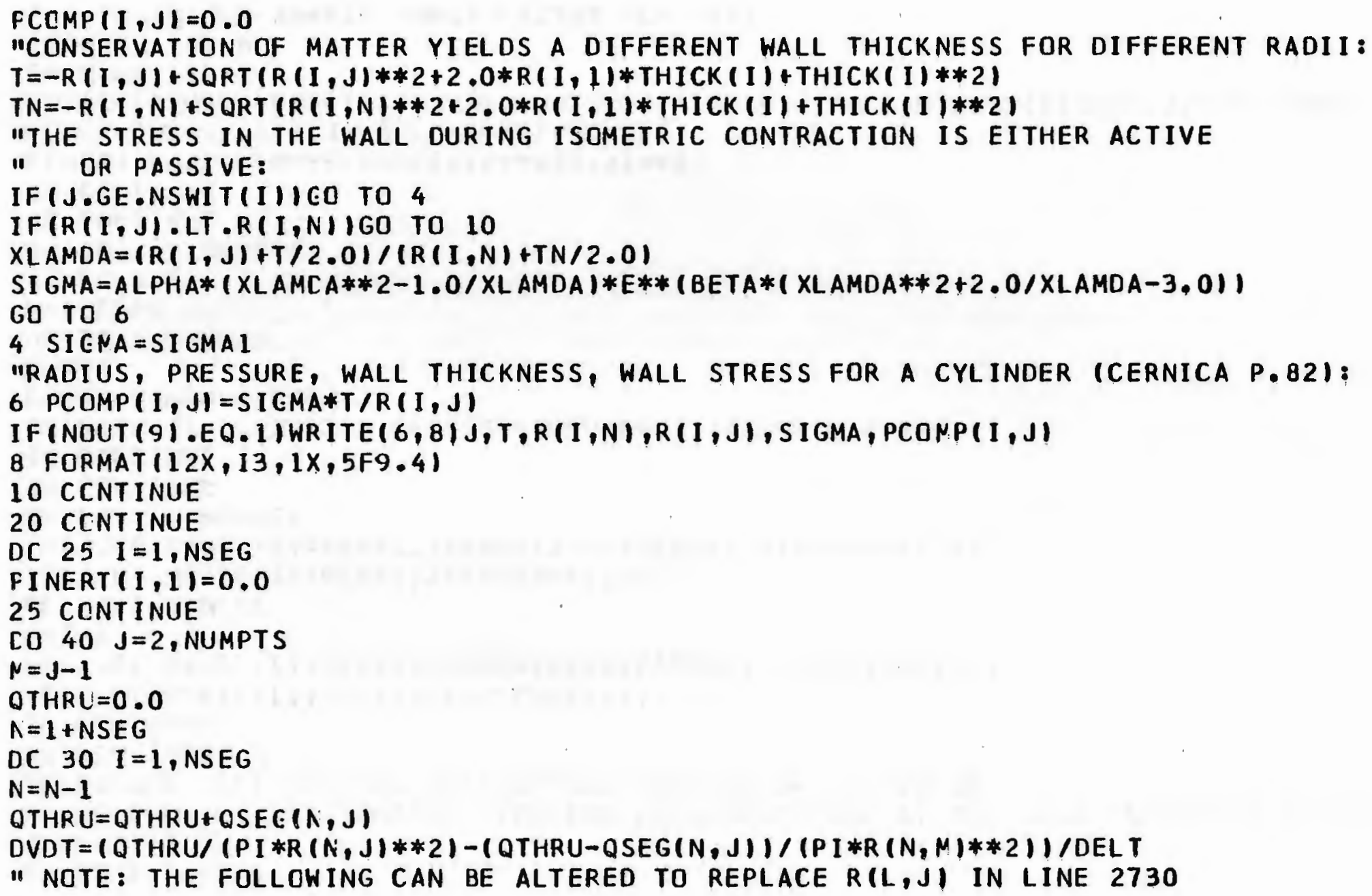


" WITH THE AORTIC INPUT RADIUS FOR I=1:

IF IN.EQ. I I L =N

IF IN.NE. I I L $=N-1$

VDVD $Z=1$ QTHRU $/(P I * R(N, J) * 2)) *(Q T H R U /(P I * R(L, J) * * 2)-Q T H R U /(P I * R(N, J) * * 2)) / D E L Z$ FORCE $=R H C * Q S E G(N, J) * D E L T *(D V D T+V D V D Z)$

PINERT $(N, J)=C C N V E F * F O R C E /(P I * R(N, J) * 2)$

30 CCNT INUE

40 CONT INUE

DO $60 \mathrm{~J}=1$, NUMPT S

QTHRU $=0.0$

$\Lambda=1+N S E G$

DO $50 \quad I=1$, NSEG

$\mathrm{N}=\mathrm{N}-1$

CTHRU $=Q T H R U+Q S E G(N, J)$

PVISC $(N, J)=(C C N V E R * 8.0 * V I S C * Q T H R U * D E L Z) /(P I * R(N, J) * * 4)$

50 CONT INUE

60 CONT INUE

DO $80 \mathrm{~J}=1$, NUMPTS

IF $(J . G E . N S W I T(1)) P L V(1, J)=\operatorname{AOP}(J)+\operatorname{PINERT}(1, J)+\operatorname{PVISC}(1, J)$

IF ( J.LT.NSWIT $(1)$ I PLV $(1, J)=P C O M P(1, J)$

DC $70 \quad I=2$, NSEG

$K=I-1$

I $F(J$.GE.NSWI T $(1)$ IPLVI I, J)=PLV $(K, J)+P I N E R T(I, J)+P V I S C(I, J)$

IF (J.LT.NSWIT $(I)$ IPLV $(I, J)=P C C M P(I, J)$

70 CCNTINUE

80 CCNTINUE

"PRESSURE DISTRIBUTION JUST BEFORE OPENING OF THE VALVE,

"CALCULATED AT ISOMETRIC TENSION AND DIMENSIONS AT THE LAST ZERO FLOW POINT: $J=N S W I T(1)-1$

DO $85 \mathrm{I}=1$, NSEG 
$T=-R(I, J)+S Q R T(R(I, J) * * 2+2,0 * R(I, 1) * T H I C K(I)+\operatorname{THICK}(I) * * 2)$

$P I S O(I)=S I G M A I * T / R(I, J)$

E5 CCNTINUE

IF(NOUT(5).NE.1)GC TO 140

WR ITE (6,90)

90 FORMAT/ $1 H 0 / 10 X, '$ AORTIC PRESSURE',5X, 'L, $\mathrm{V}$, FLOW',5X, 'INERTIAL PRESSURE',5X,-

'VISCOUS PRESSURE',5X, 'COMPLIANCE PRESSURE'।

DO $130 \quad I=1$,NSEG

WRITE $(6,100)$ I

100 FORMAT ( $1 X$, SEGMENT', I 3 )

DO $120 \mathrm{~J}=1$, NUMPTS

WRI TE $(6,110)$ AOP $(J), Q(J), P I N E R T(I, J), P V I S C(I, J), \operatorname{PCCMP(I,J)~}$

110 FORMAT $(15 X, F 10.4,4 X, F 10,4,12 X, F 10,4,11 X, F 10.4,14 X, F 10,4)$

120 CONT INUE

130 CCNTI NUE

140 IF(NOUT (6).NE 11 GO TO 180

CO $170 I=1$,NSEG

hR I TE $(6,150)$ I

150 FOFMAT 11 HO/50X,'L.V.P., SEGMENT', 13$)$

DO $160 \mathrm{~J}=1$, NUMPTS

XPLOT $(J)=F L V(I, J)$

160 CONT INUE

CALL PLCTTIXPLOT, NUMPTS, 0.0,DELT)

170 CCNT INUE

180 IFINOUT(7).NE.1)GO TO 220

DC $210 \mathrm{~J}=1$,NUMPTS

WR I TE $(6,190) \mathrm{J}$

190 FORMAT I 1 HO/50X,'L.V.P., POINT. IN SYSTOLE:', I3I

DC $200 I=1, N S E G$

$X P L O T(I)=P L V(I, J)$ 
200 CONTINUE

DELZZ=DEL $Z / 2.0$

CALL PLOTT (XPLOT,NSEG,DELZZ, DELZ)

210 CONTINUE

220 IF(NCUT 8 ). NE.1) 1 GO TO 320

IF (NSEG.LE. 20$)$ GO TO 240

WRI TE $(6,230)$

230 FORMAT $(1 \mathrm{HO} /$ "THE FORMAT FOR NOUT $(8)=1$ OUTPUT IS DESIGNED FOR NSEG.LE.2O'I

GO TO 320

240 WRI TE $(6,250)$

250 FORMAT $(1$ HO/I

SEGMENT 6 SEGMENT

TIME SEGMENT 1 SEGMENT 2 SEGMENT 3 SEGMENT 4 SEGMENT 5 DO $310 \mathrm{~J}=1$,NUMPTS

WRITE $(6,260) \mathrm{J}, \operatorname{QSEG}(1, J), \operatorname{QSEG}(2, J), \operatorname{QSEG}(3, J), \operatorname{QSEG}(4, \mathrm{~J}), \operatorname{QSEG}(5, J), Q \operatorname{SEG}(6, J),-$ $\operatorname{QSEG}(7, J), Q \operatorname{QSEG}(8, J), \operatorname{QSEG}(9, \mathrm{~J}), \operatorname{QSEG}(10, \mathrm{~J})$

260 FCRMAT $(1 \mathrm{HO} / \mathrm{O}$ QSEG,J=1, I2, 10F 10.4$)$

WR ITE $(6,270) \operatorname{PCOMP}(1, J), \operatorname{PCOMP}(2, J), \operatorname{PCOMP}(3, J), P C O M P(4, J), P C O M P(5, J), P C O M P(6, J),-$ $\operatorname{PCCMP}(7, \mathrm{~J}),-$

FCOMP( $8, J), \operatorname{PCCMP}(9, J), P C O M P(10, J)$

270 FORMAT: PCCMP $=1,10 F 10.41$

WR I TE $(6,280)$ PI NERT $(1, \mathrm{~J}), \operatorname{PI}$ NERT $(2, \mathrm{~J}), \operatorname{PINERT}(3, \mathrm{~J}), \operatorname{PINER} T(4, \mathrm{~J}), \operatorname{PINERT}(5, \mathrm{~J}),-$

PINERT $(6, \mathrm{~J})$, P INERT $(7, \mathrm{~J}), \operatorname{PINERT}(8, \mathrm{~J}), \operatorname{PINERT}(9, \mathrm{~J}), \operatorname{PINERT}(10, \mathrm{~J})$

280 FOFMAT(' PINERT $=1,10 \mathrm{~F} 10.4)$

WRITE $(6,290)$ PVI SC $(1, J), \operatorname{PVISC}(2, J), \operatorname{PVISC}(3, \mathrm{~J}), \operatorname{PVISC}(4, \mathrm{~J}), \operatorname{PVISC}(5, \mathrm{~J}),-$

PVISC $(6, J), \operatorname{PVISC}(7, \mathrm{~J}), \operatorname{PVISC}(8, \mathrm{~J}), \operatorname{PVISC}(9, \mathrm{~J}), \operatorname{PVISC}(10, \mathrm{~J})$

290 FOAMAT $(1$ PVISC $=1,10 F 10.4)$

WR I TE $(6,300)$ PLV $(1, J), P L V(2, J), P L V(3, J), P L V(4, J), P L V(5, J), P L V(6, J),-$

PLV(7,J),PLV(8,J),PLV $(9, J), P L V(10, J)$

300 FOFMAT 1 PLV $=1,10 F 10.41$

IF( J.EQ. (NSW IT (1)-1) IWRITE (6,305) PISO(1),PISO (2), PISO (3), PISO(4), P ISO(5), - 
PISO(6),PISO(7),PISO(8),PISO (9),PISO(10)

3 C5 FORMAT (IHO/ PISO $=1,10 \mathrm{~F} 10.4)$

310 CONTINUE

IF INSEG.LE.10IGO TO 320

WRITE $(6,312)$

312 FORMAT 11 HO $/$ TIME SEGMENT11 SEGMENT12 SEGMENT13 SEGMENT14 SEGMENT15 SEGMENT 16 SEGMENT 17 SEGMENT18 SEGMENT 19 SEGMENT 20!I

DO $314 \mathrm{~J}=1$, NUMPT S

WRITE $(6,260) \mathrm{J}, \operatorname{QSEG}(11, \mathrm{~J}), \operatorname{QSEG}(12, \mathrm{~J}), \operatorname{QSEG}(13, \mathrm{~J}), \operatorname{QSEG}(14, \mathrm{~J}), Q \operatorname{QSEG}(15, \mathrm{~J}),-$

$\operatorname{QSEG}(16, J), \operatorname{QSEG}(17, \mathrm{~J}), \operatorname{QSEC}(18, \mathrm{~J}), \operatorname{QSEG}(19, \mathrm{~J}), \operatorname{QSEG}(20, \mathrm{~J})$

WRITE $(6,270)$ FCOMP $(11, J), \operatorname{PCCMP}(12, J), \operatorname{PCCMP}(13, J), \operatorname{PCCMP}(14, J), \operatorname{PCCMP}(15, J),-$

$\operatorname{PCOMP}(16, J), P C C N P(17, J), P C O M P(18, J), \operatorname{PCOMP}(19, J), \operatorname{PCOMP}(20, J)$

WR I TE $(6,280)$ PINERT $(11, \mathrm{~J})$, PINERT $(12, \mathrm{~J})$, PINERT $(13, \mathrm{~J})$, PINERT $(14, \mathrm{~J}), P I N E R T(15, J),-$

PINERT $(16, \mathrm{~J})$, P INERT $(17, \mathrm{~J})$, P INERT $(18, \mathrm{~J})$, P INER T $(19, \mathrm{~J})$, PINERT $(20, \mathrm{~J})$

WRITE $(6,290)$ PVISC $(11, \mathrm{~J})$, PVISC $(12, \mathrm{~J}), \operatorname{PVISC}(13, \mathrm{~J})$, PVISC $(14, \mathrm{~J}), P V I S C(15, J),-$

PVISC $(16, \mathrm{~J}), \operatorname{PVISC}(17, \mathrm{~J}), \operatorname{PVISC}(18, \mathrm{~J}), \operatorname{PVISC}(19, \mathrm{~J}), \operatorname{PVISC}(20, \mathrm{~J})$

WR ITE $(6,300)$ PLV $(11, J), P L V(12, J), P L V(13, J), P L V(14, J), P L V(15, J),-$

PLV $(16, J), P L V(17, J), P L V(18, J), P L V(19, J), P L V(20, J)$

IF ( J.EQ. (NSW IT (1)-1) IWRITE $(6,305)$ PI SO $(11), P I S O(12), P I S O(13), P I S O(14), P I S O(15),-$

PISO(16),PISO(17), PISO(18), PISO (19), PISO(20)

314 CCNT INUE

320 RETUFN

END

SUBROUT INE AORTAZ

DIMENSION AQ(11), EQ(11),CQ(11), PHIQ(11),CP(11),PHIP(11),CZ(11),PHI2(11),AP(1),EP(11)

CCMMON DUMMY $1(855)$, NCYCLE, Q(85), DELT, DUMMY $2(26), A O P(86)$, NCUT $(10)$

"CANINE AORTIC INPUT IMPEDANCE (FROM PATEL):

$C Z(1)=3.26$

$C Z(2)=0.261$ 


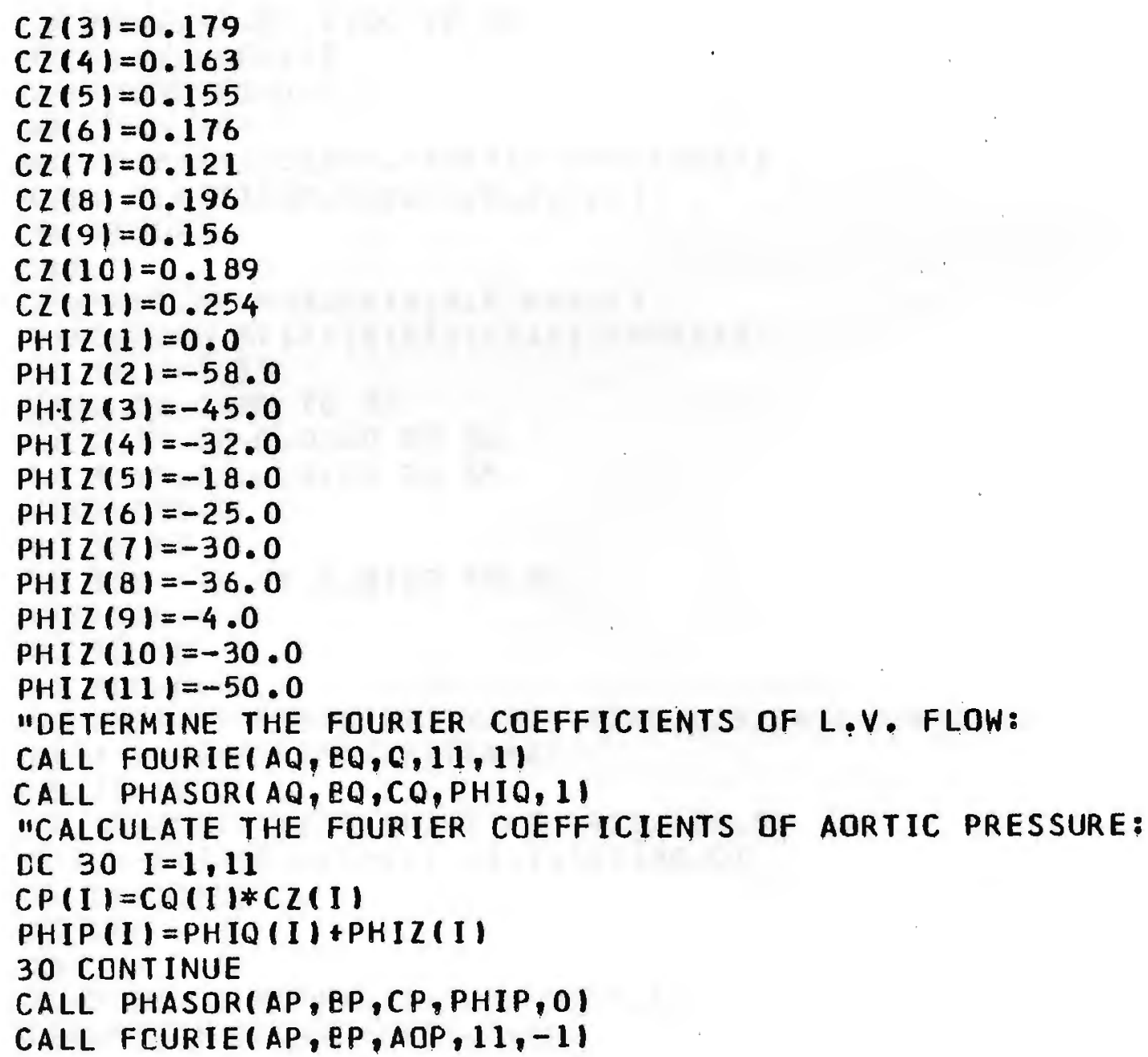




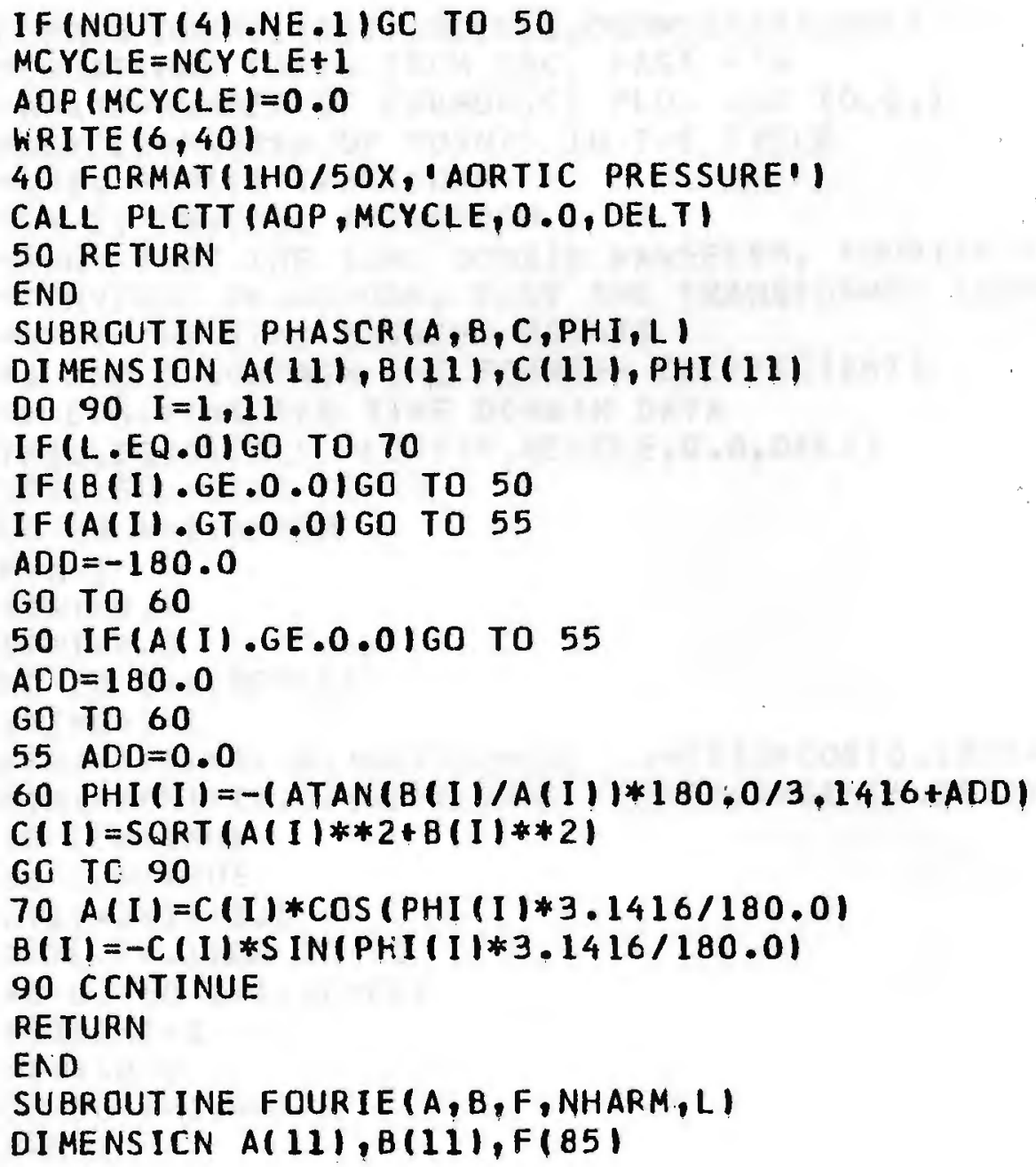


CCMMCN DUMMY 1 (855), NCYCLE, DUMMY 2 (85), DELT

"EQUATIONS TAKEN FRCM CRC, PAGE 474

"NHARM = NUMBER OF HARMONICS PLUS GNE (D.C.)

"NCYCLE=NUMBER OF POINTS IN THE CYCLE

"L=1; FOUIER TRANSFCRM

"L $=-1 ;$ INVERSE TRANSFORM

"L=0: PLCT THE TIME DOMAIN WAVEFCRM, FOURIER TRANSFORM,-

"INVERSE TRANSFORM, PLCT THE TRANSFORMED TIME DOMA IN WAVEFORM

"DELT=THE TIME BETWEEN POINTS

"A AND B CONTAIN THE FOURIER COEFFICIENTS

"F CCNTAINS THE TIME DCMAIN DATA

IF (L.EQ.0ICALL PLOTTIF, NCYCLE,0.0,DELT)

IF (L.EQ.-1)GO TO 40

DO $30 \quad N=1$, NHARM

$\mathrm{N}=\mathrm{N}-1$

$A(N)=0.0$

$B(N)=0.0$

DO $201=1$, NCYCLE

I T IME $=I-1$

$A(N)=A(N)+12.0 /(N C Y C L E * D E L T)) * F(I) * \operatorname{COS}(6.2832 * M * I T I M E / N C Y C L E) * D E L T$

$B(N)=B(N)+12.0 /(N C Y C L E * D E L T)) * F(I) * S I N(6.2832 * M * I T I M E / N C Y C L E) * D E L T$

20 CENT INUE

30 CONTINUE

$A(1)=A(1) / 2.0$

IF (L.EQ.1)GO TO 70

40 DO $60 \mathrm{I}=1$, NCYCLE

I T IME $=$ I -1

$F(I)=0.0$

DO $50 \mathrm{~N}=1$, NHARM

$N=N-1$ 
$F(I)=F(I)+A(N) * \operatorname{COS}(6.2832 * M * I T I M E / N C Y C L E)+B(N) * S I N(6,2832 * \mu * I T I M E / N C Y C L E)$ 50 CONT I NUE

60 CCNT INUE

IF (L.EQ.0 ICALL PLCTTIF, NCYCLE, 0.0,DELT)

70 RETURN

END

SUBROUTINE RADSET

CCMMCN R(10,85),J,NSEG, DEL Z, TOTVOL, NUMPTS,NCYCLE,FLOW $(85)$, DELT,DUMMY1(14),NSH1T (10),SYSDUR,DELAY,DUMMY $2(96)$, QSEG $(10,85)$

CALL RADII

CALL ZEROR

$L=$ NUMPT $S+1$

$K=$ NUMPT $S+2$

$N O=N U M P T S+3$

PERIOD $=S Y S C U R-D E L A Y$

FCT I NC $=0.0001$

DO $10 I=1, N S E G$

NSWIT $(1)=L$

10 CONTINUE

DC $100 \mathrm{~J}=2$, NCYCLE

$N=J-1$

TIME $=M * D E L T$

$N=N S E G+1$

OC $50 \quad I=1$, NSEG

$N=N-1$

$\operatorname{QSEG}(\Lambda, J)=0.0$

IF (J.GT.NUMPTS )GO TO 50

HOLD $=(N S E G-N) * D E L A Y / N S E G$

"PART OF THE SKELETON OF THE HEART, THE FIRST SEGMENT DOES NOT EXPAND,

(LINE 4875), 
" therefore, it begins contracting hHen the second Segment does: IF (N.EQ.1) HOLD $=$ (NSEG-2) *DELAY/NSEG

"TO SIMULATE AN INFARCTED SEGMENT, IT/THEY REMAIN PASSIVE UNTIL EJECTION OCCURS: "IF(N.EQ.7)HOLD $=($ NSEG-2) $*$ DEL AY /NSEG

"IF (N.EG.8)HOLD $=($ NSEG-2)*DELAY/NSEG

END = PERI CD +HOLD

IFITIME.LE.HOLDIGO TO 50

IFITIME.LE.ENDIGO TO 30

$R(N, J)=R(N, M)$

GO TO 50

30 IFINSWITINI.NE.LIGO TO 40

NSWIT $(N)=J$

$R(N, L)=(R(N, M)+R(N, N U M P T S)) / 2.0$

$R(N, K)=R(N, M)-R(N, L)$

$40 R(N, J)=R(N, L)+R(N, K) * \operatorname{COS}(3.1416 *(T I M E-H O L D) / P E R I O 0)$

$Q S E G(N, J)=3.1416 * C E L Z *(R(N, M) * * 2-R(N, J) * * 2) / D E L T$

50 CCNTINUE

$0=0.0$

DO $70 I=1$, NSEG

$\mathrm{C}=Q+Q \operatorname{QSEG}(I, J)$

70 CCNTINUE

CALL VOLI (M)

IF (TOTVOL.EQ.0.0)GO TO 100

$S A V V C L=T C T V Q L+Q * D E L T$

FACTOR $=1.0$

80 FACTOR=FACTOR+FCTINC

DO $90 I=1$, NSEG

IF(J.GE.NSWIT(I))GO TO 90

$R(I, J)=F A C T O R * R(I, M)$

$I F(I, E Q, 1) R(I, J)=R(I, M)$ 
90 CONT INUE

CALL VOLI (J)

IF (SAVVEL , GT . TOT VOLIGO TO 80

100 CONTINUE

RE TURN

END

SUBROUT INE VOL $1(K)$

COMMON R(10,85), J,NSEG,DELZ,TOTVOL, DUMMY1(102),NSWIT(10)

TOTVOL $=0.0$

DO $10 I=1$, NSEG

IFI J.GE.NSWITII)IGC TO 10

TOT VOL $=$ TOT VOL $+3,1416 * R(I, K) * 2 * D E L Z$

10 CONTINUE

RETURN

END

SUBROUT INE ZEROR

CCMMCN R $(10,85)$, CUMMY1,NSEG, DUMMY $2(2)$, NUMPT S,DUMMY3 (89),P,DUMMY4, THICK(10)

$E=2.71828$

$A L P H A=5.0$

BETA $=3.0$

$N=$ NUMPT $S+3$

DC $30 \quad I=1, N S E G$

$R(I, N)=R(I, I)$

$10 R(I, N)=R(I, N)-C .0001$

"TN IS THE WALL THICKNESS CORRESPONDING TO $R(I, N)$;

$T N=-R(I, N)+S$ QRT $(R(I, N) * * 2+2.0 * R(I, 1) * \operatorname{THICK}(I)+\operatorname{THICK}(I) * * 2)$

"STRAIN IS FIGURED AT THE MIDCIRCUMFERENCE OF THE SHELLS:

$X L A M D A=(R(I, 1)+T H I C K(I) / 2.0) /(R(I, N)+T N / 2.0)$

PRES $=($ THICK $(I) / R(I, 1)$ ) ALPHA* (XLAMDA**2-1.0/XLAMDA)*E**(BETA*(XLAMDA**2+--

$2.0 /$ XLAMC A-3.011 
IF(PRES.LT •PIGO TC 10

"WR I TE $(6,20) I, P, P R E S, R(I, 1), R(1, N)$

20 FCRMAT $(I X, I 2,1$ P,PRES, RI, RO=, $4 F 10.4)$

30 CONTINUE

RETURN

END 


\begin{abstract}
A PPENDIX E
COMPARISON BETWEEN THE INERTIAL FORCE OF THE MYOCARDIUM AND THE FORCE GENERATING STATIC PRESSURE
\end{abstract}

In developing equation (4-19), one half of a cylindrical shell was studied (see Figure 4.4). The constricting force resulting from stress in the wall of the cylindrical shell was equated to the expanding force resulting from pressure within the shell. Inertial force of the myocardium was neglected.

$$
\text { P2ray }=2 \sigma h \Delta y
$$

where $P=$ pressure within the shell

$$
\begin{aligned}
r & =\text { inside radius of the shell } \\
\Delta y & =\text { height of the shell } \\
\mathbf{b} & =\text { wall thickness of the shell } \\
\sigma & =\text { stress in the wall of the shell. }
\end{aligned}
$$

The forces on either side of equation (4-19), however, are not equal, but differ by the force required to accelerate one half of the shell wall. That is, 


$$
2 \sigma h \Delta y-P 2 r \Delta y=\frac{m}{d t^{2}} x(c m)
$$

where $m$ = mass of myocardium in one half the shell wall

$$
\begin{aligned}
X(\mathrm{~cm}) & =\text { center of mass, } m \\
t & =\text { time. }
\end{aligned}
$$

The center of mass of one half of a cylindrical strip is

$$
x(\mathrm{~cm})=\frac{\int_{-\pi / 2}^{\pi / 2} f^{r+h} r^{2} \cos \theta d r d \theta}{\frac{\pi}{2}\left((r+h)^{2}-r^{2}\right)}
$$

where $\theta$ is an angle in the plane of the cylinder. Equation $(E-2)$ yields $(61)$ :

$$
x(\mathrm{~cm})=\frac{4}{3 \pi}\left(\frac{(r+h)^{2}+(r+h) r+r^{2}}{(r+h)+r}\right)
$$

The velocity ( $v)$ of $X(c \mathbb{M})$ was determined at each point in the simulated cardiac cycle:

$$
v=\frac{\Delta X(\mathrm{~cm})}{\Delta t}
$$


page 220

The acceleration of $X(\mathrm{~cm})$ was determined at each point in the simulated cardiac cycle:

$$
\frac{d^{2} \times(\mathrm{cm})}{d t^{2}}=\frac{\Delta v}{\Delta t}
$$

The force required to accelerate the myocardium in one half of the shell wall was determined at each point in the simulated cardiac cycle:

$$
\text { Force }=\frac{m d^{2} \times(\mathrm{cm})}{d t^{2}}
$$

This force was divided by the constricting force in the shell wall (2 ah $\Delta Y$ ). At every point in the simulated cardiac cycle the quotient was less than 0.019 . Hence, the force required to accelerate the myocardium appears to be negligible compared to the force producing static pressure within the cylindrical shell. 
IIST OF REFERENCES 


\section{REFERENCES}

1. C. E. Rackley and R. O. Russell: Left ventricular function in acute and chronic coronary artery disease. Ann. Rev. Med. 26: 105-120, 1975 .

2. S. H. Rahimtoola and J. D. Bristow: The problem of assessment of left ventricular performance in coronary artery disease. Chest 65: 480-482, 1974.

3. R. F. Rushmer: Cardiovascular Dynamics. Philadelphia, W. B. Saunders Company, 1970, p. 42 .

4. D. D. Streeter, JI. and W. T. Hanna: Engineering mechanics for successive states in canine left ventricular myocardium: I. Cavity and wall geometry. Circ. Res. 33: 639-655, 1973.

5. D. D. Streeter, JI., H. M. Spotnitz, D. P. Patel, J. Ross, Jr. and E. H. Sonnenblick: Fiber orientation in the canine left ventricle during diastole and systole. Circ. Res. 24: 339-347. 1969.

6. J. R. Brobeck, Editor: Best and Taylor's Physiological Basis of Medical Practice. Baltincre, The Williams and Wilkins Co., 1973, p. 3-54.

7. A. C. Burton: Physiology and Biophysics of the Circulation. Chicago, Year Book Medical Publishers, Inc.. 1972, p. 127 .

8. J. E. Crouch: Functional Human Anatomy. Philadelphia, Lea and Febiger, 1965, p. 308.

9. A. G. Tsakiris, D. E. Donald, R. E. Sturm and E. H. Hood: Volume, ejection fraction, and internal dimensions of the left ventricle determined by biplane videometry. Fed. Proc. 28: 1358-1367, 1969.

10. R. F. Rushmer and N. Thal: The mechanics of ventricular contraction: a cinefluorographic study. Circ 4: 219-228, 1951 .

11. S. Shastri, S. Fich, 月. Relkowitz, D. Jaron, J. Tomecek and A. Kantrowitz: Determination of heart parameters by use of a ventricular assist pump. Proc. of 8 th Int. Conf. on Medical and Biological Eng., 1969, p. 6.8. 
page 223

12. S. Fich, B. Min, W. Helkowitz, D. Jaron and A. Rantrowitz: Determination of the cardiac state. Bibliotecka Cardiologica 32: 72-82, 1973.

13. S. Fich, W. Welkowitz, S. Shastri, D. Jaron and A. Kantrouitz: An equivalent pressure source for the heart. Int. J. Eng. Sci. 11, 601-611, 1973.

14. G. Elzinga and N. Nesterhof: End-diastolic volume and source impedance of the heart. In: The physiological Basis of Starling's Law of the Heart. Ciba Fcund. Symp. 24: 251-255, 1974 .

15. G. Elzinga and N. Westerhof: The pumping ability of the left heart and the effect of coronary occlusion. Circ. Res. 38: 297-302, 1976.

16. M. F. O'Rourke and M. G. Taylor: Input impedance of the systemic circulation. Circ. Res. 20: 365-380, 1967.

17. N. N. Puri and G. F. Gido: Control Systems for Circulatory Assist Devices. Philadelphia, Oniv. City Sc. Center, 1968, pp. 3-11.

18. A. D. Jose and F. Stitt: Cardiac function after combined beta-adrenergic and cholinergic blockade. Circ. Res. Supp 20, 21: III-231-III-242, 1967.

19. A. D. Jose and R. R. Taplor: Autonomic blockade by propranalol and atropine to study intrinsic myocardial function in man. J. Clin. Invest. 48: 2019-2031, 1969.

20. B. F. Robinson, S. E. Epstein, G. D. Beiser and E. Braunwald: Control of heart rate by the autonomic nervous system. Circ. Res. 19: 400-411, 1966.

21. N. Hesterhof and A. Noordergraaf: Errors in the measurement of hydraulic input impedance. J. Biomechanics 3: $351-356,1970$.

22. J. M. Kresh, B. G. Min, W. Welkowitz and J. B. Kostis: Computed isovolumic pressure generating capability of the left ventricle and a related myocardial contractility index. Proc. 4 th New Eng. Bioeng. Conf.: $181-184,1976$.

23. P. F. Salisbury, C. E. Cross and P. A. Rieben:

Influence of coronary artery pressure upon myocardial elasticity. Circ. Res 8: 794-800, 1960.

24. W. L. Gleason and E. Braunwald: Studies on the first derivative of the ventricular pressure pulse in man. J. Clin. Invest. 41: 80-91, 1962 . 
25. D. T. Mason, E. Braunwald, J. H. Covell, E. H. Sonnenblick and J. Ross, JI.: Assessment of cardiac contractility: the relation between the rate of pressure rise and ventricular pressure during isovolumic systole. Circ. 44: 47-58, 1971.

26. M. V. Herman, R. A. Heinle, M. D. Klein and R. Gorlin: Localized disorders in myocardial contraction: asynergy and its role in congestive heart failure. $N$. Eng. J. Hed. 277: 222-232, 1967 .

27. F. L. Abel: Analysis of the left ventricle as a pressure and a flow generator in the intact systemic circulation. IEEE Trans. Biomed. Eng. 13: 182-188, 1966.

28. J.M. Dieudonne: The left ventricle as confocal prolate spheroids. Bul. Math. Biophysics 31: 433-439, 1969.

29. E. Braunwald, J. Ross, JI. and E. H. Sonnenblick: Mechanisms of contraction of the normal and failing heart. N. Eng. J. Med. 277: 794-800, 1967 .

30. E. H. Sonnenblick, J. Ross, JI., J. W. Covell, H. M. Spotnitz and D. Spiro: The ultrastructure of the heart in systole and diastole: changes in sarcomere length. Circ. Res. 21: 423-431, 1967.

31. A. Matz: patterns of energy production and energy utilization in cardiac and skeletal muscle. In: Factors Influencing Myocardial contractility, edited by R. D. Tanz, F. Kavaler and J. Roberts. New York, Academic Press, 1967, pp. 401-415.

32. A. M. Katz: Contractile proteins of the heart. Physiol. Rev. 50: 63-158, 1970 .

33. K. S. Lee: The role of cardiac sarcoplasmic reticulum in excitation-contraction coupling. In: Factors Influencing Myocardial contractility, edited by R. D. Tanz, F. Kavaler and J. Roberts. New York, Academic Press, 1967, pp. 363-372.

34. H. Demiray: A note on the elasticity of soft biological tissues. J. Biomechanics 5: 309-311, 1972.

35. M. Heiss and H. Forster: A model for the assessment of left ventricular compliance: effect of hypertrophy and infarction. Cardiovasc. Res. 9: 544-553, 1975.

36. A. J. Brady: Active state in cardiac muscle. physicl. Rev. 48: 570-600, 1968. 
37. V. J. Fisher, R. J. Lee, A. Gourin, H. Bolooki, J. H. Stuckey and F. Kavaler: Muscle fiber length: a determinant of left ventricular contraction pattera. Am. J. Physiol. 211: 301-306, 1966.

38. D. J. Patel, F. M. Defreitas and D. L. Fry: Hydraulic input impedance to aorta and pulmonary artery in dogs. J. App. Physiol. 18: 134-140, 1963.

39. L. N. Cothran, W. C. Bowie, J. E. Hinds and E. W. Hawthorne: Left ventricular wall thickness changes in unanesthetized horses. In: Factors Influencing Myocardial Contractility, edited by R. D. Tanz, F. Kavaler and J. Roberts. New York, Academic Press, 1967, pp. 163-176.

40. E. O. Feigl and D. L. Fry: Myocardial mural thickness during the cardiac cycle. Circ. Res. 14: 541-545, 1964 .

41. D. D. Streeter, Jr. and W. T. Hanna: Engineering mechanics for successive states in canine left ventricular myocardium: II. Fiber angle and sarcomere length. Circ. Res. 33: 656-664, 1973.

42. J. Ross, Jr., E. H. Sonnenblick, J. R. Corell, G. A. Kaiser and D. Spiro: The architecture of the heart in systole and diastole: techniques of rapid fixation and analysis of left ventricular geometry. Circ Res 21: 409-421, 1967 .

43. R. R. Taylor: Contractile properties of cardiac muscle in hyperthyroidism. Circ. Res. 27: 539-549, 1970.

44. R. H. F. Pao: Fluid Mechanics. New York, John Wiley and Sons, 1966, p. 186 .

45. H. M. Spotnitz, E. H. Sonnenblick and D. Spiro:

Relation of ultrastructure to function in the intact heart: sarcomere structure relative to pressure volume curves of intact left ventricles of dog and cat. Circ. Res. 18: 49-66, 1966.

46. E. H. Sonnenblick, D. Spiro and H. M. Spotnitz: The ultrastructural basis of starling's law of the heart. The role of the sarcomere in determining ventricular size and stroke volume. Am. Heart J. 68: 336-346, 1964 .

47. R. R. Taylor, J. Ross, Jr., J. W. Covell and E. H. Sonnenblick: A quantitative analysis of left ventricular myocardial function in the intact, sedated dog. Circ. Res. 21: 99-115, 1967. 
48. W. G. Guntheroth: Changes in left ventricular wall thickness during the cardiac cycle. J. App. Physiol. $36: 308-312,1974$.

49. D. D. Streeter, Jr., R. N. Vaishnav, D. J. Patel, H. H. Spotnitz, J. RosS, Jr. and E. H. Sonnenblick: Stress distribution in the canine left ventricle during diastole and systole. Biophys. J. 10: 345-363, 1970.

50. S. J. Leshin, K. Wildenthal, C. B. Mullins and J. H. Mitchell: Measurement of left ventricular dimensions from implanted radiopaque markers. J. App. Physiol. 33: $132-136,1972$.

51. E. M. Hawthorne: Instantaneous dimensional changes of the left ventricle in dogs. Circ. Res. 9: 110-119, 1961 .

52. P. R. Lynch and A. A. Bove: Geometry of the left ventricle as studied by high speed cineradiographic technique. Fed. Proc. 28: 1330-1333, 1969.

53. M. E. Sanmarco and J. C. Davila: Continuous measurement of left ventricular volume in dogs: estimation of volume-dependent variables using the ellipsoid model. In: Factors Influencing Mocardial Contractility, edited by R. D. Tanz, F. Kavaler and J. Roberts. New York, Academic Press, 1967, Pp. 199-214.

54. H. Sandler and D. N. Ghista: Mechanical and dynamic implications of dimensional measurements of the left ventricle. Fed. Proc. 28: 1334-1350, 1969 .

55. J. S. Rankin, P. A. MC Hale, C. E. Arentzen, D. Ling, J. C. Greenfield and R. W. Anderson: The three dimensional geometry of the left ventricle in the conscious dog. Circ. Res. 39: 304-313, 1976.

56. B. C. Abbott and R. J. Baskin: Volume changes in frog muscle during contraction. J. Physiol. 161: 379-391, 1962 .

57. E. Barbato, F. Pileggi, A. C. Debes, T. Fujioka, M. S. Magalhaes, J. Tranchesi, E. San Juan and L. V. Decourt: Study of the sequence of ventricular activation and the QRS complex of the normal human heart using direct epicardial leads. Am. Heart J. 55: $867-880,1958$.

58. D. Durrer, R. Th. van Dam, G. E. Freud, M. J. Janse, F. L. Meijler and R. C. Arzbaecher: Total excitation of the isolated human heart. Circ. 41: 899-912, 1970. 
59. D. Durrer, J. P. Roos and J. Buller: The spread of excitation in canine and human hearts. In: Electrophysiology of the Heart, edited by B. Taccardi and G. Marchetti. New York, Pergamon Press, 1965, pp. 203-214.

60. V. S. Bishop, L. D. Horwitz, H. L. Stone, H. F. Stegall and B. J. Engelkin: Left ventricular internal diameter and cardiac function in conscious dogs. J. App. Physiol. 27: 619-623, 1969.

61. R. J. Tallarida, B. F. Rusy and M. H. Loughnane: Left ventricular wall acceleration and the law of Laplace. Cardiovasc. Res. 4: 217-223, 1970.

62. J. H. Mitchell, K. Fildenthal and C. B. Mullins: Geometric studies of the left ventricle utilizing biplane cinefluorography. Fed. Proc. 28: 1334-1343, 1969 .

63. R. R. Taylor, J. W. Covell and J. Ross, Jr.:

Volume-tension diagrams of ejecting and isovolumic contractions in left ventricle. Am. J. Physiol. 216: 1097-1102, 1969 .

64. E. N. Moore, J. B. Preston and G. K. Moe: Durations of transmembrane action potentials and functional refractory periods of canine false tendon and ventricular myocardium: comparisons in single fibers. Circ. Res. 17: 259-273, 1965.

65. F. Kavaler: Membrane depolarization as a cause of tension developmemt in mamalian ventricular muscle. Am. J. Physiol. 197: 968-970, 1959.

66. I. D. Horvitz, V. S. Bishop, H. I. Stone and H. F. Stegall: Continuous measurement of internal left ventricular diameter. J. App. Physiol. 24: 738-740, 1968.

67. H. P. Pieper: Catheter-tip instrument for measuring left ventricular diameter in closed-chest dogs. J. App. Physiol. 21: 1412-1416, 1966.

68. V. S. Bishop and L. D. Horwitz: Left ventricular transverse internal diameter: value in studying left ventricular function. Am. Heart J. 80:507-514, 1970.

69. R. P. Rushmer: Initial phase of ventricular systole: asynchronous contraction. Am. J. Physiol. 184: 188-194, 1956. 
70. I. Ninomiya and M. F. Nilson: Analysis of ventricular dimension in the unanesthetized dog. Circ. Res. 16: 249-260, 1965.

71. S. Goldstein and J. T. Jong: Changes in left ventricular wall dimensions during regional myocardial ischemia. Am. J. Cardiol. 34: 56-62, 1974.

72. J. J. Van der Meer, A. H. M. Jageneau, G. Elzinga, R. V. Grondelle and R. S. Reneman: Changes in myocardial wall thickness in open chest dogs. Pflugers arch. 340: 35-50, 1973.

73. G. Ray, Y. K. Liu, K. B. Chandran, D. N. Ghista and H. Sandler: Potential energy distribution prior to ejection as a basis for post surgical evaluation of left ventricular efficiency. Proc. 29th ann. Conf. on Eng. in Med. and Biol. 18: 126, 1976.

74. J. W. Burns, J. W. Covell, R. Myers and J. Ross, Jr.: Comparison of directly measured left ventricular vall stress and stress calculated from geometric reference figures. Circ. Res. 28: 611-621, 1971.

75. E. O. Feigl, G. A. Simon and D. L. Fry: Auxotonic and isometric cardiac force transducers. J. App. Physiol. 23: $597-600,1967$.

76. G. W. Hamilton, J. A. Murray and J. W. Kennedy: Quantitative angiocardiography in ischemic heart disease. Circ. 45: 1065-1080, 1972.

77. R. E. Kerber, M. L. Marcus, J. Ehrhardt, R. Wilson and F. M. Abboud: Correlation between echocardiographically demonstrated segmental dyskinesis and regional myocardial perfusion. Circ. 52: 1097-1104, 1975 .

78. P. A. MC Hale, C. A. Haliasos and J. C. Greenfield, Jr.: An improved transducer to measure left ventricular wall thickness in open-chest dogs. J. App. Physiol. 32: 257-258, 1972.

79. T. G. Guntheroth: Systolic changes in ventricular thickness in intact dogs. Circ. Supp. 43, 44: II-173, 1971 .

80. I. W. Tice: In-situ studies of the sarcotubular system. In: Factors Influencing Myocardial Contractility, edited by R. D. Tanz, F. Kavaler and J. Roberts. New York, Academic Press, 1967, pp. 339-350. 
page 229

81. G. A. Langer: The control of myocardial calcium exchange and its relation to contractility in the mammalian heart. In: Factors Influencing Myocardial Contractility, edited by R. D. Tanz, F. Kavaler and J. Roberts. New York, Academic Press, 1967, pp. 351-361. 
INDEX 
INDEX

$\begin{array}{ll}\text { A band } & 168\end{array}$

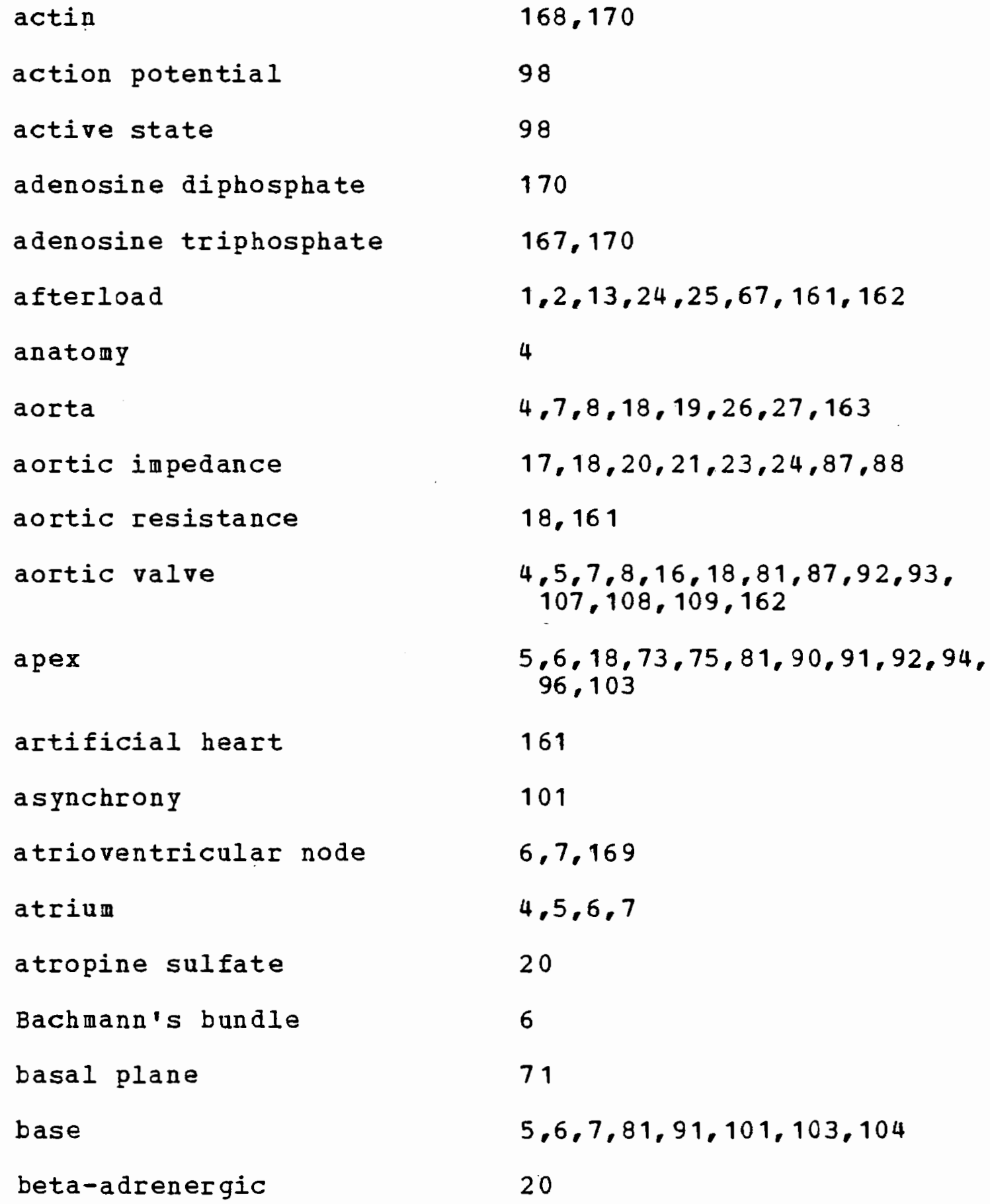


Biotronex

blockade

bundle branch

bundle of His

calcium

cardiac assist device

cardiac catheterization

cardiac cycle

cardiac index

cardiac output

carotid artery

catheter

cholinergic

cinefluorography

compliance

confocal

contractility

convective acceleration

coronary artery

coronary bypass

coronary occlusion

correlation coefficient

denervation

density

depolarization

diastole
18

14,20

6,7

7

$169,170,171$

161

162

$2,5,6,7,8,27,67,74,90,91,92$, $93,94,95,96,98,99,102,105$, $109,162,163$

163

$1,2,13,72,82,89$

18

100,162

20

100

$77,89,92$

67,69

$24,26,27,97,98,170$

83

$20,99,107,164$

108

$14,24,25$

23

27,28

85

$6,7,166,169,170$

$19,102,103$ 


\begin{tabular}{|c|c|}
\hline $\mathrm{ap} / \mathrm{d} t$ & $26,27,28$ \\
\hline dysfunction & 105 \\
\hline dyskinesis & 108,110 \\
\hline ectopic focus & 101 \\
\hline ejection & $\begin{array}{r}72,81,82,89,90,92,95,98,99, \\
100,101,105,106,108,109,163\end{array}$ \\
\hline electromagnetic flowmeter & 18,163 \\
\hline ellipsoid & $67,68,69,70,71$ \\
\hline end-diastole & $69,78,89,101$ \\
\hline end-diastolic pressure & $14,21,22,23,24,25,26,72,89$ \\
\hline end-diastolic volume & 81,94 \\
\hline endocardi um & $67,100,104$ \\
\hline end-systole & 101 \\
\hline epicardium & 67,104 \\
\hline equator & $5,91,101,104$ \\
\hline excitation-contraction & $27,99,169$ \\
\hline femoral artery & 18 \\
\hline fiber & $\begin{array}{l}5,65,66,67,94,95,106,163 \\
166,167,170,171\end{array}$ \\
\hline finite interval & 84 \\
\hline flow source & 17,18 \\
\hline fluoroscopic techniques & 162 \\
\hline focal point & 68 \\
\hline Fourier analysis & $20,23,27,88$ \\
\hline frequency domain & $1,13,15,20,21,65,88,161$ \\
\hline frequency response & 20 \\
\hline Eagen - Poiseuille & 86 \\
\hline heart disease & 161 \\
\hline
\end{tabular}




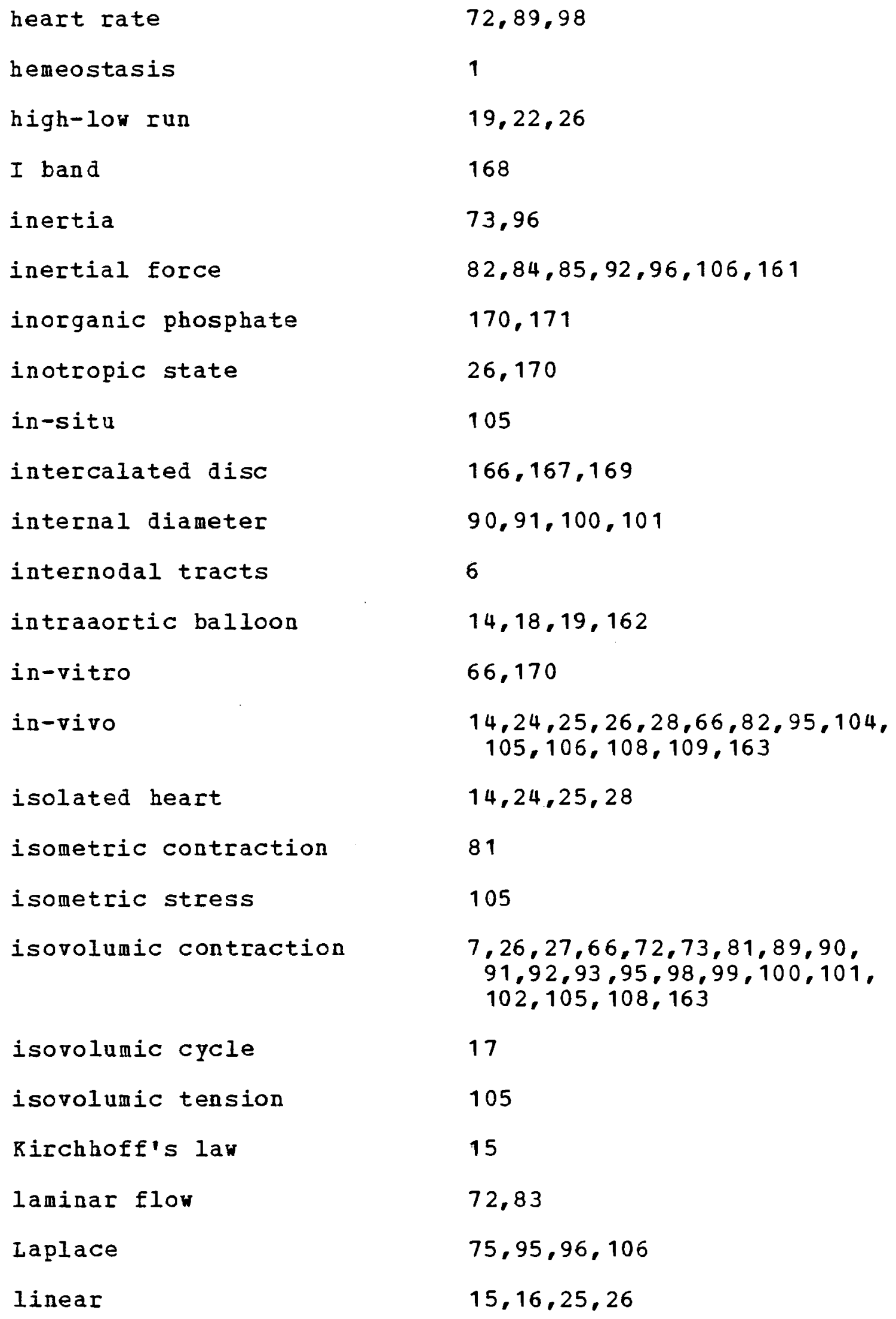

$19,22,26$

168

73,96

$82,84,85,92,96,106,161$

$$
170,171
$$

26,170

105

$166,167,169$

$90,91,100,101$

6

$14,18,19,162$

66,170

$14,24,25,26,28,66,82,95,104$, $105,106,108,109,163$

$14,24,25,28$

81

105

$7,26,27,66,72,73,81,89,90$, $91,92,93,95,98,99,100,101$, $102,105,108,163$

17

105

15

72,83

$75,95,96,106$

$15,16,25,26$ 


\begin{tabular}{|c|c|}
\hline linear regression & 22,23 \\
\hline local acceleration & 83 \\
\hline low-high run & $19,20,22,26$ \\
\hline lumped parameter & 15 \\
\hline lung & 4 \\
\hline material time derivative & 82 \\
\hline Millar & 18 \\
\hline mitochondria & 166 \\
\hline mitral valve & $4,5,7,8$ \\
\hline M-I complex & 168 \\
\hline modulating proteins & 170 \\
\hline momentum & 82 \\
\hline muscle fiber bundle & 166 \\
\hline myocardial cell & $65,166,169$ \\
\hline myocardial infarct & $\begin{array}{l}28,67,88,92,99,107,108,109 \\
162,163,164\end{array}$ \\
\hline myocardial ischemia & $20,24,25,26,27$ \\
\hline m yocardi um & $\begin{array}{c}2,4,6,7,8,65,66,73,76,77,80, \\
82,90,92,93,96,98,99,102, \\
105,106,109,164,166,169\end{array}$ \\
\hline myofibril & $65,166,167,170$ \\
\hline myofilament & 99,168 \\
\hline myogenic & 169 \\
\hline myosin & 168,170 \\
\hline myosin cross bridges & 168 \\
\hline Newtonian fluid & 72,86 \\
\hline nucleus & 166 \\
\hline Ohm's law & 15 \\
\hline
\end{tabular}




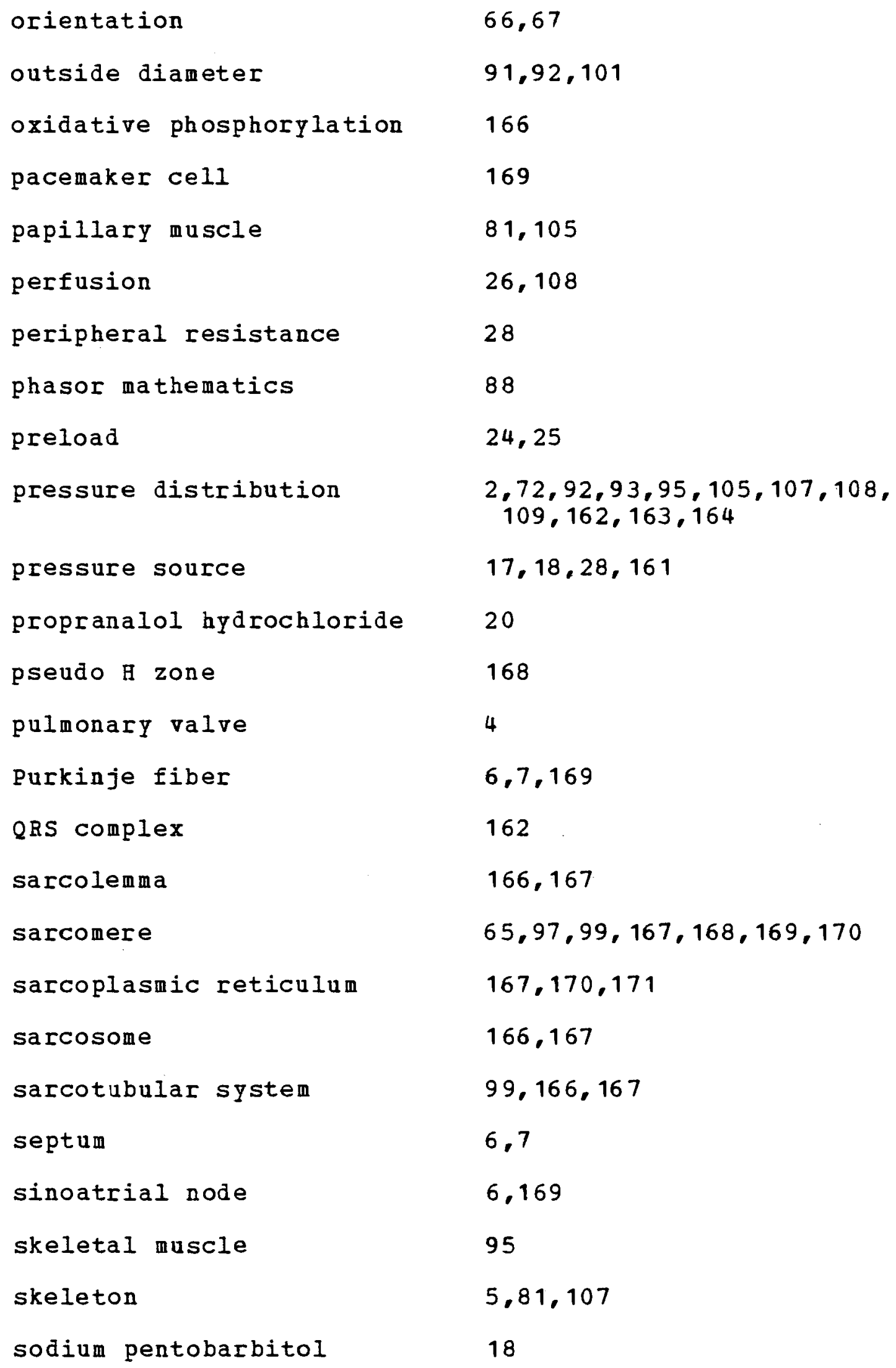


sonomicrometer

source impedance

source pressure

source resistance

steady state

strain

strain gage

stress

striated muscle

stroke volume

student's t-test

superposition

syncitium

tension

terminal cisternae

Therenin's equivalent

time domain

time-invariant

transverse tubule

triad

tricuspid valve

tropomyosin

troponin

ultrasonic techniques
100

$$
\begin{aligned}
& 2,13,14,15,16,17,18,21,22, \\
& 23,24,25,26,161 \\
& 2,13,14,15,16,17,21,22,23, \\
& 24,25,26,27,161 \\
& 18,28,161 \\
& 20,21,26 \\
& 65,72,73,76,77,80,81,89,90, \\
& 97 \\
& 102,103,105 \\
& 65,66,72,75,76,77,78,80,81, \\
& 89,90,92,94,105,106
\end{aligned}
$$

167

73,82

21

15

169

$98,99,103,170$

167.170

$14,15,17,24$

$2,17,23,24,26,27,88,161,162$, 163

15

167,170

167

4

170

170

101,104 
ultrasonic transducer

vascular tone

viscosity

viscous force

wall thickness

$z$ line
100,104

1

86,87

$86,92,106,161$

$66,67,74,75,76,79,90,102$, $103,104,105,109$

168 